OAK RIDGE

NATIONAL LABORATORY MANAGED BY UT-BATTELLE

FOR THE DEPARTMENT OF ENERGY
RECEIVET

JUL 102000

OSTI

ORNL/TM-2000/133

\title{
A Roadmap and Discussion of Issues for Physics Analyses Required to Support Plutonium Disposition in VVER-1000 Reactors
}

R. T. Primm III

J. D. Drischler

A. M. Pavlovichev

Y. A. Styrine

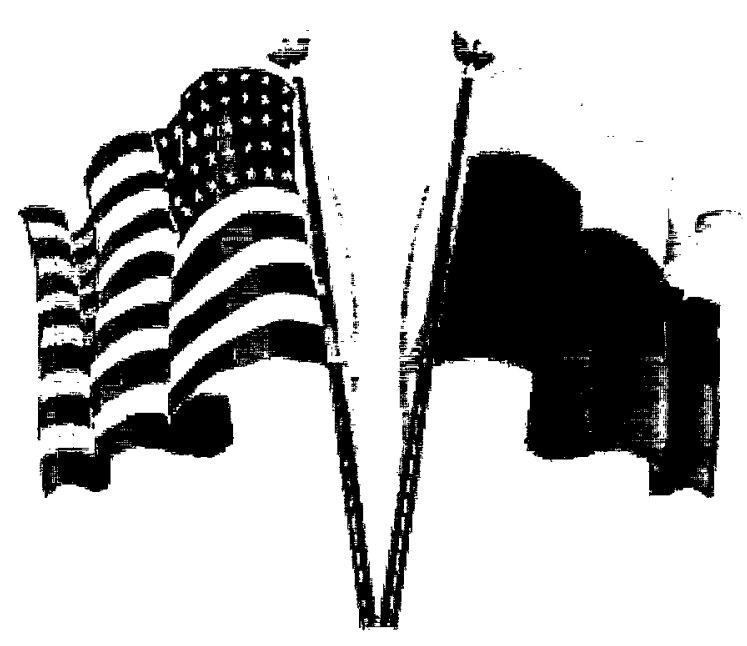

Fissile Materials Disposition Program 


\section{DOCUMENT AVAILABILITY}

Reports produced after January 1, 1996, are generally available free via the U.S.

Department of Energy (DOE) Information Bridge.

Web site http://www.osti.gov/bridge

Reports produced before January 1, 1996, may be purchased by members of the public from the following source.

National Technical Information Service

5285 Port Royal Road

Springfield, VA 22161

Telephone 703-605-6000 (1-800-553-6847)

TDD 703-487-4639

Fax 703-605-6900

E-mail info@ntis.fedworld.gov

Web site http://www.ntis.gov/support/ordernowabout.htm

Reports are available to DOE employees, DOE contractors, Energy Technology Data Exchange (ETDE) representatives, and International Nuclear Information System (INIS) representatives from the following source.

Office of Scientific and Technical Information

P.O. Box 62

Oak Ridge, TN 37831

Telephone 865-576-8401

Fax 865-576-5728

E-mail reports@adonis.osti.gov

Web site http://www.osti.gov/contact.html

This report was prepared as an account of work sponsored by an agency of the United States Government. Neither the United States Government nor any agency thereof, nor any of their employees, makes any warranty, express or implied, or assumes any legal liability or responsibility for the accuracy, completeness, or usefulness of any information, apparatus, product, or process disclosed, or represents that its use would not infringe privately owned rights. Reference herein to any specific commercial product, process, or service by trade name, trademark, manufacturer, or otherwise, does not necessarily constitute or imply its endorsement, recommendation, or favoring by the United States Government or any agency thereof. The views and opinions of authors expressed herein do not necessarily state or reflect those of the United States Government or any agency thereof. 


\section{DISCLAIMER}

Portions of this document may be illegible in electronic image products. Images are produced from the best available original document. 


\title{
A ROADMAP AND DISCUSSION OF ISSUES FOR PHYSICS ANALYSES REQUIRED TO SUPPORT PLUTONIUM DISPOSITION IN VVER-1000 REACTORS
}

\author{
R. T. Primm III and J. D. Drischler \\ Oak Ridge National Laboratory \\ A. M. Pavlovichev and Y. A. Styrine \\ Russian Research Center "Kurchatov Institute"
}

Date Published: June 2000

\author{
Prepared by \\ Russian Research Center "Kurchatov Institute" \\ Institute of Nuclear Reactors \\ under \\ Subcontract Number 85B99398V \\ Funded by \\ Office of Fissile Materials Disposition \\ U.S. Department of Energy \\ Prepared by \\ Computational Physics and Engineering Division \\ OAK RIDGE NATIONAL LABORATORY \\ Oak Ridge, Tennessee 37831 \\ managed by \\ UT-BATTELLE, LLC \\ for the \\ U.S. DEPARTMENT OF ENERGY \\ under contract DE-AC05-00OR22725
}




\section{CONTENTS}

LIST OF FIGURES

Page

LIST OF TABLES

ACKNOWLEDGMENTS

ABSTRACT

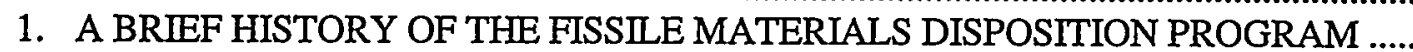

2. PURPOSE AND SCOPE OF THIS REPORT

3. METHODOLOGIES FOR ANALYSES

4. WEAPONS PARTS PROCESSING

4.1 CRITICALITY SAFETY

4.2 SHIELDING

4.3 ENVIRONMENTAL SOURCE TERMS

4.4 DECAY HEAT SOURCE TERM AND OTHER ANALYSES ..

5. TRANSPORTATION OF OXIDE POWDER TO THE FUEL FABRICATION

FACILITY.

5.1 CRITICALITY SAFETY.

5.2 SHIELDING.

5.3 ENVIRONMENTAL SOURCE TERMS

5.4 DECAY HEAT SOURCE TERM AND OTHER ANALYSES

6. THE MOX FUEL FABRICATION FACILITY.

6.1 CRITICALITY SAFETY

6.2 SHIELDING, ENVIRONMENTAL SOURCE TERMS, DECAY HEAT SOURCE TERM, AND OTHER ANALYSES

7. TRANSPORTATION FROM THE FUEL FABRICATION FACILITY TO THE REACTOR SITES

7.1 CRITICALITY SAFETY

7.2 SHIELDING, ENVIRONMENTAL SOURCE TERMS, DECAY HEAT SOURCE TERM, AND OTHER ANALYSES

8. MOX OPERATIONS AT THE REACTOR SITE AND IRRADIATION IN THE REACTOR

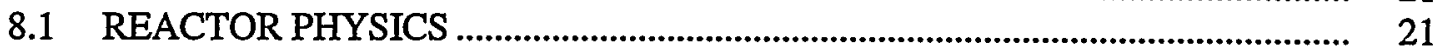

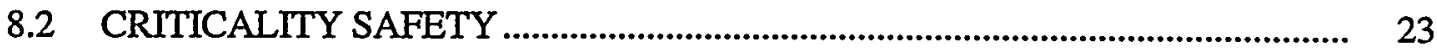

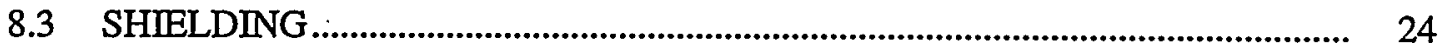

8.4 ENVIRONMENTAL SOURCE TERMS........................................................... 24

8.5 DECAY HEAT SOURCE TERM AND OTHER ANALYSES ............................. 24

9. THE AWAY-FROM-REACTOR SPENT FUEL OPERATIONS ................................... 25

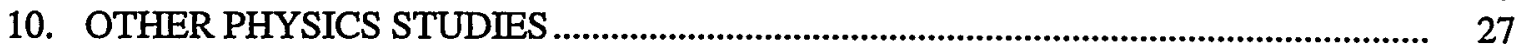

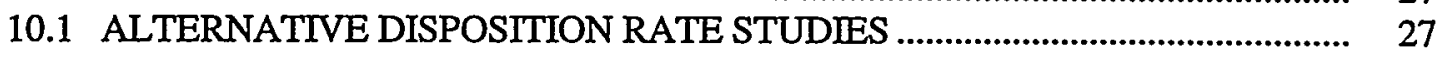

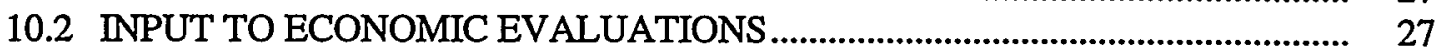

10.3 TECHNICAL SUPPORT TO DISPOSITION IN CANDU REACTORS ............... 27

10.4 TECHNICAL SUPPORT TO DISPOSITION IN FAST REACTORS .................... 27

10.5 TECHNICAL SUPPORT TO DISPOSITION IN GAS-COOLED REACTORS... 27

11. A COMPREHENSIVE ROADMAP FOR PHYSICS ANALYSES................................. 29

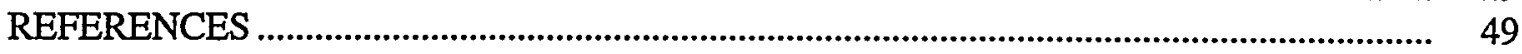

Appendix A. GOSATOMNADZOR REVIEW PROCESS .............................................. A-1

Appendix B. COMPUTER PROGRAMS AND DATA LIBRARIES .................................... B-1

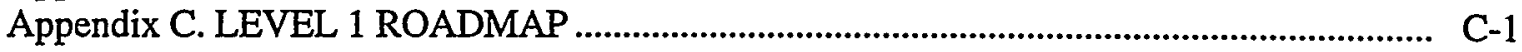

Appendix D. INPUT TO LEVEL 2+ ROADMAP ......................................................... D-1

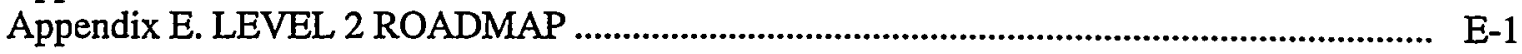




\section{LIST OF FIGURES}

Figure $\quad$ Page

1 Process flow description of an American plutonium conversion facility ................ 10

$2 \quad$ Generic MOX FFF process diagram......................................................................... 16

3 Level 2+ roadmap for physics analyses to support plutonium disposition

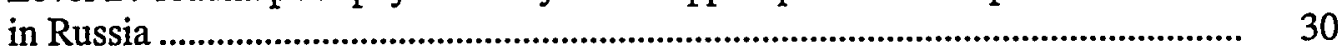

A.1 Certification passport contents ........................................................................ A-3

A.2 Arrangement of codes certification .................................................................. A-4

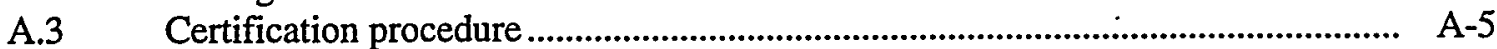

C.1 Russian Nuclear Materials Disposition Program logic, Level 1 ........................... C-3

E.1 Russian Nuclear Materials Disposition Program logic, VVER-1000 and nuclear fuels, Level 2 .

\section{LIST OF TABLES}

Table

Page

B.1 Nuclear methods and data to be validated ........................................................ B-3

B.2 Database for Russian code verification ................................................................... B-4 


\section{ACKNOWLEDGMENTS}

The authors wish to acknowledge the careful and helpful reviews of this document performed by ORNL staff members D. T. Ingersoll, C. V. Parks, J. C. Gehin, R. J. Ellis, and C. C. Southmayd. This work was sponsored by the Office of Fissile Materials Disposition, Office of Nuclear Nonproliferation, U.S. Department of Energy. 


\title{
A ROADMAP AND DISCUSSION OF ISSUES FOR PHYSICS ANALYSES REQUIRED TO SUPPORT PLUTONIUM DISPOSITION IN VVER-1000 REACTORS
}

\author{
R. T. Primm III and J. D. Drischler \\ Oak Ridge National Laboratory \\ A. M. Pavlovichev and Y. A. Styrine \\ Russian Research Center "Kurchatov Institute"
}

\begin{abstract}
The purpose of this report is to document the physics analyses that must be performed to successfully disposition weapons-usable plutonium in VVER-1000 reactors in the Russian Federation. The report is a document to support programmatic and financial planning. It does not include documentation of the technical procedures by which physics analyses are performed, nor are the results of any analyses included. The scope of the discussion includes all plutonium processing operations, beginning with the disassembly of weapons parts and ending with the transportation of irradiated VVER-1000 mixed-oxide (MOX) fuel assemblies to their final destination and all parts of the fuel cycle between these two end points. Discussion is limited to analyses that are to be performed in the areas of reactor physics (statics and kinetics), criticality safety, radiation transport and shielding, decay heat generation, and source term generation for accident consequence analyses (source terms for environmental analyses). Three goals-safety, disposition rate, and cost, in that order-are the motivations for all the physics analyses discussed in this report. Analyses to support licensing documents are regarded as an inherent part of the safety goal
\end{abstract}

\section{A BRIEF HISTORY OF THE FISSILE MATERIALS DISPOSITION PROGRAM}

In September 1993, Presidents Clinton and Yeltsin established a policy to commit the United States (U.S.) and the Russian Federation (R.F.) to seek to eliminate, where possible, the accumulation of stockpiles of highly enriched uranium and plutonium. The U.S. Government initiated the Fissile Materials Disposition Program (FMDP)_administered by the Office of Fissile Materials Disposition (OFMD) in the U.S. Department of Energy (DOE)-to perform a comprehensive review of long-term alternatives for plutonium disposition, taking into account technical, nonproliferation, environmental, budgetary, and economic considerations. In April 1996, a Nuclear Safety Summit was held in Moscow, Russia. Participants at the summit agreed that the spent fuel standard, which makes weapons-usable plutonium as inaccessible as reactor-grade plutonium in spent, low-enriched uranium (LEU) fuel, should be adopted as the goal for plutonium disposition. Summit participants also endorsed a technology program composed of small-scale equipment and process demonstrations. Almost concurrently, a joint U.S./R.F. commission, commonly called the Holdren/Velikhov Commission, concluded that disposition of weapons-usable plutonium in 
light-water reactors should be one of the technological options pursued by both the Russian Federation and the United States. On January 14, 1997, the DOE announced the formal Record of Decision (ROD) for the Storage and Disposition of Weapons Usable Fissile Materials. The disposition strategy allows for immobilizing plutonium in glass or ceramic forms and burning plutonium as mixed-oxide (MOX) fuel in existing reactors. On April 1, 2000, the OFMD became a part of the Office of Nuclear Nonproliferation at DOE.

With the plutonium disposition mission defined to include the irradiation of MOX fuel in reactors, the U.S. and R.F. experts began the task of identifying facilities in Russia to accomplish the mission. The U.S. officials were informed that the safety review process in Russia stipulates that all fuel cycle facilities and reactors must submit a request-for-operation to the Russian regulatory authority, Gosatomnadzor (GAN). This request is then subjected to technical review, evaluation, and eventual approval or rejection. The U.S. officials were also informed that the use of MOX fuel in VVER-1000 reactors, and the fuel cycle to support such use, would require new requests-for-operation to be filed with GAN. (The review process is summarized in Appendix A.)

The OFMD has established policy decisions that influence the MOX fuel cycle promoted by the DOE for implementation in Russia. The OFMD has specified that it will consider funding modifications to the physical plant of VVER-1000s to enhance the disposition rate of plutonium. The OFMD has also stipulated that the disposition of plutonium in Russia may slightly lag the disposition of plutonium in the United States. The current disposition schedule proposed by Duke/Cogema/Stone \& Webster (DCS)-the consortium responsible for MOX fuel fabrication and irradiation services in the United States-is to initiate irradiation of lead assemblies in 2004, begin initial loading of an equilibrium batch of MOX fuel in 2008, and complete the irradiation mission in 2022.

For the Russian Federation to meet the U.S. disposition schedule with only those reactors in current operation (six VVER-1000s and one fast reactor, the BN-600), each VVER-1000 must disposition $400 \mathrm{~kg}$ of plutonium per reactor year. The R.F. schedule contains an additional "frontend" step not present in the U.S. disposition program. Lead MOX fuel pins would be irradiated in LEU assemblies starting in 2003 for 2 years. While these pins are being destructively analyzed, lead test assemblies (LTAs) are loaded to a VVER-1000 in 2005 and irradiated for two, 1-year cycles. Allowing a year for destructive investigation of pins from the LTAs, loading of MOX assemblies to one of the six VVER-1000s could begin in 2009. Fueling of all six reactors should be achieved by 2015 . The six VVER-1000s and the BN-600 will have a combined disposition rate of 3.7 MT/year of plutonium. To disposition $34 \mathrm{MT}$ of plutonium will require 9 years and will be completed shortly following the completion of the U.S. program in 2022.

Several discussions between the U.S. and R.F. governments have been held regarding the disposition of more than $34 \mathrm{MT}$ of plutonium although a U.S./R.F. agreement has not been approved. To accomplish this goal would require modifications to the current VVER-1000 fuel assembly design and likely require modifications to the reactor.

At the beginning of fiscal year 1997 (October 1996), the Water Reactors-1 Task was established to provide technical support to Russia in the area of physics analyses for MOX-fueled VVER-1000s. The initial mission of this task was to verify and validate computational methods for the analysis of MOX fuels in VVER-1000s. Verification is the process of confirming that the algorithms encoded in computer programs work as intended; validation is the process of comparing computer programs and their associated nuclear data libraries to measured physics parameters.) The U.S. role was to provide technology transfer of MOX data to Russia and to perform independent analyses and reviews of Russian neutronics calculations. The initial goal established in 1996 will be reached when GAN issues Certification Certificates for Russian reactor physics computer programs that are to be used for the analyses of MOX fuels.

Approximately 1 year following the initiation of Water Reactors-1 Task (late 1997), both the U.S. and R.F. task members jointly agreed to expand the scope of the task to include design of lead test/use assemblies and review of the design of the equilibrium (sometimes designated as 
mission) fuel assembly - the equilibrium fuel design task being the primary responsibility of a joint French/German/Russian group. These assembly designs were to be formulated on the basis that no changes or improvements were to be made to the existing VVER-1000 reactor infrastructure. This programmatic stage, including the verification and validation design studies mentioned previously, eventually came to be called Phase 1 of the Russian disposition program of the FMDP. This phase is expected to be completed at the loading of the first LTAs into the Balakovo reactor unit 4 (2004).

Verification and validation studies required that both the U.S. and R.F. staffs analyze the same problems and data. Otherwise, there would have been no mechanism for certifying to GAN that Russian computer programs and data were acceptable for analyzing MOX fuels. As the joint studies progressed to the design of fuel assemblies, the two staffs did not replicate all studies. The R.F. staff performed parametric studies to provide data for decisions regarding an assembly design. These parametric studies were seldom replicated by the U.S. staff. Tentative designs, however, were evaluated by both staffs.

During fiscal year 2000, DOE requested that Russian reactor physicists propose options for increasing the plutonium disposition rate (Phase 2). Suggestions received from Russia will be the basis of joint U.S./R.F. studies during future fiscal years. The U.S. staff will not duplicate the work of the Russian staff, but both staffs will work as a unified team to examine all identified options. Phase 2 is expected to be completed by 2010.

The Russian Federation has designated the Russian Research Center "Kurchatov Institute" (RRC-KD) and the Institute for Physics and Power Engineering (IPPE) as the institutes to work with the United States in the implementation of weapons-grade plutonium disposition. Generally, RRC-KI has assumed the lead role in at-reactor-site physics analyses, and the IPPE has contributed significantly in away-from-reactor fuel cycle analyses. Oak Ridge National Laboratory (ORNL) has served and will serve as an independent technical reviewer-the need for such is a requirement of GAN_-and will provide confirmatory analyses to GAN. As requested, ORNL will also provide technical advice to DOE on Russian reactors and fuel cycle facilities.

Once Russian computer programs and nuclear data libraries are certified by GAN, the need for technical support in the reactor physics area from ORNL staff is planned to slowly decline. ORNL staff will continue to coordinate with R.F. staff in the design of the Phase 1 and Phase 2 assemblies and in evaluating any modifications to the reactor plant. However, after the first equilibrium loading (Phase 1 of the program), fuel management calculations (determining which assembly goes where in the reactor core) will likely be done exclusively in Russia with no confirmation performed in the United States unless requested by Russia or by DOE.

The plan for nuclear engineering analyses to support away-from-reactor facilities is vague. It will be shown that extensive criticality safety, shielding, decay heat, and environmental source term analyses are required. How these analyses are to be integrated with other engineering disciplines and programmatic goals is currently unclear. 


\section{PURPOSE AND SCOPE OF THIS REPORT}

The purpose of this report is to document the physics analyses that must be performed to successfully disposition weapons-usable plutonium in VVER-1000 reactors in the Russian Federation. The report is a document to support programmatic and financial planning. Consequently, with the exception of the listing of computer programs and nuclear data sources in Appendix B, the report does not include documentation of the technical procedures by which physics analyses are performed, nor are the results of any analyses included. (Appendix B also contains a brief description of the current database of measurements available to the Russian Federation for validation and the uses of these measurements.)

The scope of the discussion in this document includes all plutonium processing operations beginning with the disassembly of weapons parts and ending with the transportation of irradiated VVER-1000 MOX fuel assemblies to their final destination and all parts of the fuel cycle between these two endpoints. Discussion is limited to analyses that are to be performed in the areas of reactor physics (statics and kinetics), criticality safety, radiation transport and shielding, decay heat generation, and source term generation for accident consequence analyses (source terms for environmental analyses).

The primary goal of all physics analyses is to certify the safety of all operations related to the disposition of weapons-usable plutonium. Analyses are performed to support the fuel cycle facility operations and also for presentation to and review by the Russian regulatory agency, GAN (see Appendix A). Under the constraint of safety, the second most important goal is to disposition the amount of plutonium that has been mutually determined by the U.S. and R.F. governments within the amount of time that has also been determined by mutual agreement. The third goal, in order of importance, is the achievement of the first two goals at minimal cost. Though third in priority, obtaining an economic optimum requires considerably more resources (e.g., a greater number of studies, a greater depth of study, a greater number of calculations) than achieving the first two goals. Equipment protection from excessive radiation, design of facilities for ease of maintenance, and minimization of the quantity of construction materials and labor costs are all examples of studies that would not impact safety but that would, if performed improperly, yield significant economic penalties.

These three goals-safety, disposition rate, and cost, in that order-are the motivations for all the physics analyses discussed in this report. Analyses to support licensing documents are regarded as an inherent part of the safety goal. 


\section{METHODOLOGIES FOR ANALYSES}

All physics analyses rely on one or more of four methodologies: (1) reference to a nuclear facility of similar design that is either currently operating or has operated in the past, (2) solutions from handbooks or other reference literature, (3) measurements and/or experiments, or (4) solution of the problem through the use of digital computer programs (these programs usually require electronic data "libraries" of measured physical constants). The fourth method is the one being developed for MOX fuels under the Water Reactors-1 Task.

Implementing nuclear facility designs from existing or previously operated facilities can satisfy all three goals of the physics analyses (see Sect. 2). Unfortunately, neither the United States nor the Russian Federation has ever constructed and operated MOX fuel fabrication facilities (FFFs) of the size needed to meet the disposition goals of the FMDP. European facilities of sufficient size have been constructed but not for weapons-grade plutonium. Furthermore, the design and operational aspects of European facilities are proprietary and not currently available to U.S. and R.F. personnel.

Note that the Russian Federation currently operates a fast reactor fuel production line. Consequently, some experience with plutonium operations may be transferable to a VVER-1000 fuel production facility without the need for additional physics analyses. However, since fast reactor fuels have a plutonium content of $20 \mathrm{wt} \%$ and VVER-1000 MOX would have a plutonium content of approximately $5 \mathrm{wt} \%$, it is unlikely that facilities based on the fast reactor production facility designs would be economically optimal.

Handbooks, American and international standards, and other reference materials are used in safety assessments of facility designs because they provide expert, peer-reviewed advice quickly to both experienced and inexperienced engineers. Use of reference publications facilitates education on safety-related issues and enables acceptance of facility designs and operations by regulatory authorities. However, reference publications are extremely limited in the number of configurations studied. Many European publications are proprietary; the extent of configurations and materials studied is not known and is not available to the United States or the Russian Federation.

It is generally not possible to extrapolate to new, uninvestigated configurations based on previously published work. Because MOX fabrication plants exist in Europe, publications relevant to nuclear safety analyses exist. However, for some applications, such as the startup of a reactor, expected values of startup physics tests are not available for fuels that have never been placed in the reactor in question (significant quantities of fresh MOX fuel have not been placed in a VVER-1000). When applicable and available, reference publications achieve the FMDP goal of safety, but disposition rate and economic goals may not (and likely would not) be achievable.

Implementation of the MOX fuel cycle in Russia could be accomplished by conducting experiments or in-situ facility measurements. These procedures, along with analytic calculations (commonly called "hand calculations"), were utilized in the United States before the advent of digital computers. For fuel cycle facilities, measurements in critical facilities are required. These measurements are time-consuming-requiring several years to complete-and would cost millions of dollars. In-situ measurements at the reactor would lead to a gradual introduction of MOX. The time to reach a one-third core loading would be greater than reliance on computational methods because measurements of reactor performance must be made each time the loading of MOX (number of MOX assemblies) in the reactor core is increased. For the FMDP, the goal of safety could be obtained, but the disposition rate and economic goals would likely not be achieved.

Computer programs offer the most versatile method of performing physics analyses. Essentially any geometric configuration and material composition can be evaluated. The analyst is not limited to facility designs or configurations previously constructed, nor is the analyst constrained to the simplistic geometries or the limited materials choices frequently found in handbooks or 
reference literature. Safety, disposition rate, and minimum cost goals can all be met through the use of computational methods.

American and Russian computer programs and data libraries that were selected in 1996 for inclusion in the FMDP are listed in Appendix B. The list in Appendix B is expected to be revised in the future. Technology will evolve during the course of the FMDP, and new programs and libraries or improved versions of existing programs will likely be added to the list. Analyses to date that have been performed with these programs are documented in Refs. 1-18.

Computer programs and data libraries must be verified and validated with experimental data that are shown to be applicable to the system under study. When available and applicable, existing facility operations and analyses can also be sources of data for validation.

Verification, in the context of neutron physics computer programs, is the process of ensuring that the software solves the problem that was intended to be solved. That is, the encoded algorithms produce an accurate approximation to the true solution for the problem. Verification of neutron physics software should be performed independently of the nuclear data that are input to the analyses. Consequently, physicist-created computational benchmarks frequently provide the simplest or "cleanest" mechanism for verifying computer programs.

Validation is the process of demonstrating the degree to which software and associated data libraries needed as input to the software meet their requirements-the level of accuracy for the systems modeled. In the context of neutron physics software, any biases in computer program/data library combinations are identified by comparison of calculated to experimentally measured physics parameters.

This report includes brief, qualitative discussions of a variety of experimental measurements that are used to validate selected computer programs/data library combinations. Verification and validation studies may be costly and time-consuming and sometimes must be repeated if computer hardware or software is updated. 


\section{WEAPONS PARTS PROCESSING}

The initial step in the fuel cycle is to convert plutonium metal parts into plutonium oxide. Weapons parts will first be converted to metal ingots. These ingots will be chemically dissolved in nitric acid and then precipitated as plutonium oxide powder. The powder will be dried, milled, and poured into metal canisters. A large number of canisters will likely be stored, temporarily, in a vault until transportation to the FFF.

A schematic diagram of the proposed, American plutonium conversion facility is shown in Fig. 1. The concept for the American facility differs from that of the Russian one because nonaqueous processes will be utilized. Nevertheless, Fig. 1 provides an overview of the processes required to convert feed material into oxide product.

Because a weapons parts disassembly and conversion facility (WPDCF) will contain operations that will be conducted with pure plutonium, the designs and operations of existing R.F. facilities may be immediately applicable to the FMDP. The components of any new facilities could be adapted from existing facilities and satisfy the criteria of safety and economics. (In fact, the realignment of former weapons facilities to serve conversion roles for the FMDP would be highly desirable from a nonproliferation policy viewpoint.) Increases to a reference disposition rate could be achieved by parallel production lines. Criticality safety, shielding, and radionuclide source term analyses could all be "grandfathered" from current designs.

New studies would be performed only if existing facilities or associated documentation was judged unacceptable to GAN. In anticipation that some existing facilities would not meet the current regulatory requirements of GAN, the scope and content of new facility design studies are summarized below by discipline.

\subsection{CRITICALITY SAFETY}

Analysts would receive from facility designers the engineering drawings and the description of the chemical process-termed material flow sheets-for the WPDCF. While normal operating conditions will be defined from material flow sheets and the safety of normal operations confirmed by nuclear analysts, credible abnormal conditions must be identified by the criticality safety analyst working in conjunction with process designers. A probabilistic risk assessment methodology is an excellent mechanism for determining credible abnormal conditions, but expert opinion may be equally as accurate. After computational programs and libraries have been validated, computational models of the facilities must be prepared, and the facility must be shown to remain subcritical during normal and credible abnormal operations. In some instances, handbook values of process equipment dimensions may be used in lieu of computations.

Criticality safety benchmarks - needed for validation of computational methods-that would be applicable to this facility design should be those in which plutonium is the only actinide. Critical configurations with plutonium metal and with plutonium oxide are required. A range of moderation ratios should be examined in the experimental configurations because while some of the processes will be nonaqueous, accidents or abnormal conditions may result in the introduction of water or other hydrogeneous materials to the operations. Both single-unit and array critical configurations will be required because there will be storage configurations at both the "head" and "back" ends of the facility. For aqueous operations in the facility, single-unit and array configurations of containers filled with plutonium nitrate solution will be required as benchmarks. A range of moderation ratios should be considered.

After subcriticality during normal and credible abnormal conditions has been assured, criticality accidents must be postulated and defined; the consequences must be evaluated through the use of computational methods or by reference to handbooks or standards if appropriate. The results of the studies of postulated criticality accidents will be used to assess facility design 
ORNL 2000-1285 EFG

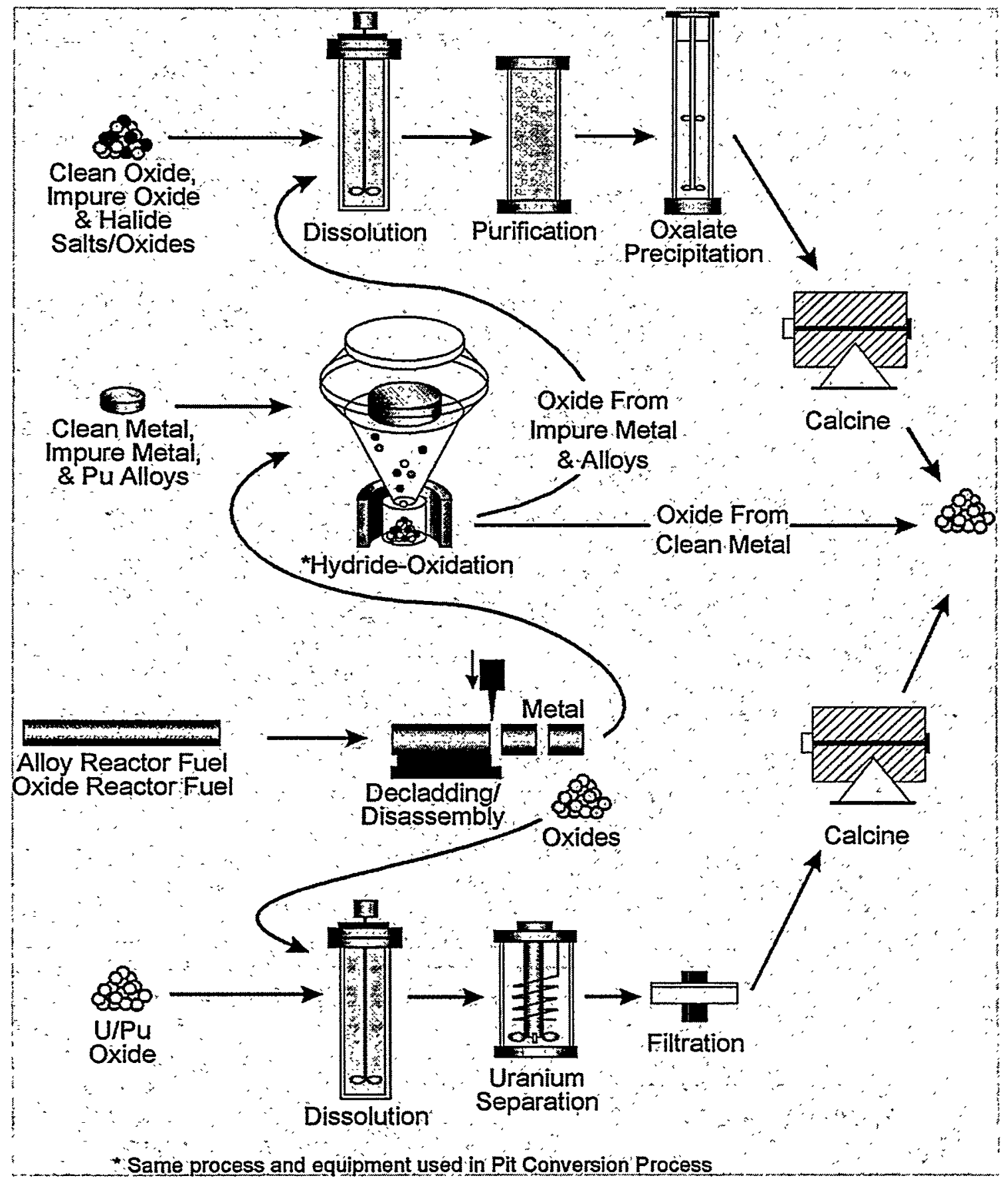

Note: This figure is not meant to convey the actual process flow of the plutonium conversion facility, only to show the kinds of process steps that will be used.

Fig. 1. Process flow description of an American plutonium conversion facility. 
(i.e., adequate shielding and effluent confinement) and adequacy of safety alarm systems, and they will provide source terms for environmental consequence analyses.

\subsection{SHIELDING}

The definition of radiation sources for normal operation will have as an initial basis the facility description and process flow sheets mentioned previously. However, it is a common occurrence that the principal contributors to the radiation source term are trace isotopes or process impurities that may not appear on the process flow sheet. Consequently, the shielding analyst must first define the reference shielding source terms based on the process flow sheet, examination of similar facilities, expert opinion, and computational methods (zero-dimensional, irradiation and depletion programs). The reference source terms for normal, credible abnormal, and postulated accident conditions must be specified. While some of the computational methods used for shielding source term generation are the same as those used for criticality safety, frequently the important radiation source nuclides for shielding concerns are not the same nuclides that are most important for assessing criticality safety.

Either computational methods or reference literature may be used to perform the radiation transport analyses. Computational methods require that validation studies be performed but usually yield a more economical facility design than reliance on reference literature. The selection of shielding experiments for validation of computer programs would depend on the type of radiation, the energy spectra of the radiation sources, and the construction materials for the facility. The most penetrating radiations are neutrons and gamma rays; however, gamma ray interactions with matter are generally easier to calculate accurately than neutron interactions. The most difficult shielding problems are the calculations of radiation streaming through cracks or small gaps formed between bulk components. Also, calculation of "deep penetration" problems can be challenging. Deep penetration refers to the transmission of either neutrons or photons through physically large distances in solids. Knowledge of the facility design is a prerequisite to the assessment of the difficulty of the shielding problems.

\subsection{ENVIRONMENTAL SOURCE TERMS}

The estimations of radionuclide source terms for normal, credible abnormal, and accident conditions are usually achieved by using computational tools. These tools are frequently the same as those used for criticality accident and shielding calculations. However, the nuclides of interest are usually different than those of interest to criticality safety and shielding analysts. The degree to which a radionuclide is an environmental hazard is a function of the activity, type and energy of radiation, and the degree to which the nuclide interacts with the environment (e.g., how readily it is absorbed by the body).

For the shielding studies, the initial activity for this task would be to develop a reference document that identifies the nuclides of interest. The analyst must consider the reference flow sheet, the identified credible abnormal and accident conditions from the criticality safety studies, the identified radiation source terms from the radiation study, and biological "uptake" data from reference literature. Once the reference document for normal, credible abnormal, and accident conditions has been completed, the computation of the source terms is usually a modest task.

\subsection{DECAY HEAT SOURCE TERM AND OTHER ANALYSES}

Because only unirradiated materials will be processed, decay heat is expected to be insignificant. However, a related quantity, the amount of americium and other alpha emitters in the processed plutonium oxide, is important. Alpha activity results in helium generation, and if the metal containers holding the finished product are kept for a long time, an excessive internal gas pressure may result in failure of the plutonium oxide containment. 


\section{TRANSPORTATION OF OXIDE POWDER TO THE FUEL FABRICATION FACILITY}

If the FFF and the.WPDCF were at the same location, there would be no consideration of transportation of oxide powder. If the facilities were at different locations, then a transportation package would have to be designed and constructed. Nuclear analyses would be a part of the design process.

\subsection{CRITICALITY SAFETY}

The analyst will have to define normal and credible abnormal conditions based on the proposed mechanical design of the transportation package. The package design is an input to the analysis and must specify all materials and geometry. Likewise, reference and credible abnormal plutonium oxide container descriptions must be supplied to the safety analyst. Either computational methods or reference literature could be employed for analyses. Should computational methods be used, validation studies performed to support the design of a storage array at the WPDCF would likely support these analyses as well.

\subsection{SHIELDING}

For criticality safety, a complete description of the plutonium oxide container (including specifications of all impurities and trace isotopes) and the transportation package must be provided to the shielding analyst. Because the fuel is fresh, the most important shielding consideration is likely to be the neutron dose from the package. Either computational methods or reference literature could be employed for analysis.

\subsection{ENVIRONMENTAL SOURCE TERMS}

The identification of the environmental source term should be relatively simple. The plutonium oxide itself is the source term. However, particular attention should be paid to specification of trace nuclides that have significant biological impacts. These should have been identified in the source term analyses for the WPDCF.

\subsection{DECAY HEAT SOURCE TERM AND OTHER ANALYSES}

These analyses are the same as those for the storage array for the WPDCF. 


\section{THE MOX FUEL FABRICATION FACILITY}

The fabrication facility will receive plutonium oxide powder from the WPDCF. The chemical and mechanical processes that will be performed inside the MOX FFF are shown in Fig. 2.

Canisters of plutonium oxide will be unloaded from the transportation package and stored. The storage area is likely to be very similar to, if not the same as, the design for the WPDCF. Natural or depleted uranium will be received and stored. Uranium and plutonium oxides will be blended. It is expected that a "master mix" of $30 \mathrm{wt} \%$ plutonium oxide and $70 \mathrm{wt} \%$ uranium oxide will be prepared.

The master mix will be mechanically processed, and then additional uranium oxide will be added to achieve the plutonium contents specified by the reactor physics analyses (discussed subsequently). The MOX powder will then be pressed into pellets. The pellets will be sintered in a furnace (parallel lines may be in operation to achieve the necessary throughput) and sent to an intermediate storage area. Pellets will then be loaded to pins, and the pins sent to a storage area. Pins will then be loaded to assemblies, and assemblies sent to a storage area.

Common to all of the nuclear analyses are a facility description document and a "materials flow" description for each of the processes shown in Fig. 2. It is also necessary to define the operation of the facility, but experience shows that operating procedures are usually not available when nuclear analyses are requested for a new facility. Consequently, it will likely be the responsibility of the nuclear analyst to work with the facility designers to tentatively establish some operating procedures. In fact, the definition of normal, credible abnormal, and accident conditions will require that operating procedures be defined. As was mentioned earlier, the shielding and environmental source term analyses will require specifications for trace nuclides that may not appear in the materials flow documents. The addition of the source terms must be a cooperative effort between safety analysts and facility designers.

The facility description, materials flow, and operating procedure documents need not and, in fact, should not be the final versions. The nuclear analyses described subsequently should be an integral part of the facility design process.

\subsection{CRITICALITY SAFETY}

Because the initial processes in the MOX FFF are the same as those for the fast reactor fuel cycle (i.e., storage of plutonium oxide and subsequent blending to $30 \mathrm{wt} \%$ plutonium in MOX and breeder blanket plutonium with a high fissile content), it is possible that the MOX FFF design could be approved by referencing an existing facility that supports fuel fabrication for the BN600 . However, the remainder of the fuel assembly fabrication processes do not have existing counterparts in either the United States or the Russian Federation (due to the size of the operations). Applicable European data almost certainly exist but are proprietary and may be limited to high ${ }^{240} \mathrm{Pu}$ content fuels. Application of reference publications may be possible, but, as stated previously, they are unlikely to yield the most efficient and therefore cost-effective design. Most likely, computational methods will be employed to perform the criticality safety analyses.

After definition of the normal, credible abnormal, and accident conditions as noted previously, safety analyses will be performed with verified and validated computational methods. A variety of benchmarks will be required for computer code certification. For the design of storage and blending operations, the benchmarks would be the same as those previously described for the WPDCF. Intermediate storage of MOX powder (production of a master mix that is subsequently diluted with uranium oxide), MOX pellet production, and fuel rod fabrication operations will utilize single-unit MOX critical configurations as benchmarks. Fuel rod assembly into bundles and bundle storage will require interacting array data for MOX fuel pins. The verification of computer programs for the postulated criticality accidents will require a consensus of expert opinion. 


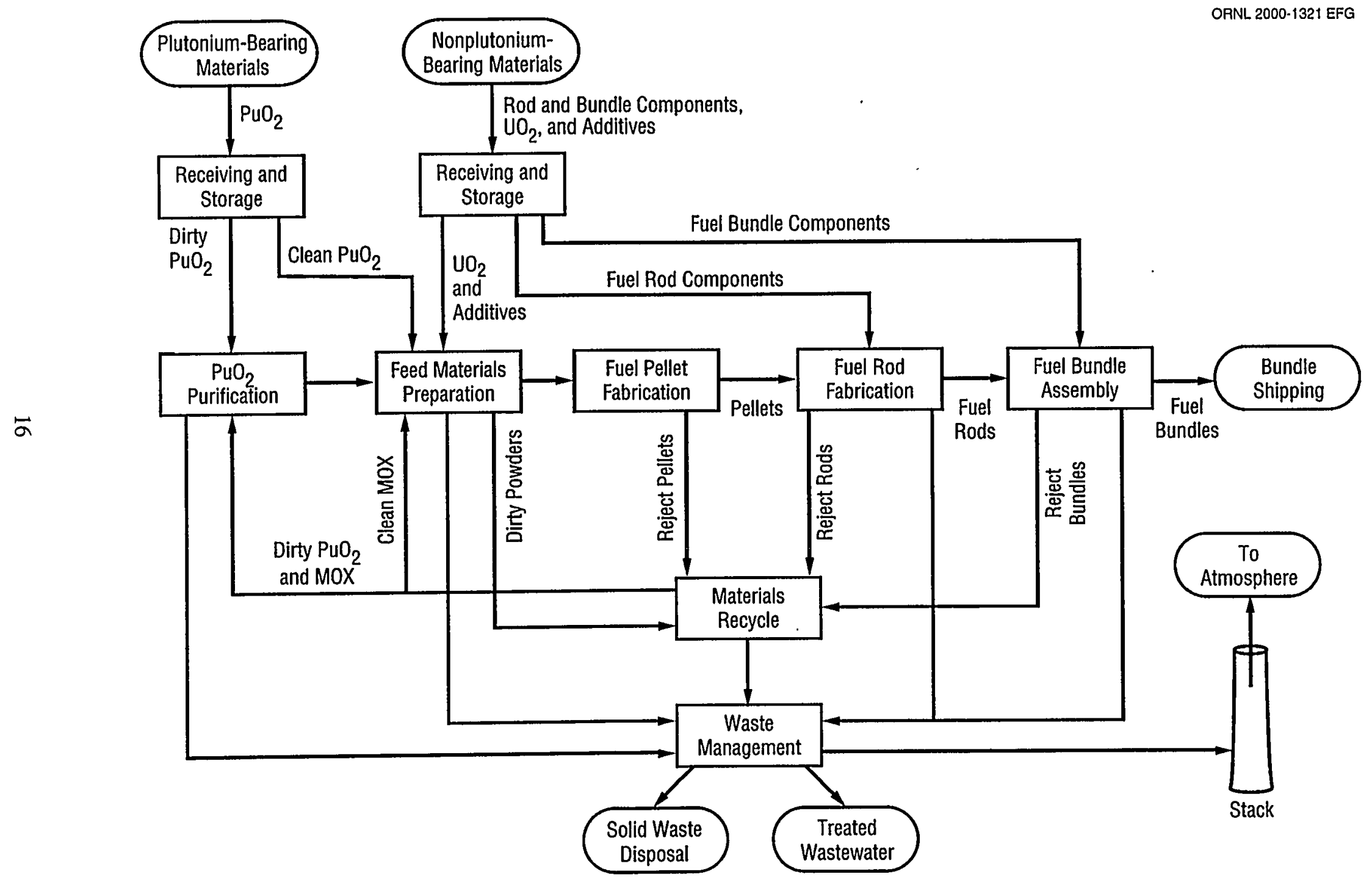

Fig. 2. Generic MOX FFF process diagram. 


\subsection{SHIELDING, ENVIRONMENTAL SOURCE TERMS, DECAY HEAT SOURCE TERM, AND OTHER ANALYSES}

Because only fresh fuel will be processed in the fabrication facility, analysis and benchmark needs in these areas will be essentially the same as those for the WPDCF. Identification of the isotopics of the plutonium and uranium to a high degree of accuracy (for some nuclides, partsper-billion concentration levels must be known) is a requirement. Likewise, the quantities of trace nuclides in the MOX must be very well known if unnecessary conservatism in facility designand therefore unnecessary cost-is to be avoided. 


\section{TRANSPORTATION FROM THE FUEL FABRICATION FACILITY TO THE REACTOR SITES}

Shipping casks similar to those currently used for the transport of LEU fuel will be required for transport of MOX fuel from the fabrication facility to the reactor site.

\subsection{CRITICALITY SAFETY}

There is an economic advantage to using an existing shipping cask to transport MOX fuel assemblies from the fabrication facility to the reactor sites. Initial studies performed jointly by U.S. and R.F. analysts indicate that, under normal operation, Russian casks can safely accommodate MOX fuel assemblies (see Ref. 7). Studies of credible, abnormal conditions of MOX assemblies in casks have not been conducted. Possible abnormal conditions must be defined and studied with verified and validated computational methods.

\subsection{SHIELDING, ENVIRONMENTAL SOURCE TERMS, DECAY HEAT SOURCE TERM, AND OTHER ANALYSES}

Because the fuel being transported is unirradiated, radiation sources will be quite small, and decay heat generation will be insignificant. Because of spontaneous fission and alpha- $n$ reactions, the neutron source from MOX fuel is considerably greater than that of LEU fuel. Neutron shields that are not needed for LEU transport may be required for MOX transport. Potential accidents and corresponding releases of fuel to the environment must be identified. However, the radiological source terms for the environmental consequences analyses will be derivable from the fresh fuel specifications. 


\section{MOX OPERATIONS AT THE REACTOR SITE AND IRRADIATION IN THE REACTOR}

At the reactor sites, MOX fuel must be unloaded from the shipping casks and transferred to a fresh fuel storage area. At each refueling outage, spent MOX assemblies must be removed from the reactor core and placed into a spent fuel storage pool. Assemblies within the core are shuffled. Then fresh MOX assemblies are brought from the storage area and loaded into the reactor core. It is possible that irradiated assemblies will be removed from the reactor, stored in the spent fuel storage pool for some period of time, and then reinserted in the reactor. Irradiation intervals in VVER-1000s are 12 months.

Fresh fuel storage locations are currently licensed for LEU fuel. Storage of the MOX fuel will require reanalysis with computational methods. Validation of these methods requires criticality data for water-moderated arrays of MOX pins. These same data should be applicable to certifying some of the physics parameters of MOX fuel in the reactor core. However, configurations that are to be used for certifying reactor physics codes for reactor core design must include accurate measurement of the relative power generation among the piris that compose the critical configuration.

Certification of the reactor core configuration will require critical experiments (either new experiments, proprietary data from Europe, or in-situ measurements at the reactor) in which the reactivity worth of the reactor control materials is verified, the effect of temperature from cold-tooperating conditions on reactivity can be verified, and the effect of moderator voiding can be verified. Some data regarding the composition of the fuel as a function of burnup (both actinides and fission products) should be procured and analyzed, though the establishment of critical configurations may not be feasible. Data for these burnup applications have been procured for MOX fuels in Germany through the use of on-site gamma-scanning equipment for LTAs. Such equipment could potentially be used in Russia.

If cores are to be partially loaded with MOX assemblies, critical experiment benchmarks containing both LEU and MOX fuel pins will be required. Some of these data exist and have already been analyzed. Flux and power measurements at the LEU-MOX interfaces will be especially important.

Spent fuel storage can be licensed based on the same data as for fresh fuel storage. However, it should be possible to economically justify procuring critical experiment data that would allow the incorporation of burnup-credit analyses in the spent fuel storage design. Some applicable burnup credit data may be available from European organizations.

\subsection{REACTOR PHYSICS}

Because MOX fuel has never been loaded to a VVER-1000, fuel assemblies must be designed. This is a resource-intensive procedure requiring many person-years of effort. The goal in designing a fuel assembly is to have a uniform' power density among all pins in the assembly during the lifetime of the assembly. Economic factors (reactor fuel cycle costs) lead the designer to maximize the length of time that the fuel assembly remains in the reactor. Available experience with MOX fuel in France only extends to a burnup of 50,000 MWd/MT. The MOX fuel irradiation should not exceed this value until fuel qualification tests are performed.

Concurrent with assembly design is the development of optimal fuel loading patterns for the reactor core. Fresh and irradiated fuel assemblies can be loaded to the reactor core in an almost infinite number of patterns. However, only a few of these patterns (perhaps only one) will simultaneously meet all safety-related criteria at minimum cost. The search for this optimal loading pattern is a significant effort.

Policy goals influence the fuel cycle and, consequently, the fuel assembly design. Rapid disposition of plutonium dictates that the program be initiated as rapidly as possible and, therefore, 
spend as little time as possible on improvements or modifications to VVER-1000 reactors. As a consequence, the number of MOX assemblies in a reactor core at any given time could not exceed approximately one-third of the total number of assemblies in the core. It is the policy of the Russian Federation that the spent fuel standard for MOX fuel is interpreted as maximizing the energy recovered from a given amount of plutonium. (This policy differs from that of the United States where the utility is only required to achieve a burnup of $20,000 \mathrm{MWd} / \mathrm{MT}$ in the MOX assemblies.) These criteria determine the maximum MOX loading fraction for the core and that, in turn, establishes the fuel assembly design for Phase 1 of the program. Phase 2, by definition, allows for changes to the reactor structure, and as a consequence, a different assembly design will likely be considered.

To illustrate the differences in assembly designs that might arise from the two phases, consider the number of types ("type" meaning fissile fraction of plutonium in the MOX) of plutonium pins that might be fabricated. In Phase 1 , a MOX assembly will be loaded next to an LEU assembly in a reactor. To produce a uniform power distribution, multiple pin types will be loaded in the assembly (probably three or four different types of pins with varying fissile fractions). In Phase 2, a VVER might be fully loaded with MOX assemblies, thereby maximizing the plutonium disposition rate. In an "all-MOX" core, a MOX assembly would have fewer pin types (perhaps only one or two) and would likely have a different pitch (i.e., distance between centers of pins in the assembly) from the Phase 1 assembly. (In addition, for all-MOX cores, the control rod design may have to be modified because of its reduced reactivity worth in the MOX assembly. This might require adding more control rod assemblies or changing the absorber material.)

Economic constraints from other parts of the fuel cycle also impact assembly design. Fuel fabrication plant operators prefer to minimize the number of types of fuel pins that they must manufacture. A large number of fuel pin types is more expensive than a small number. There is also a strong economic incentive to maintain existing fuel assembly designs-existing fuel pin diameter, clad thickness, and rod pitch. Yet these dimensions were optimized for an LEU fuel cycle, and optimal parameters for MOX fuel would likely be different.

Once policy and infrastructure constraints are established, the design of a fuel assembly is an iterative procedure requiring reactor physicists to work with thermal-hydraulics analysts, fuel performance analysts, and reactor control specialists. The core loading configuration must be analyzed as a part of the fuel assembly design process. Safety limits related to departure from nucleate boiling must be demonstrated to be acceptable. Adequate shutdown margin must be preserved. Temperature and void reactivity coefficients must be shown to be acceptable.

After the "equilibrium" or "mission" fuel is designed, then an LTA design must be prepared. The MOX LTA will be irradiated in an "all-LEU" core configuration; therefore, the LTA may be different in some ways from the mission fuel. It may be desirable to have the LTA incorporate larger plutonium loadings than the mission assembly design in order to bound possible operational occurrences expected for mission fuel. Current Russian mission fuel designs call for 6 to 12 uranium-gadolinum (U/Gd) pins to be included in the MOX assembly for reactivity control and power flattening. Consequently, the LTA should also include U/Gd pins to be as representative of mission fuel as possible.

The expected MOX fraction in the mission core will significantly impact the design of the LTA. An LTA for a one-third MOX core would likely be very similar to the mission fuel design. However, an LTA for an all-MOX core would have to be different from the mission fuel assembly design because of edge power-peaking problems. To simulate the interface conditions expected to exist in an all-MOX core, two or perhaps three MOX LTAs would have to be placed side-by-side. An LTA for a one-third MOX core would require only one LTA per symmetric core fragment because the normal operating condition for a MOX assembly in a one-third core would be to be adjacent to an LEU assembly.

Before the design procedure for a MOX assembly can begin, computer programs and data libraries must be verified and validated with applicable data. Some of these studies have been 
completed and are documented in Refs. 1-18. Because the assembly design process is iterative, it may be difficult to determine which data are applicable. The validation process itself is iterative. The initial validation study must be performed, the assembly design studies conducted, and then the validation study reviewed. It may be determined that additional validation experiments and/or calculations are required. These may, in turn, lead to revisions in the assembly design that may again necessitate a review of the applicability of the validation study. At some point in time, the process converges.

The Russian Federation has no critical experiment data for MOX fuel pins. Applicable data have been supplied by the United States. Data are known to exist in Europe but are proprietary and have not been supplied to the Russian Federation. The Russian Federation has stipulated that no new critical experiment data are required for insertion of LTAs into a VVER-1000. No decision has been made regarding the need for additional critical experiments for loading a one-third MOX core into a VVER-1000. If experiments are required, they would likely be performed in the SUPR facility at the IPPE.

Accurate assessment of the reactor operation requires benchmarking of reactor physics methodologies for the calculation of power densities for small spatial regions. The magnitude and location of the "hot spot" in a fuel pin, fuel assembly, or the entire reactor core must be identified because these values will ultimately determine the maximum operating power for the reactor. Hot spot assessments require knowledge of three-dimensional flux and power distributions in addition to fuel thermal properties and heat transfer coefficient calculations. This data need differentiates reactor physics from the criticality safety studies performed to certify the fresh and spent fuel storage areas.

Reactor physicists must certify that computational methodologies are accurate over a range of temperatures (i.e., from room temperature to reactor operating temperatures and beyond for accident analyses). The analyst must be able to predict the time-dependent performance of the neutron flux (and therefore the power of the reactor) under both normal fuel configurations and credible abnormal changes in the physical conditions of the reactor (e.g., inadvertent control rod withdrawal, cold water ingress to the core, and turbine trip). Prediction of reactor response under transient conditions (e.g., pump startup or shutdown, turbine trip, depressurization accidents, stuck control rods, wrongly identified fuel types, and erroneous log-rate signals leading to control rod withdrawal) frequently requires more time and resources than the static design calculations. These studies must be carefully coordinated with thermal-hydraulics analysts. In fact, in certain situations, the physics analyses must be directly coupled to the thermal-hydraulics analyses.

\subsection{CRITICALITY SAFETY}

Fresh and spent fuel storage areas at VVER-1000 reactors are designed for the safe storage of LEU fuel. Calculations are required to determine if existing configurations are safe for MOX assemblies. If existing storage arrays are determined to have an inadequate margin of safety, then facilities must be redesigned and reconstructed. In addition to certifying that the facilities are adequately safe for MOX fuel, the consequences of potential criticality accidents must be evaluated. The time-dependent behavior of a criticality accident must be postulated and studied to ensure that plant personnel are adequately shielded and that criticality alarms are placed in sufficient numbers in proper locations.

Critical experiment data for benchmarking computer programs and data libraries will include data for arrays of MOX fuel pins and for mixtures of MOX and LEU fuel. While reactor physicists must certify that computational methodologies are accurate over a range of temperatures (i.e., from room temperature to reactor operating temperatures and beyond for accident analyses), generally, criticality safety calculations only require "room temperature" data. Criticality excursions generally self-terminate prior to significant changes in the system temperature. 


\subsection{SHIELDING}

MOX fuel is considerably more radioactive than LEU fuel. While the absolute values of the neutron and gamma dose rates remain quite small, the large relative difference between MOX and LEU values (a factor of 1000) may result in violations of some regulatory limits. Modifications to the physical plant might be required.

Inside the reactor vessel, during irradiation, the neutron leakage spectra is harder (energy of the escaping neutrons is higher) than that for an LEU assembly. The impact of this higher-energy neutron flux on both in-core components and on the reactor pressure vessel will have to be assessed. Computational methods will be required for these analyses.

For spent MOX fuel storage, shielding considerations should be the same as those for LEU fuel, albeit the neutron source for MOX will be greater than for comparably irradiated LEU. Some reanalysis will be required, but the additional work will be relatively small.

\subsection{ENVIRONMENTAL SOURCE TERMS}

Actinide and fission product inventories in a MOX-fueled VVER will be significantly different from those of an LEU core. These inventories will have to be calculated for beginning- and end-of-life and will be dependent on the fraction of the assemblies in the core that are MOX.

\subsection{DECAY HEAT SOURCE TERM AND OTHER ANALYSES}

The decay heat source term for a MOX-fueled core (or a single MOX assembly) will differ from that of an LEU core. The decay heat source for a MOX core in the reactor should be lower than that of an LEU core, but the decay heat source for multiyear-cooled MOX assemblies will be higher than that for comparably cooled LEU assemblies. For the reactor core, the source will depend on the number of assemblies in the core that are MOX. For an individual assembly, the value will depend on the fuel management scheme employed. 


\section{THE AWAY-FROM-REACTOR SPENT FUEL OPERATIONS}

The away-from-reactor spent fuel operations include transportation of spent MOX fuel. Significant safety-related differences exist between the spent LEU and spent MOX fuels. The neutron source strength for MOX fuels will be higher than for comparably irradiated LEU fuels. Fission product inventories in spent MOX fuel differ from spent LEU with some hazardous fission product inventories being lower but other hazardous actinide inventories being higher. While existing spent fuel transport casks may be acceptable for MOX fuel, safety analyses will have to be repeated for MOX fuel because of the differences in source terms. Types of analyses will be similar to those noted for fresh MOX fuel.

Note that it may be possible to load MOX assemblies in the center of the shipping cask with LEU assemblies loaded in the external positions. The LEU assemblies would then shield the MOX assemblies so that dose rates external to the shipping cask would be essentially the same as those for a cask containing all LEU assemblies. 


\section{OTHER PHYSICS STUDIES}

\subsection{ALTERNATIVE DISPOSITION RATE STUDIES}

Policy decisions within the FMDP are still being made. It is currently uncertain whether the U.S. government will urge modifications to VVER-1000s to enhance plutonium throughput or will urge the participation of other countries with VVER-1000s in the FMDP. There is a congressional mandate to link the U.S. and Russian programs in terms of quantity of plutonium disposed. If policy decisions are made which impact the fraction of assemblies in the VVER core that will be MOX, then the entire design process (with the exception of validation and verification studies) must be replicated.

\subsection{INPUT TO ECONOMIC EVALUATIONS}

An output of reactor physics studies is the expected annual demand for MOX and LEU assemblies. These parameters are very important input to economic studies of the cost of plutonium disposition in Russia. Furthermore, these values must be known to properly size MOX fuel fabrication plants, to plan for transportation shipments, and to assess storage requirements at reactor sites.

\subsection{TECHNICAL SUPPORT TO DISPOSITION IN CANDU REACTORS}

One option for plutonium disposition is to manufacture Canadian deuterium-uranium (CANDU) reactor MOX fuel elements in Russia and irradiate the material in Canadian reactors. The physics effort for such a fuel cycle is comparable to that required for disposition in VVERs in Russia. Responsibility for these physics analyses is assigned to Canada.

\subsection{TECHNICAL SUPPORT TO DISPOSITION IN FAST REACTORS}

Fast reactor fuel elements will be manufactured in Russia and irradiated in the fast reactor, $\mathrm{BN}-600$. The physics analysis effort for such a fuel cycle is less than that required for disposition in VVERs in Russia because the BN-600 was originally designed to be fueled with MOX. Responsibility in the United States for these physics analyses is assigned to staff at Argonne National Laboratory.

\subsection{TECHNICAL SUPPORT TO DISPOSITION IN GAS-COOLED REACTORS}

One option for plutonium disposition is to manufacture gas-cooled reactor fuel elements in Russia and irradiate the material in a Russian modular gas-cooled reactor. Responsibility in the United States for these physics analyses is assigned to General Atomics. 


\section{A COMPREHENSIVE ROADMAP FOR PHYSICS ANALYSES}

As a tool for program managers, a set of "roadmaps" has been created to show the extent of the FMDP. The "Level 1" roadmap, provided in Appendix C, is intended to provide a large-scale view of the entire program. In this section, a detailed dissection of selected Level 1 tasks (boxes) is provided. This expansion of Level 1 tasks is provided as Fig. 3 and is termed a "Level 2+" roadmap. This roadmap is based on data presented in Appendix D. The Level 1 tasks are identified in the level " $A$ " boxes in Fig. 3. The assembly of the multiple pages that compose Fig. 3 into a single sheet is accomplished by matching the diamond connectors at the edges of the pages.

Figure 3 is termed a Level $2+$ roadmap because it includes multiple programmatic administrative levels. A separate task within the FMDP led to the development of a draft "Level 2" roadmap, which is contained in Appendix E. A future task for program management is to integrate the Level $1,2+$, and 2 roadmaps. 

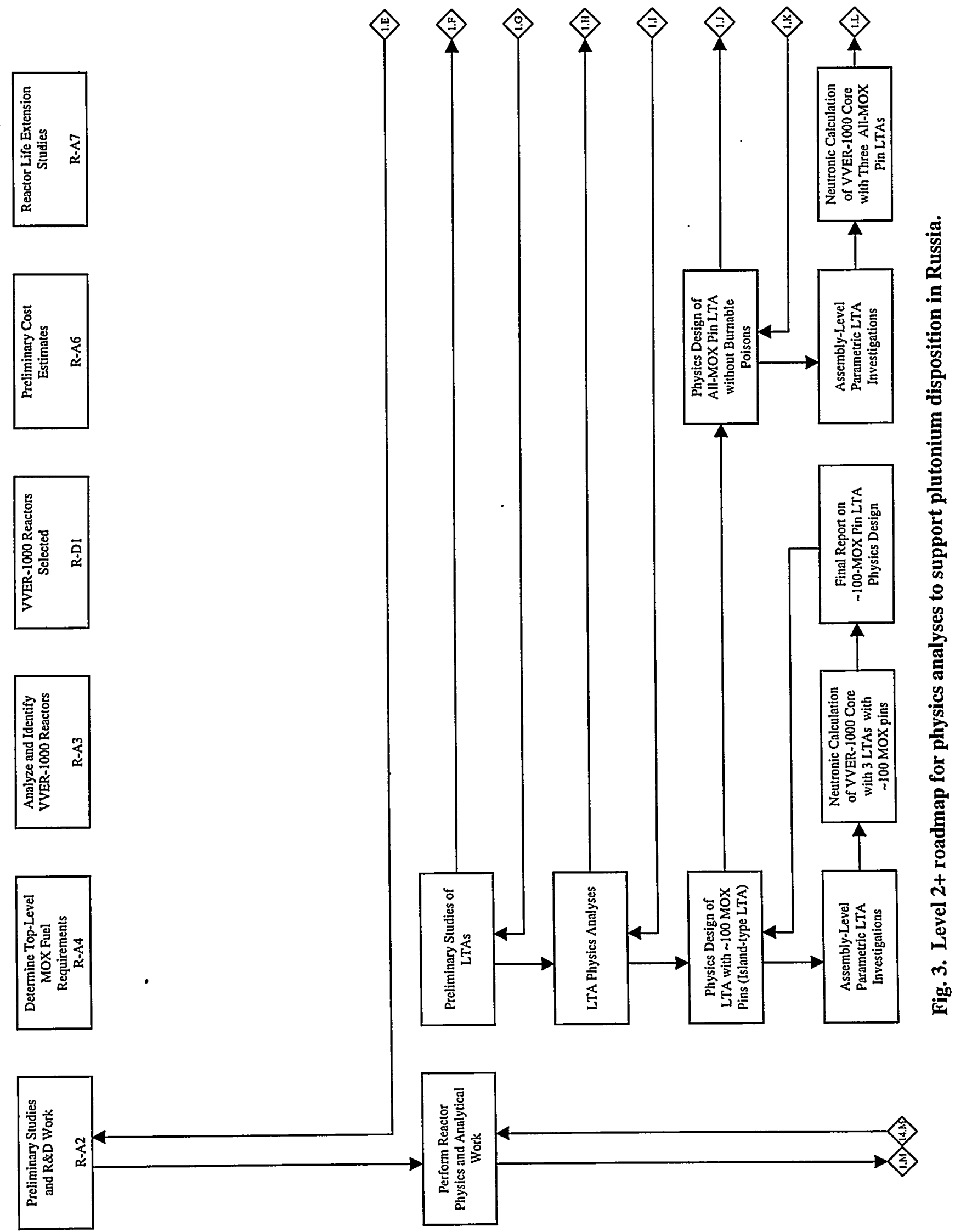

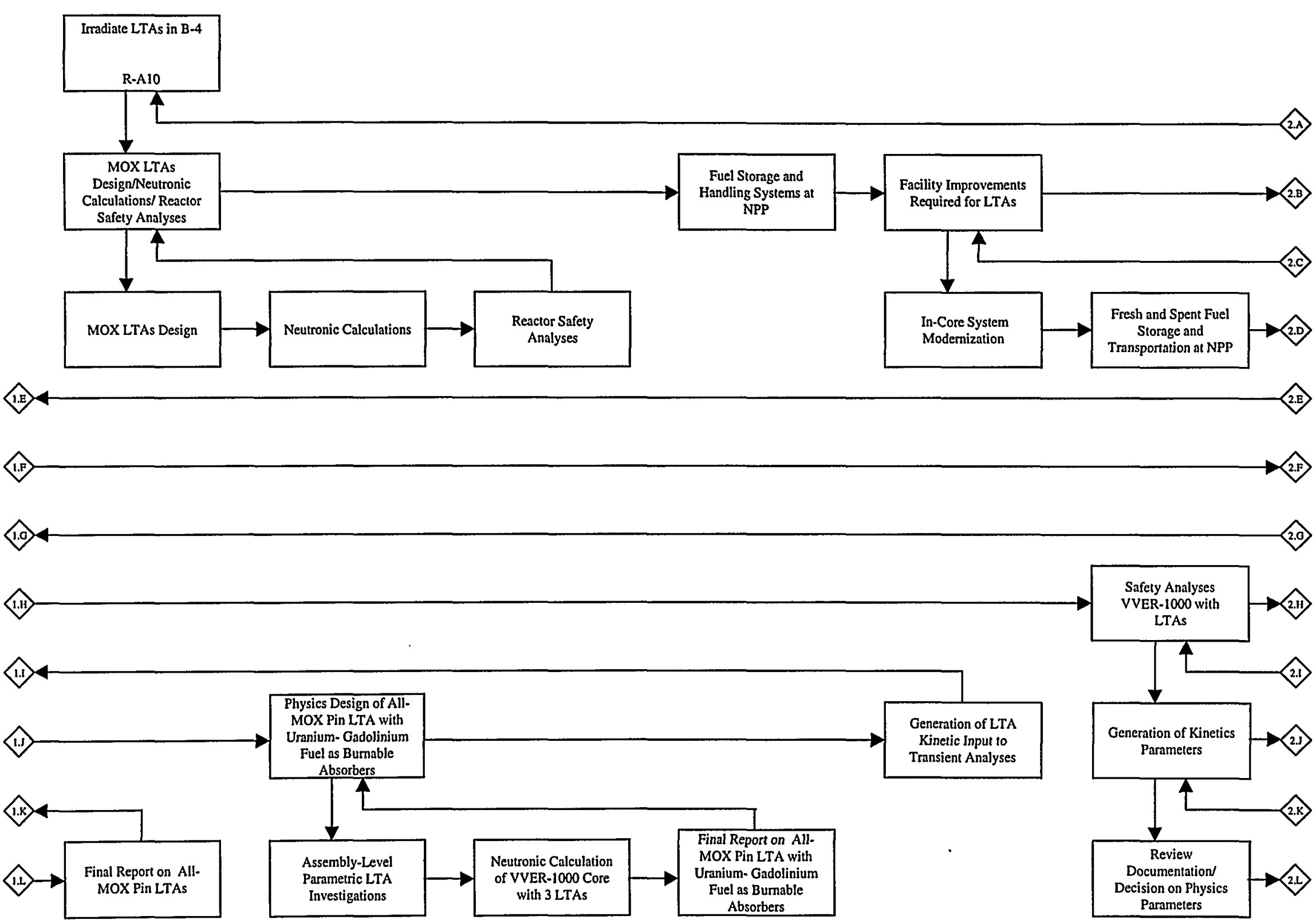

Fig. 3. (continued). 


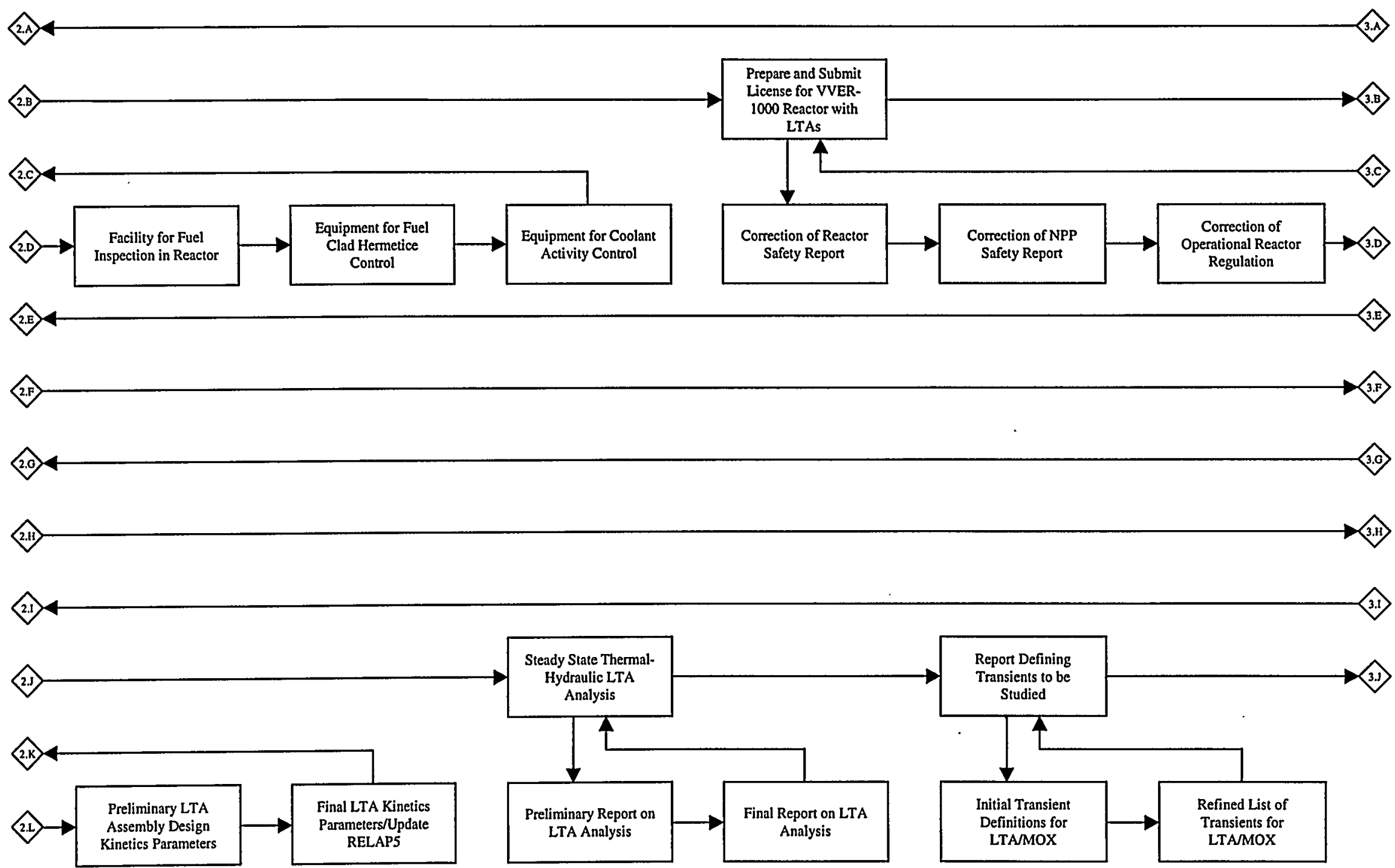

Fig. 3. (continued). 

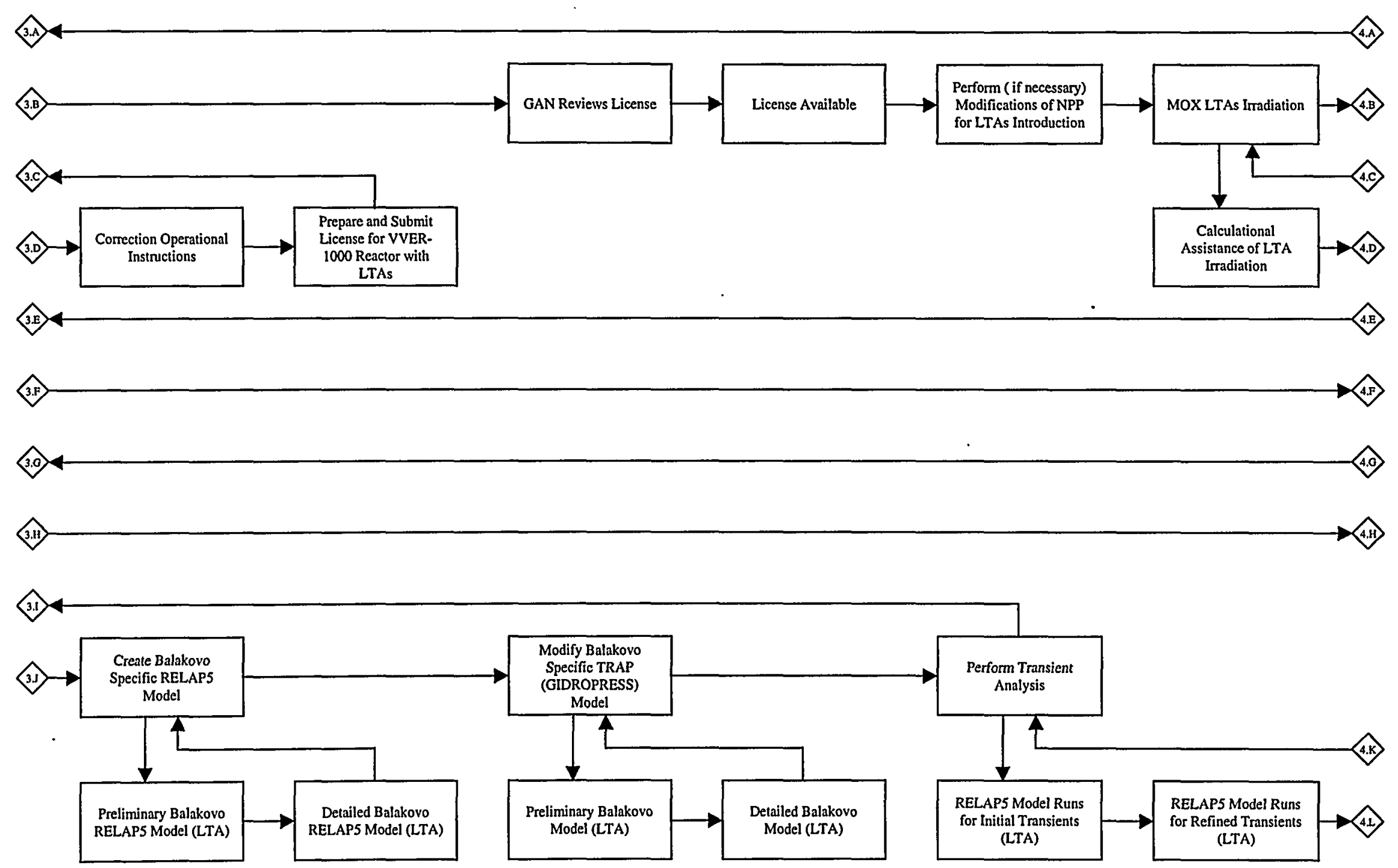

Fig. 3. (continued). 

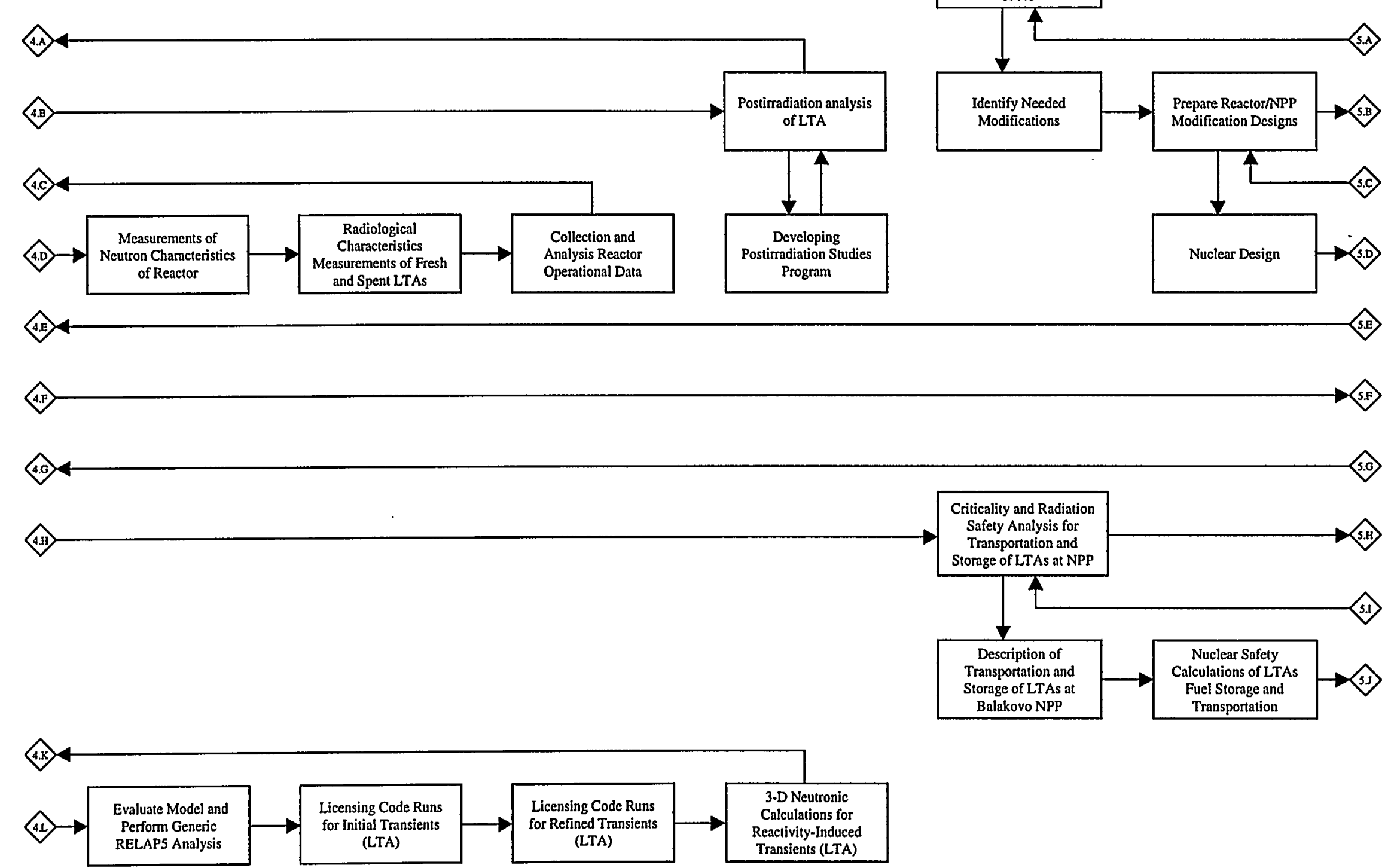

Fig. 3. (continued). 


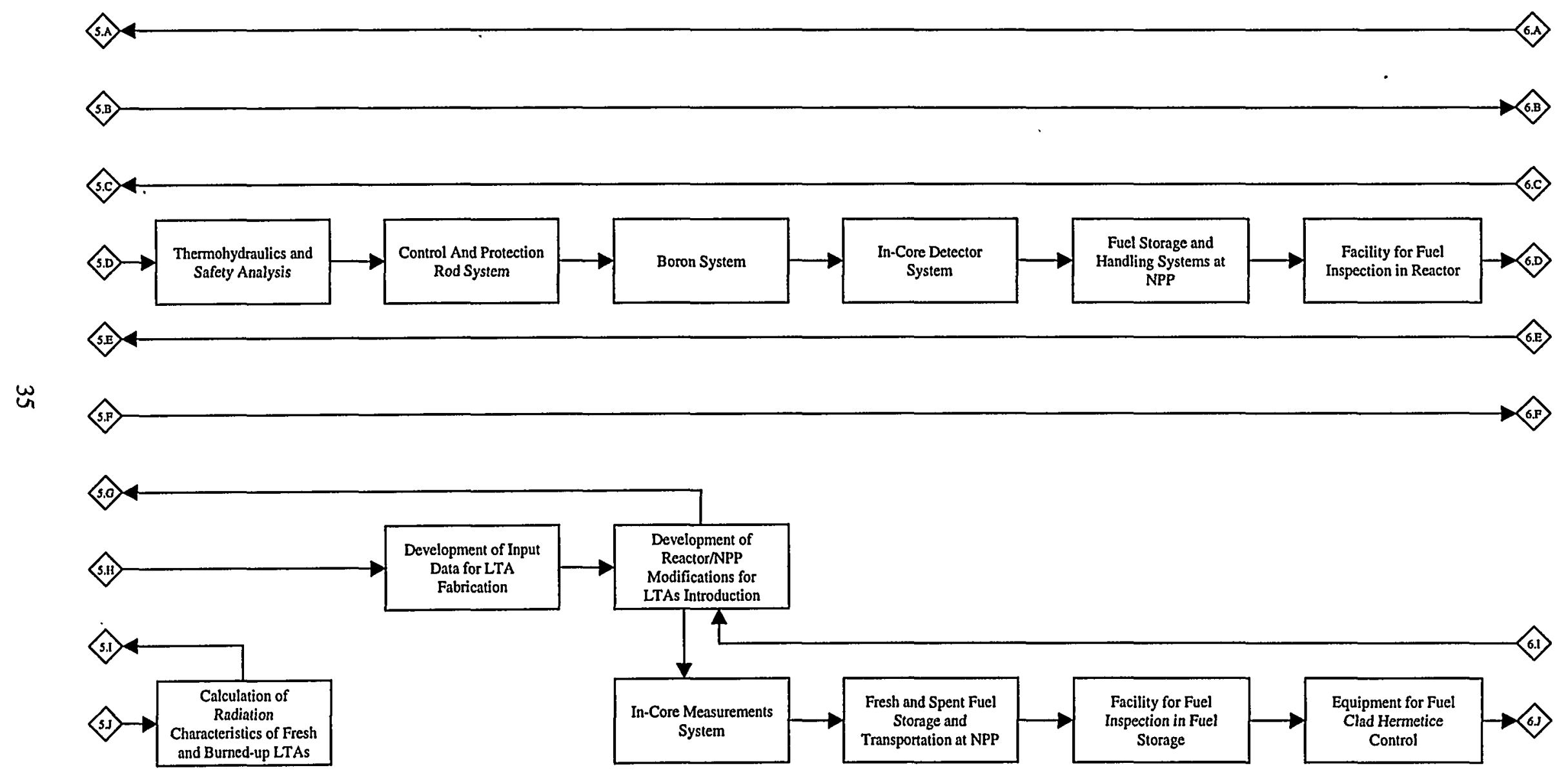

Fig. 3. (continued). 


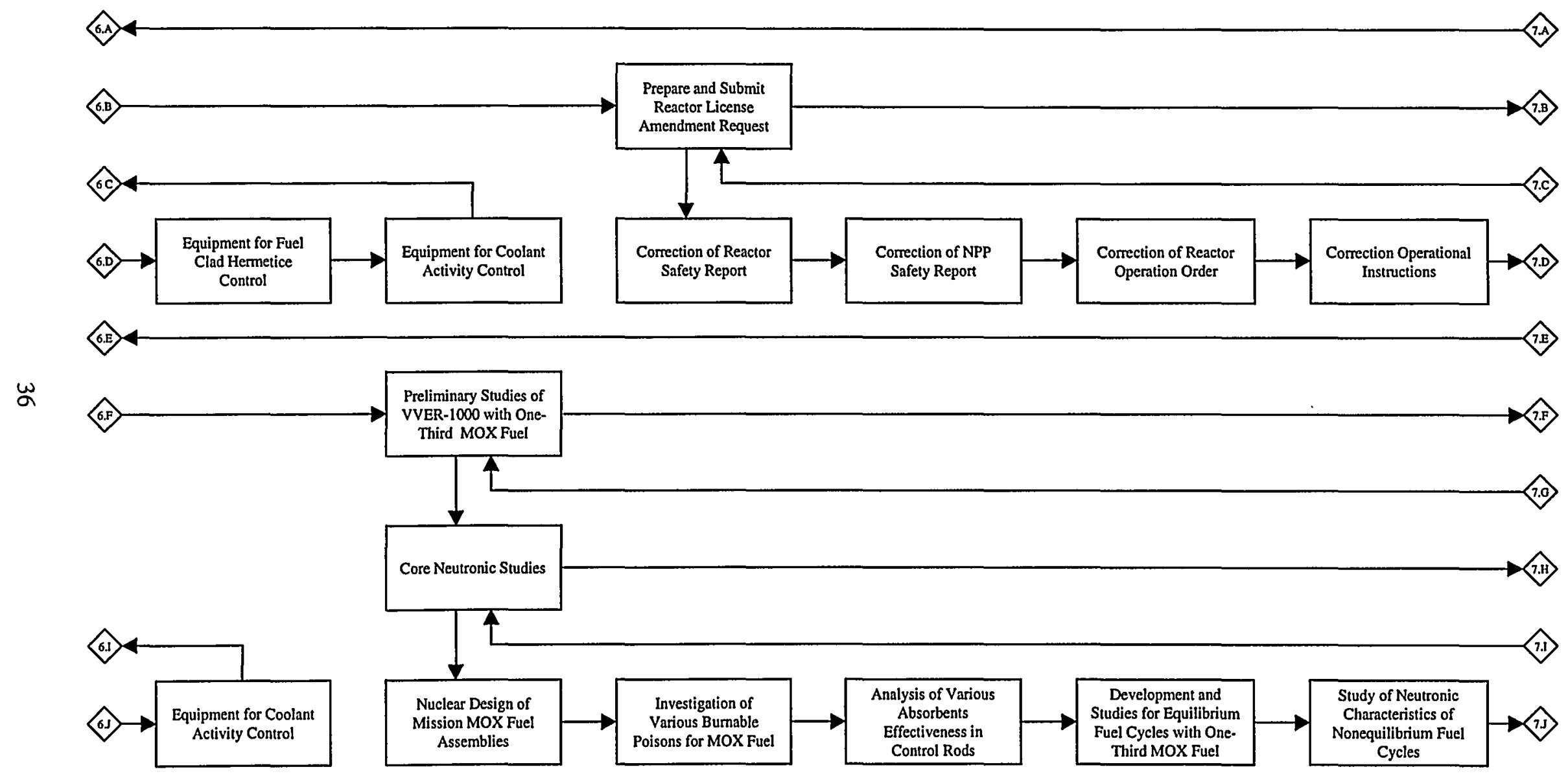

Fig. 3. (continued). 


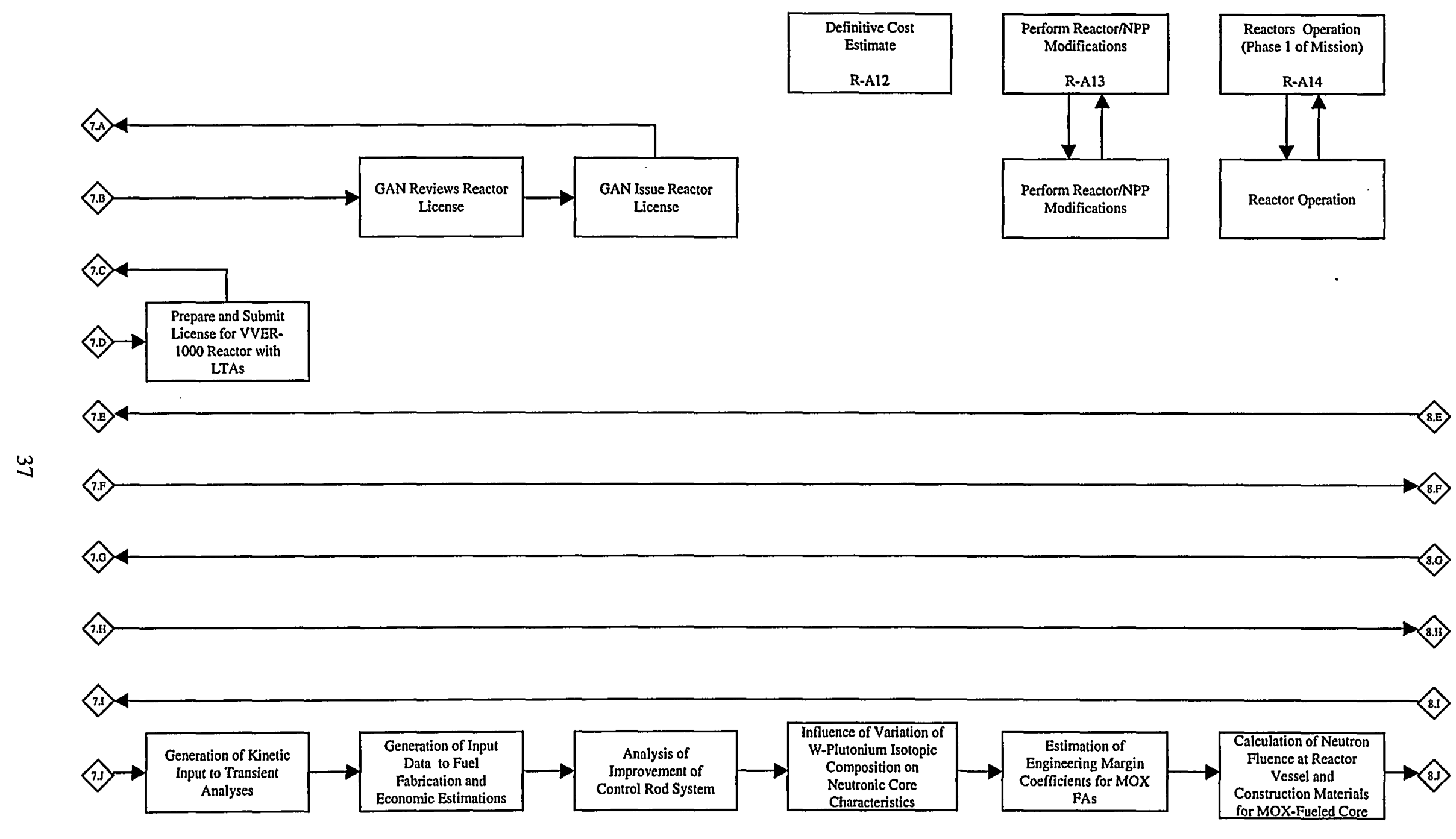

Fig. 3. (continued). 

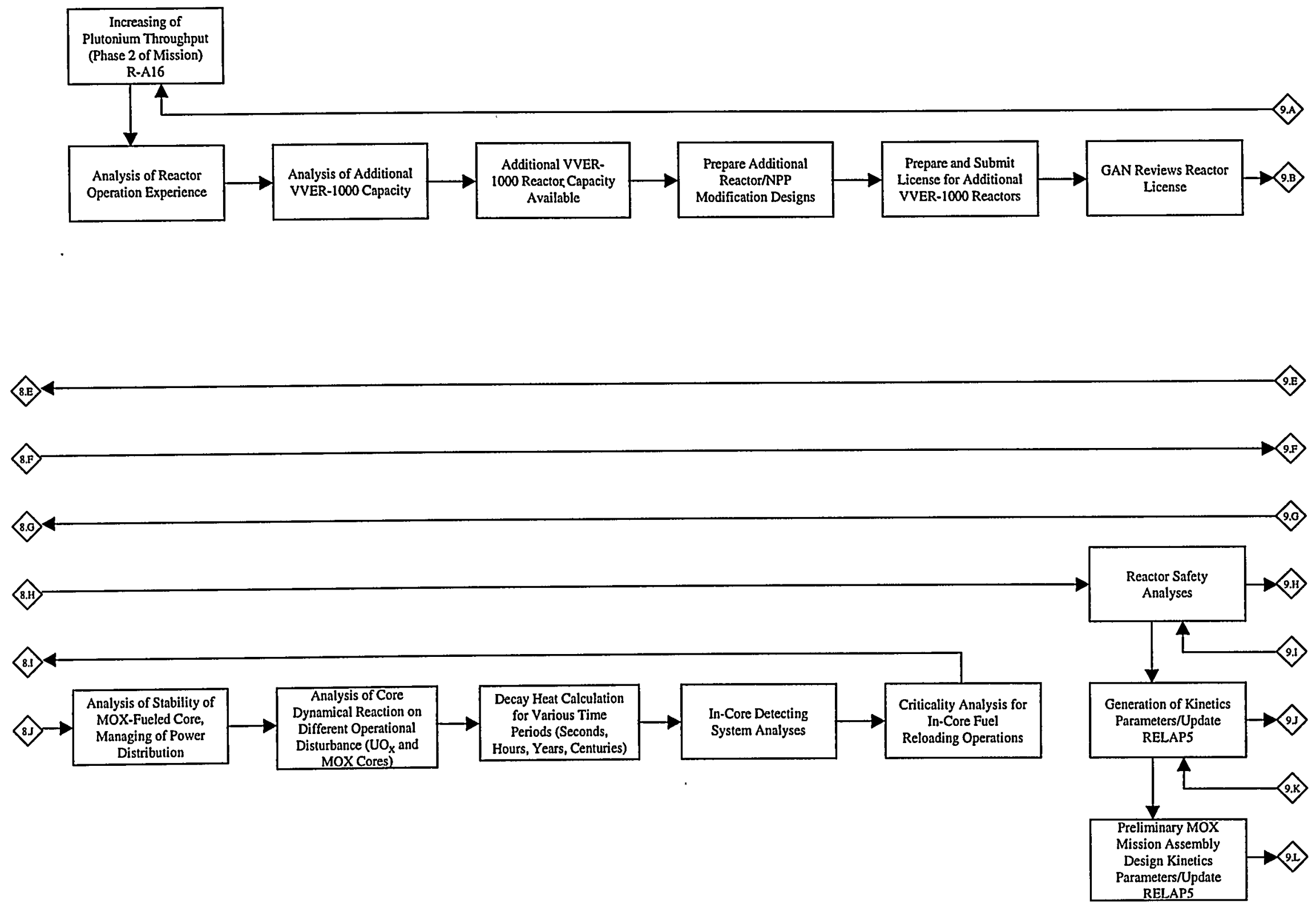

Fig. 3. (continued). 

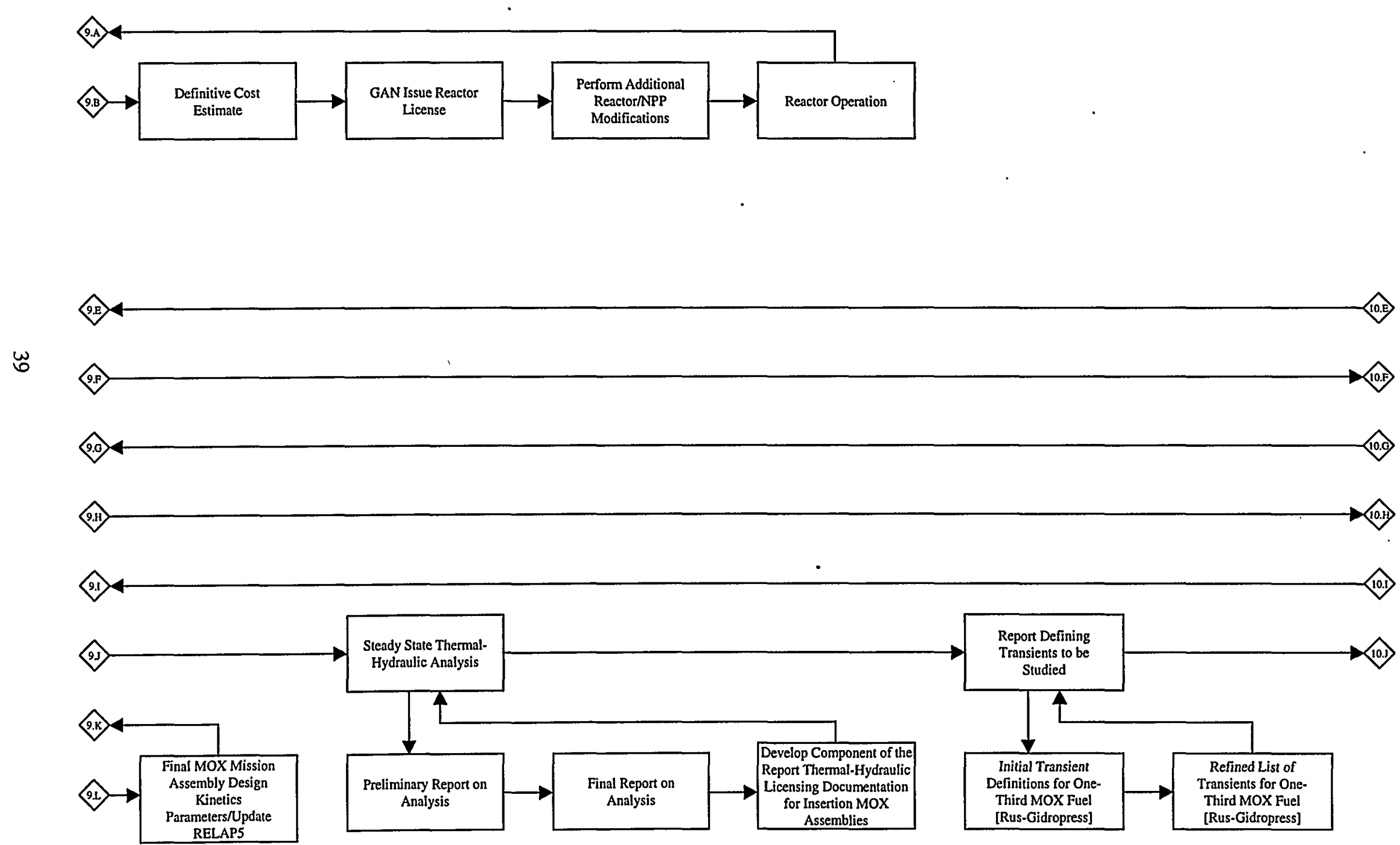

Fig. 3. (continued). 


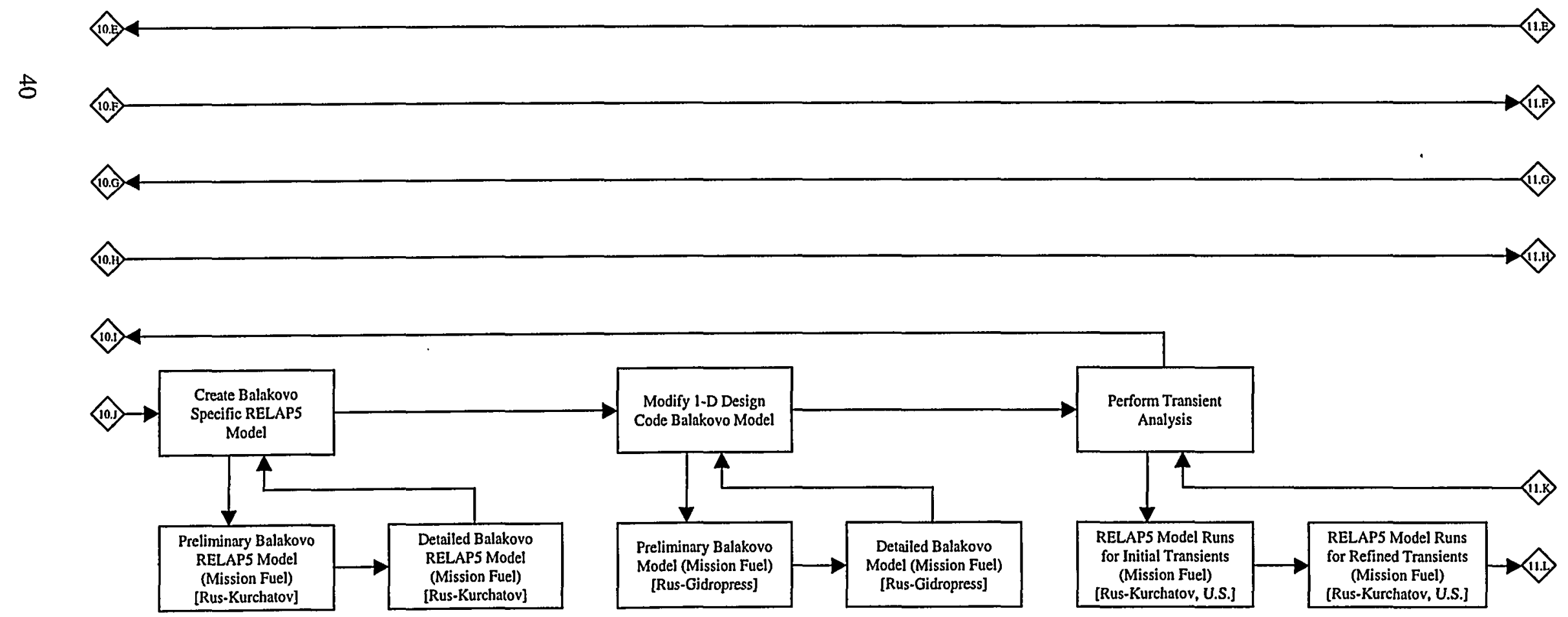

Fig. 3. (continued). 

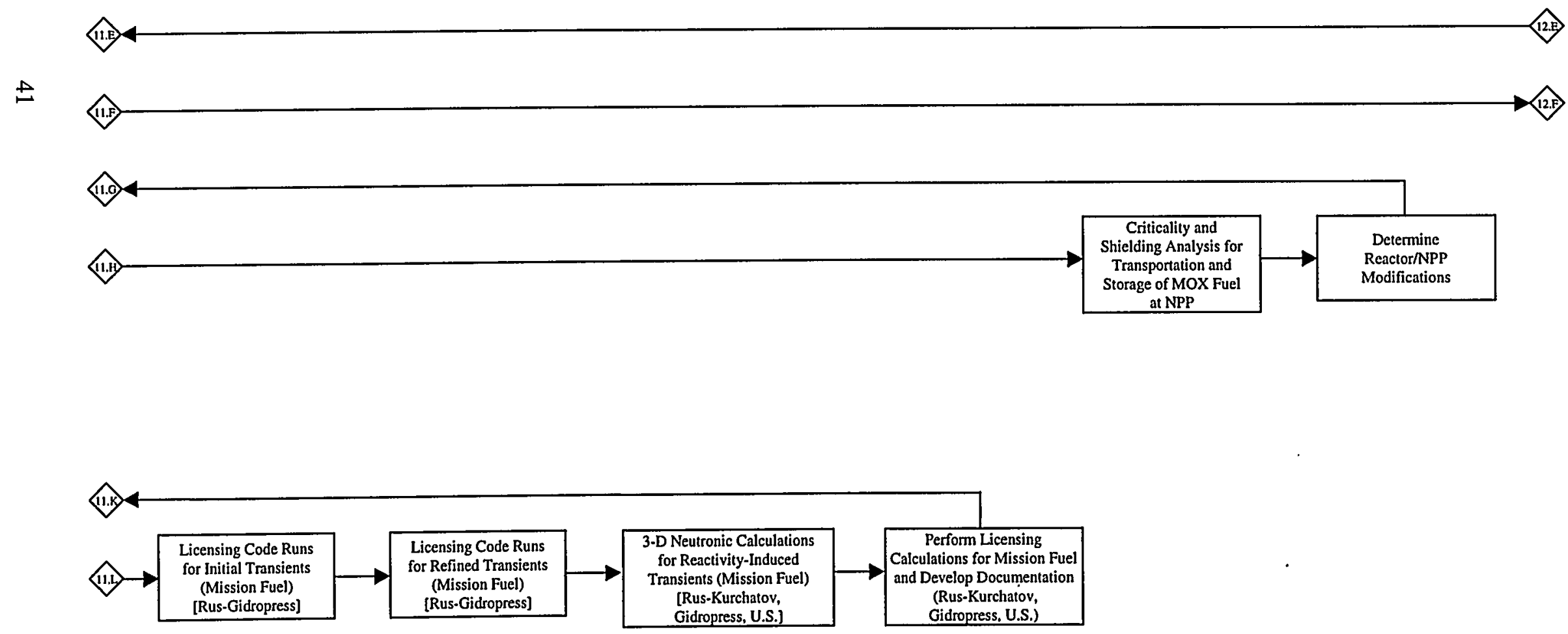

Fig. 3. (continued). 


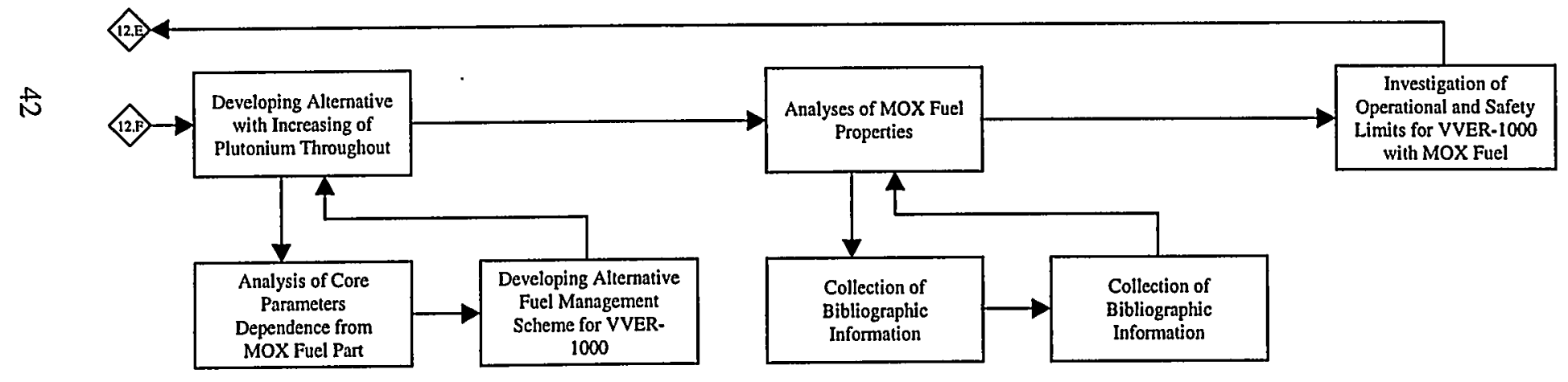

Fig. 3. (continued). 


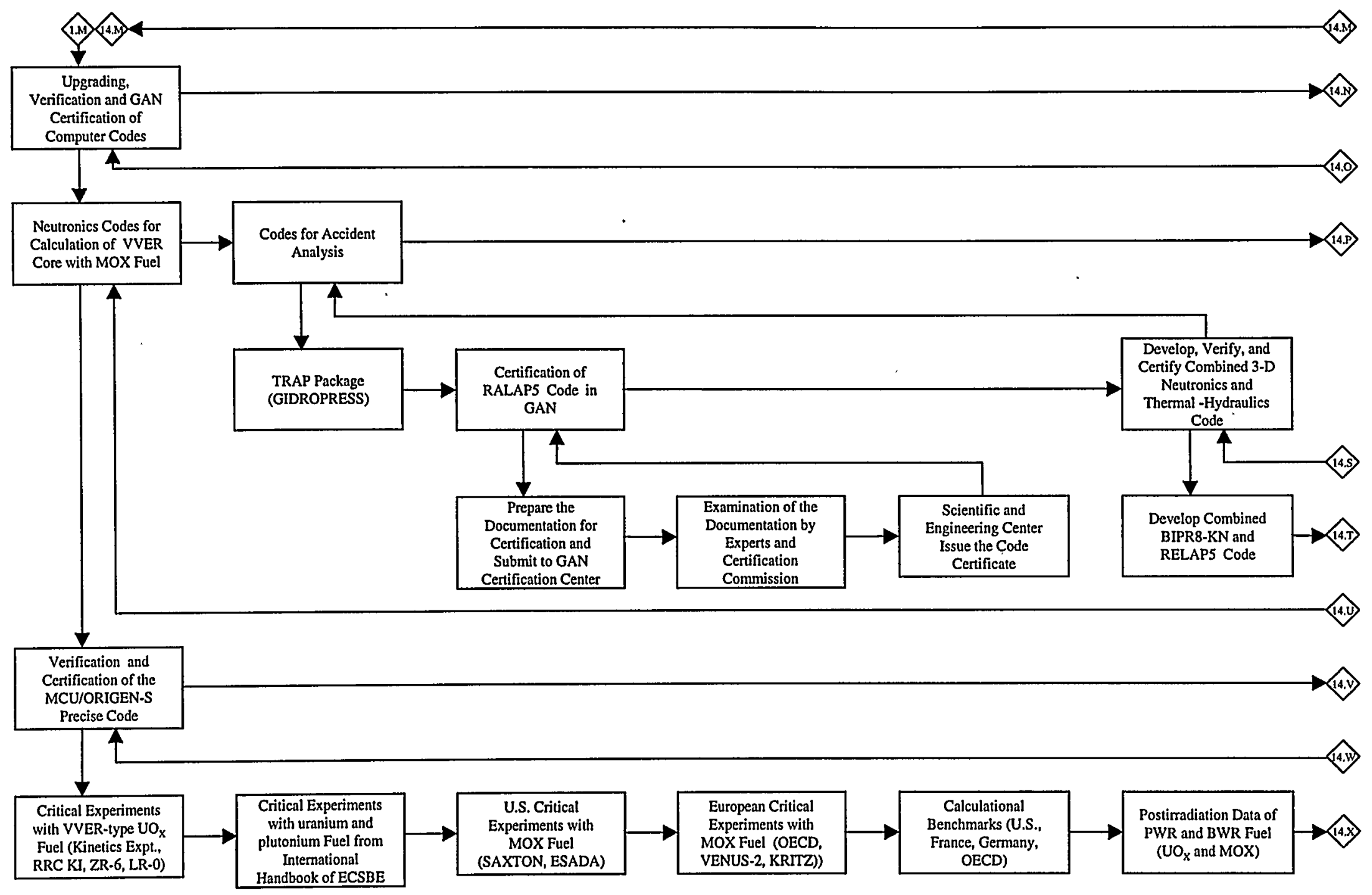

Fig. 3. (continued). 

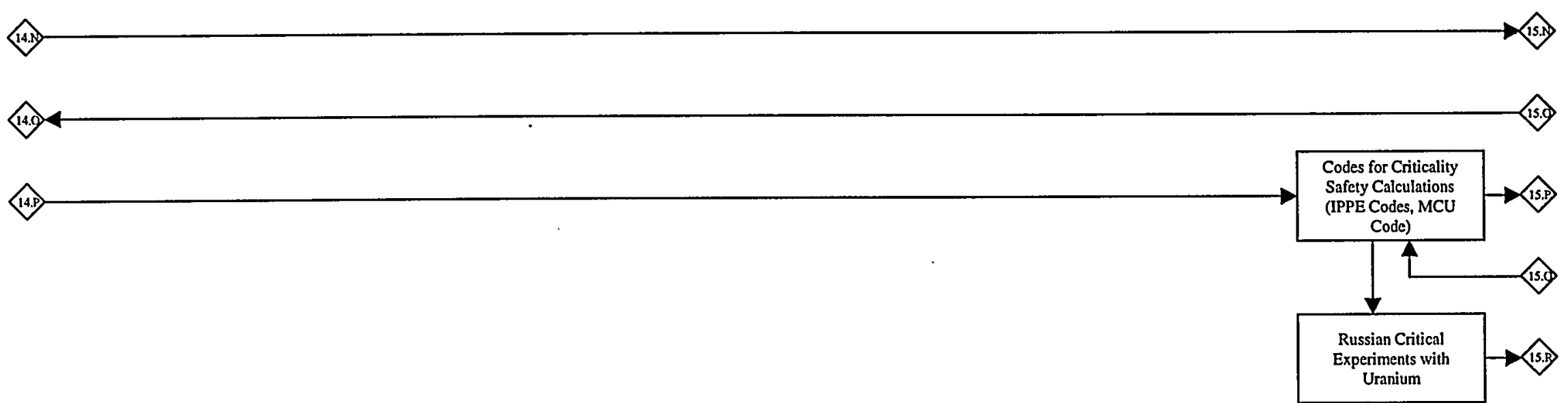

太
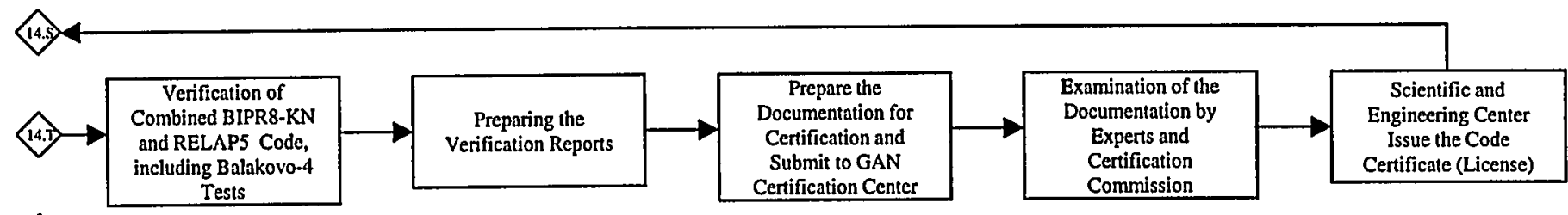

(14.1)

(14.)

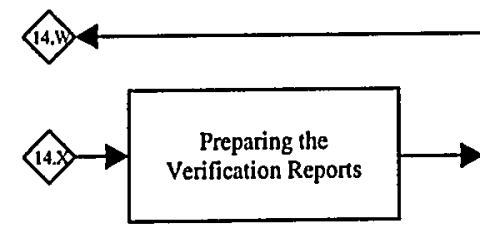

\begin{tabular}{c} 
Certification of \\
MCU/ORIGEN-S \\
Code for MOX Fuel \\
Calculations in GAN \\
\hline
\end{tabular}
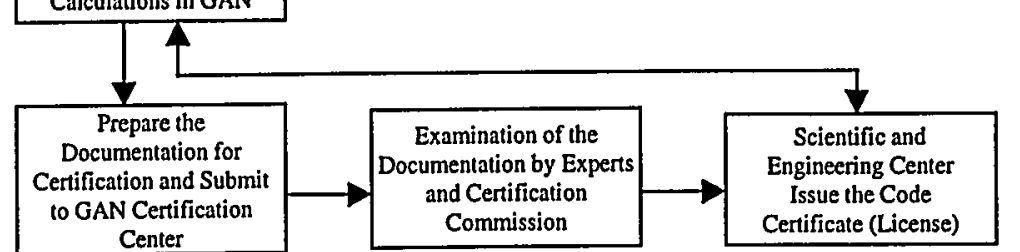

Additional Verification
of the MCU/ORIGEN-S Precision Code

Fig. 3. (continued).

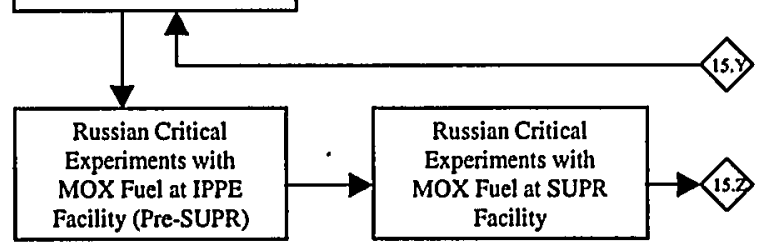



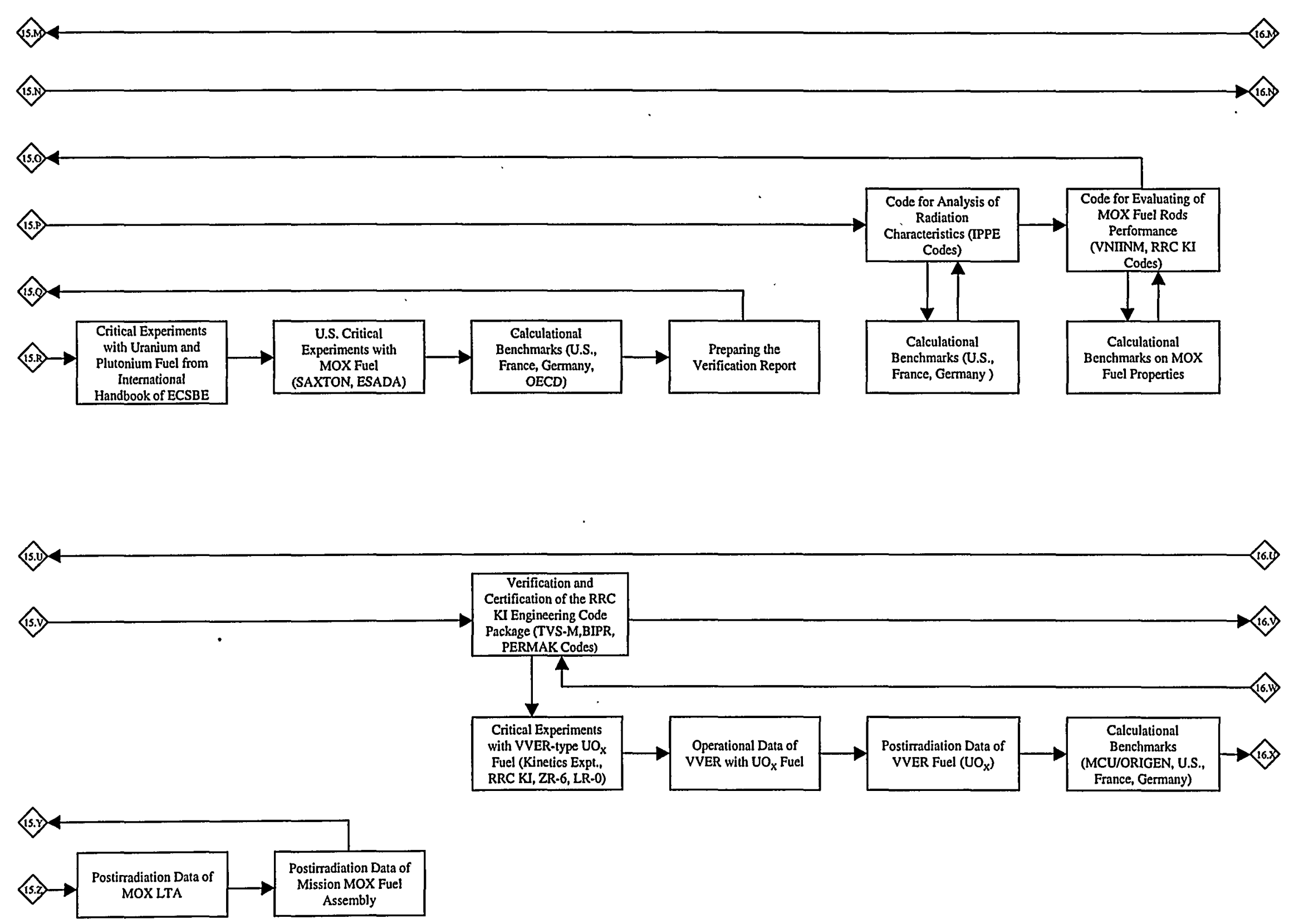

Fig. 3. (continued). 

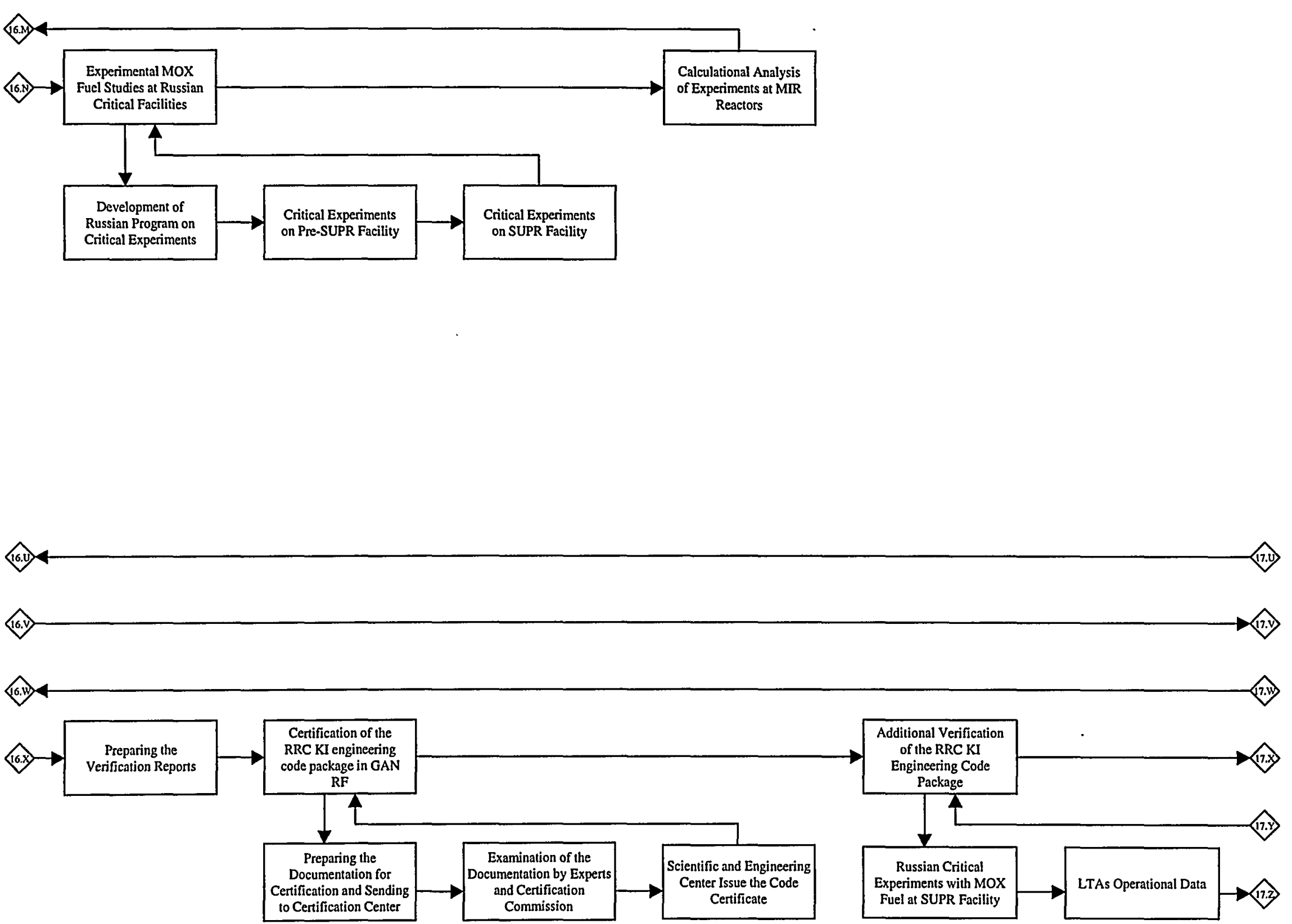

Fig. 3. (continued). 


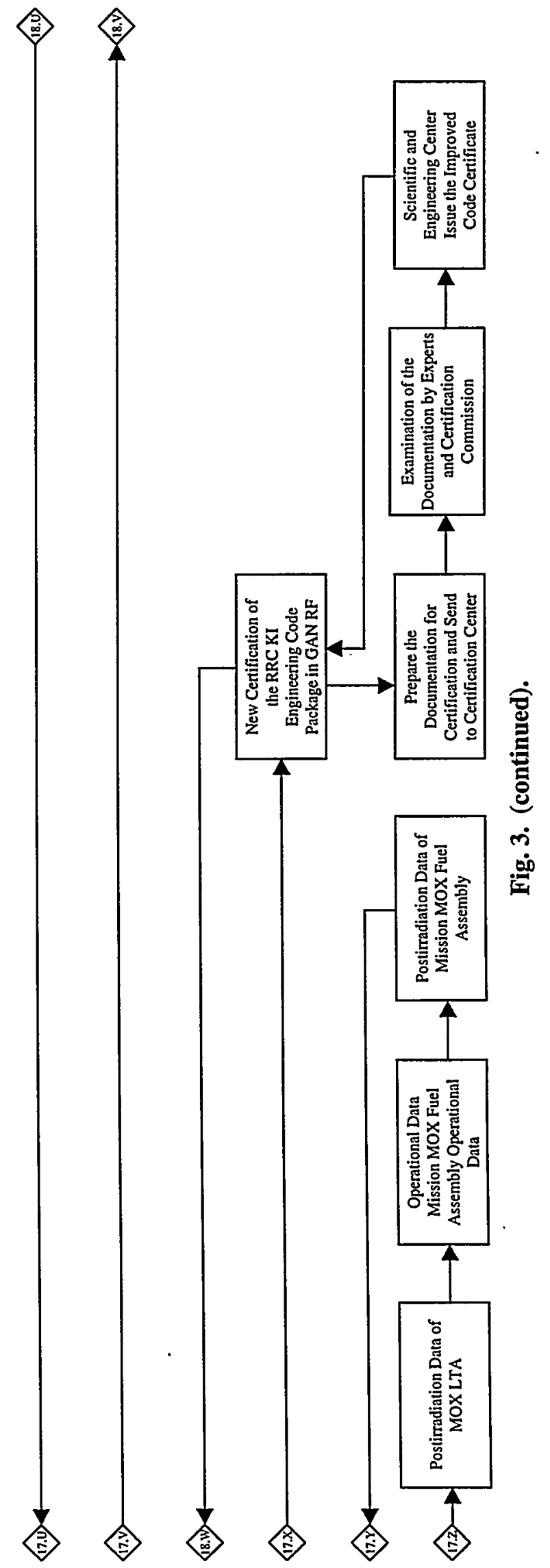




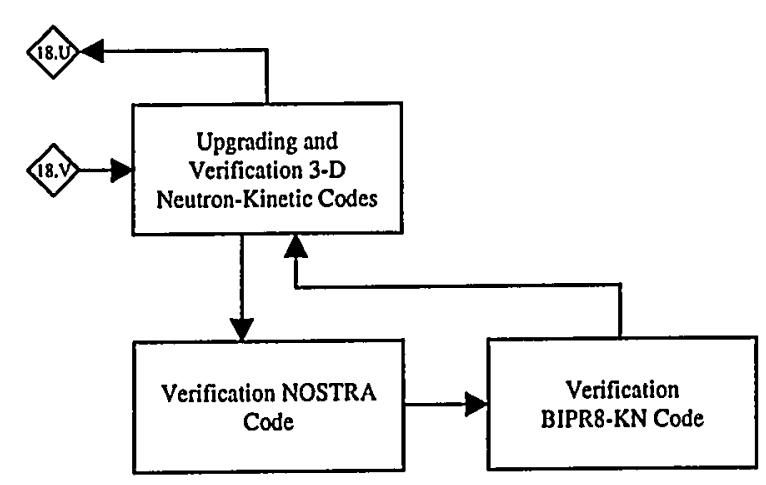

Fig. 3. (continued). 


\section{REFERENCES}

1. R. T. Primm III, ed. Neutronics Benchmarks for the Utilization of Mixed-Oxide Fuel: Joint U.S./Russian Progress Report for Fiscal Year 1997, Volume 3-Calculations Performed in the Russian Federation, ORNL/TM-13603/V3, Lockheed Martin Energy Research Corp., Oak Ridge National Laboratory, June 1998.

2. B. D. Murphy, J. Kravchenko, A. Lazarenko, A. M. Pavlovitchev, V. Siderenko, and A. Chetveikov, Simulation of Low-Enriched Uranium (LEU) Burnup in Russian VVER Reactors with the HELIOS Code Package, ORNL/TM-1999/168, Lockheed Martin Energy Research Corp., Oak Ridge National Laboratory, March 2000.

3. O. W. Hermann, San Onofre PWR Data for Code Validation of MOX Fuel Depletion Analyses-Revision 1, ORNL/TM-1999/108/R1, Lockheed Martin Energy Research Corp., Oak Ridge National Laboratory, March 2000.

4. J. C. Gehin, C. Dourougie, M. B. Emmett, and R. A. Lillie, Analysis of Weapons-Grade MOX VVER-1000 Benchmarks with HELIOS and KENO, ORNL/TM-1999/78, Lockheed Martin Energy Research Corp., Oak Ridge National Laboratory, July 1999.

5. H. Akkurt and N. M. Abdurrahman, Neutronics Benchmarks for the Utilization of MixedOxide Fuel: Joint U.S./Russian Progress Report for Fiscal Year 1997, Volume 4, Part 4 -ESADA Plutonium Program Critical Experiments: Single-Region Core Configurations, ORNL/SUB/ 99-XSZ175V-1, Lockheed Martin Energy Research Corp., Oak Ridge National Laboratory, May 1999.

6. H. Akkurt and N. M. Abdurrahman, Neutronics Benchmarks for the Utilization of MixedOxide Fuel: Joint U.S./Russian Progress Report for Fiscal Year 1997, Volume 4, Part 5-ESADA Plutonium Program Critical Experiments: Multiregion Core Configurations, ORNL/SUB/ 00-XSZ175V-1, Lockheed Martin Energy Research Corp., Oak Ridge National Laboratory, February 2000.

7. E. B. Emmett, Calculational Benchmark Problems for VVER-1000 Mixed Oxide Fuel Cycle, ORNL/TM-1999/207, Lockheed Martin Energy Research Corp., Oak Ridge National Laboratory, March 2000.

8. A. M. Pavlovitchev, A. A. Gorokhov, V. K. Ivanov, and Y. A. Styrin, Kinetics Parameters of WVER-1000 Core with 3 MOX Lead Test Assemblies to be Used for Accident Analysis Codes, ORNL/SUB/99-B99398V-2, Lockheed Martin Energy Research Corp., Oak Ridge National Laboratory, February 2000.

9. A. M. Pavlovitchev, A. G. Kalashnikov, M. A. Kalugin, A. P. Lazarenko, L. V. Maiorov, and V. D. Sidorenko, Creation of Computational Benchmarks for LEU and MOX Fuel Assemblies Under Accident Conditions, ORNL/SUB/99-B99398V-1, Lockheed Martin Energy Research Corp., Oak Ridge National Laboratory, November 1999.

10. M. Yavuz, Neutronics Benchmarks for the Utilization of Mixed-Oxide Fuel: Joint U.S./Russian Progress Report for Fiscal Year 1997, Volume 4, Part 7-Homogeneous Mixtures of Polystyrene-Moderated Plutonium and Uranium Oxides, ORNL/SUB/99-XSZ175V-2, Lockheed Martin Energy Research Corp., Oak Ridge National Laboratory, May 1999.

11. M. Yavuz, Neutronics Benchmarks for the Utilization of Mixed-Oxide Fuel: Joint U.S./Russian Progress Report for Fiscal Year 1997, Volume 4, Part 8-Neutron Poison Plates in Assemblies Containing Homogeneous Mixtures of Polystyrene-Moderated Plutonium and Uranium Oxides, ORNL/SUB/99-XSZ175V-3, Lockheed Martin Energy Research Corp., Oak Ridge National Laboratory, May 1999.

12. A. M. Pavlovitchev, A. A. Alioshin, S. N. Bolshagin, S. A. Bychkov, A. P. Lazarenko, A. D. Sidorenko, and Y. A. Styrin, Design Studies of "Island" Type MOX Lead Test Assembly, ORNL/SUB/99-B99398V-3, Lockheed Martin Energy Research Corp., Oak Ridge National Laboratory, March 2000. 
13. S. E. Fisher and F. C. Difilippo, Neutronics Benchmark for the Quad Cities-1 (Cycle 2) Mixed-Oxide Assembly Irradiation, ORNL/TM-13567, Lockheed Martin Energy Research Corp., Oak Ridge National Laboratory, April 1998.

14. O. W. Hermann, Benchmark of SCALE (SAS2H) Isotopic Predictions of Depletion Analyses for San Onofre PWR MOX Fuel, ORNL/TM-1999/325, Lockheed Martin Energy Research Corp., Oak Ridge National Laboratory, February 2000.

15. D. F. Hollenbach and P. B. Fox, Neutronics Benchmarks of Mixed-Oxide Fuels Using the SCALE/CENTRM Sequence, ORNL/TM-1999/299, Lockheed Martin Energy Research Corp., Oak Ridge National Laboratory, February 2000.

16. A. M. Pavlovitchev, S. A. Bychkov, A. A. Lazarenko, V. D. Sidorenko, and Y. A. Styrin, Results of Parametric Design Studies of MOX Lead Test Assembly, ORNL/SUB/ 98-85B99398V-1, Lockheed Martin Energy Research Corp., Oak Ridge National Laboratory, December 1998.

17. A. M. Pavlovitchev, A. A. Aleshin, S. N. Bolshagin, N. A. Bychkova, Y. A. Styrin, and M. Y. Tomilov, Results of Parametric Design Studies of VVER-1000 Core with MOX Lead Test Assemblies, ORNL/SUB/98-85B99398V-2, Lockheed Martin Energy Research Corp., Oak Ridge National Laboratory, December 1998.

18. Z. N. Chizhikova, A. G. Kalashnikov, E. N. Korobitsy, G. N. Manturov, and A. A. Tsiboulia, Verification Calculation Results to Validate the Procedures and Codes for Pin-by-Pin Power Computation in VVER Type Reactors with MOX Fuel Loading, ORNL/SUB/ 98-85B99398V-3, Lockheed Martin Energy Research Corp., Oak Ridge National Laboratory, December 1998. 
Appendix A

GOSATOMNADZOR REVIEW PROCESS

A-1 
A-2 


\section{Appendix A. GOSATOMNADZOR REVIEW PROCESS}

The first interaction between the FMDP and GAN in the physics area will be the certification of Russian computer programs and nuclear data for the analyses of MOX fuels (both the safety of the fuel cycle and the analyses of the reactor). This certification is marked by the issuance of a Certification Passport. The contents of this passport are shown in Fig. A.1. Current plans call for a joint U.S./R.F. submission to GAN in mid-2001 of all necessary analyses to support issuance of Passports for the Russian computer programs and nuclear data libraries that are noted in Appendix B.

The procedure for code certification follows the organization structure of GAN that is shown in Fig. A.2. The "Experts" noted at the base of the organization structure will include individuals from the Kurchatov Institute, IPPE, and other organizations. Details of the certification procedure are shown in Fig. A.3.

- Name of the code

ORNL 2000-1271 EFG

- Hardware

- Operational system

- Code author(s) - name(s) and organization

- Main user (applicant)

- The problems solved by code

- Reactor type

- Reactor regimes

- Restrictions

- Permitted values of the reactor (installation) parameters

- Accuracy of calculations

- Methods involved

- Databases (libraries) used

- Users that have the permission to use the code

- Auxiliary information

- Official experts approved by commission

Fig. A.1. Certification passport contents. 


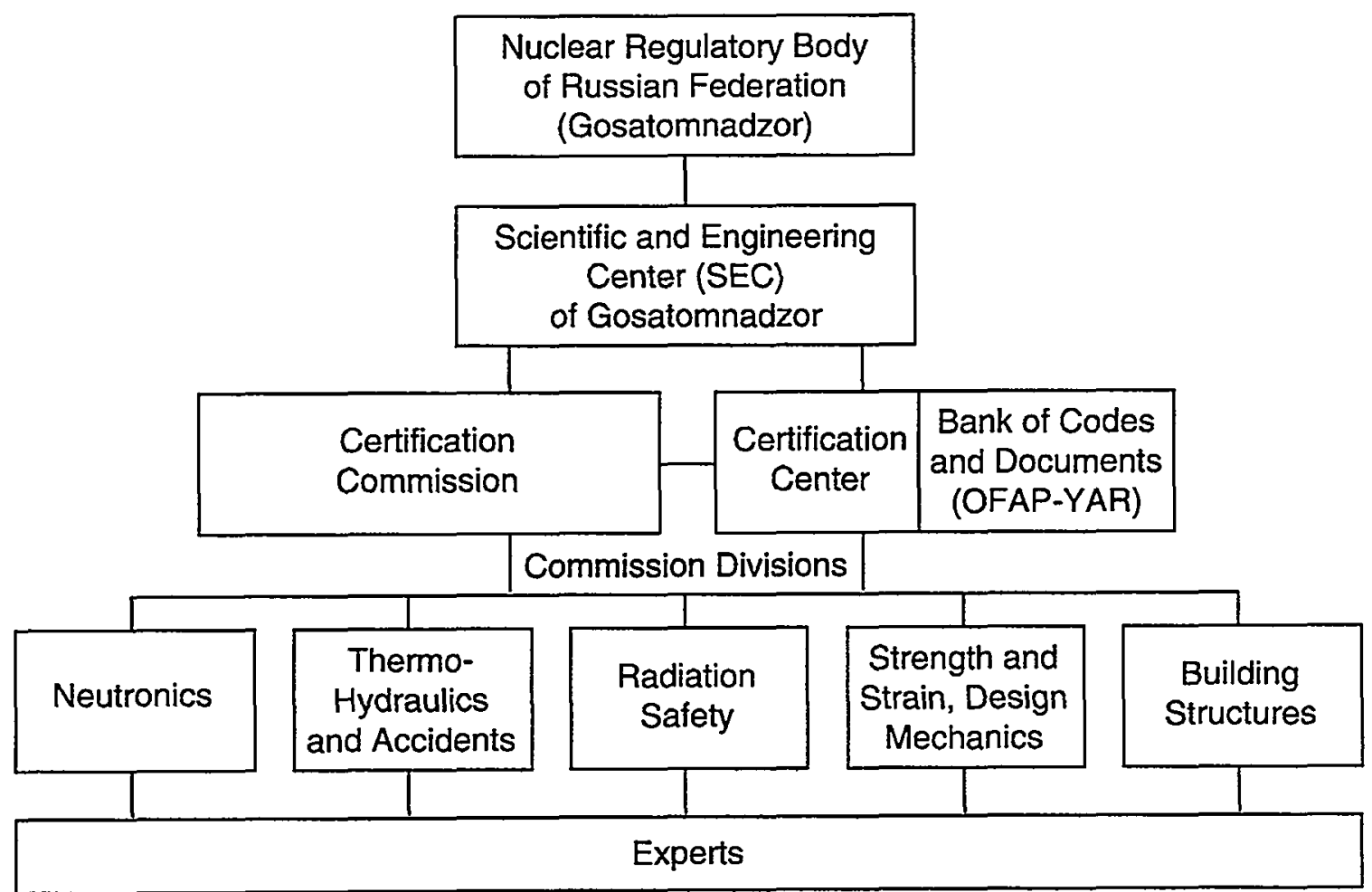

Fig. A.2. Arrangement of codes certification. 
- Request for the code certifying

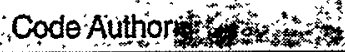

- Preparing the verification report

- Preparing the draft passport

- Preparing the code and documentation for testing and depositing in certification center

- Checking the documentation

- Testing the code

- Depositing the code and the documentation

Fommission Division

- Preliminary evaluating the code and verification report

- Evaluating necessary volume and tasks of examination

- Nominating experts
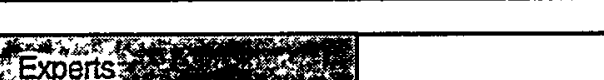

- Making examination of the verification report

- Making proposals for passport

- Considering the results of examination

- Formulating the passport taking into account the results of examination

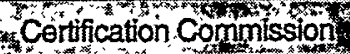

- Considering the results of examination and division proposals

- Approving the certification and passport content

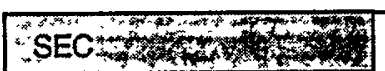

- Issuing and delivering the passport to the code author

Centification Center

- Depositing the materials of certification and passport copy

- Gosatomnadionat

- Checking the use of only certified codes in the calculations of nuclear installation's safety

Fig. A.3. Certification procedure. 
Appendix B

COMPUTER PROGRAMS, DATA LIBRARIES, AND USES

B-1 


\section{Appendix B}

\section{COMPUTER PROGRAMS, DATA LIBRARIES, AND USES}

Table B. 1 provides descriptions of the physics programs and data libraries that are being used for analyses in the FMDP. Table B.2 provides a description of the measurements and computational benchmarks that have been analyzed in Russia and the areas of application for these measurements.

Table B.1. Nuclear methods and data to be validated

\begin{tabular}{|c|c|c|}
\hline Usage & $\begin{array}{l}\text { U.S. Libraries/Computer } \\
\text { Programs }\end{array}$ & $\begin{array}{c}\text { Russian Libraries/Computer } \\
\text { Programs }\end{array}$ \\
\hline Nuclear data libraries & $\begin{array}{l}\text { SCALE ENDF-V Point, 44, } \\
\text { 199, and } 238 \text { group libraries; } \\
\text { HELIOS ENDF/B-VI } \\
\text { libraries }\end{array}$ & $\begin{array}{l}\text { ABBN-90, } 93 \\
\text { WIMS } \\
\text { MCUDAT }\end{array}$ \\
\hline Nuclear data processing & $\begin{array}{l}\text { NJOY (point data), AMPX } \\
\text { (point data or pin cell), } \\
\text { SCALE (pin cell), HELIOS } \\
\text { (2D assembly collapse), } \\
\text { WIMS-4D and WIMS-7 (2D } \\
\text { assembly collapse) }\end{array}$ & ABBN, CONSYST \\
\hline $\begin{array}{l}\text { Criticality safety, fuel } \\
\text { assembly and reactor } \\
\text { core physics parameters } \\
\text { (Monte Carlo method) }\end{array}$ & KENO-Va, KENO-VI, MCNP & $\begin{array}{l}\text { MCC, MCU, MCNP, } \\
\text { CONKEMO }\end{array}$ \\
\hline $\begin{array}{l}\text { Fuel assembly physics } \\
\text { parameters (deterministic } \\
\text { methods) }\end{array}$ & $\begin{array}{l}\text { HELIOS, WIMS-4D and -7, } \\
\text { DIF3D, VENTURE, DORT }\end{array}$ & TVS-M, TRIANG \\
\hline $\begin{array}{l}\text { Reactor core physics } \\
\text { parameters (deterministic } \\
\text { methods) }\end{array}$ & DIF3D, VENTURE, NESTLE & BIPR, PERMAK, TRIANG \\
\hline Fuel management & NESTLE, FORMOSA & BIPR, PERMAK \\
\hline $\begin{array}{l}\text { Thermal-hydraulic data } \\
\text { library }\end{array}$ & RELAP properties library & $\begin{array}{l}\text { Russian properties library, } \\
\text { RELAP library }\end{array}$ \\
\hline $\begin{array}{l}\text { Thermal-hydraulic/ } \\
\text { transient analysis }\end{array}$ & RELAP & $\begin{array}{l}\text { DYNAMICA, RELAP, } \\
\text { TECH-M }\end{array}$ \\
\hline
\end{tabular}


Table B.2. Database for Russian code verification

\begin{tabular}{|c|c|c|c|c|c|c|c|c|c|c|c|c|c|c|c|}
\hline \multirow[b]{2}{*}{ Verification data } & \multirow[b]{2}{*}{$\begin{array}{l}\text { Fuel } \\
\text { type }\end{array}$} & \multirow[b]{2}{*}{$\begin{array}{c}\text { Fuel } \\
\text { geometry }\end{array}$} & \multirow[b]{2}{*}{$\mathbf{k}_{\text {eff }}$} & \multirow[b]{2}{*}{$\begin{array}{c}\text { Power } \\
\text { distribution }\end{array}$} & \multicolumn{4}{|c|}{ Effects of reactivity } & \multicolumn{3}{|c|}{ Absorption efficiency } & \multirow[b]{2}{*}{$\begin{array}{c}\text { Isotopic } \\
\text { composition }\end{array}$} & \multirow[b]{2}{*}{$\begin{array}{c}\text { Kinetic } \\
\text { parameters }\end{array}$} & \multirow[b]{2}{*}{$\begin{array}{l}\text { Verifiable } \\
\text { code }\end{array}$} & \multirow[b]{2}{*}{$\begin{array}{c}\text { Year of } \\
\text { deliverables }\end{array}$} \\
\hline & & & & & Boron & Temperature & Doppler & $\begin{array}{c}\text { Xe and } \\
\text { Sm } \\
\text { poisoning }\end{array}$ & $\begin{array}{c}\text { CPC } \\
\text { rods } \\
\text { (boron) }\end{array}$ & $\begin{array}{c}\text { Burnable } \\
\text { poison } \\
\text { (boron) }\end{array}$ & $\begin{array}{c}\text { U/Gd } \\
\text { fuel }\end{array}$ & & & & \\
\hline \multicolumn{16}{|c|}{ Critical experiments } \\
\hline $\begin{array}{l}\text { RU, RRC KI, “II"' (Latt., } \\
\text { FAs) }\end{array}$ & $\mathbf{U}$ & Hex & $\mathrm{O}$ & 0 & & & & & 0 & 0 & 0 & & & MTPB & 99 \\
\hline Hungary-RU, ZR-6 & $\mathbf{U}$ & Hex & $\mathrm{O}$ & $\mathrm{O}$ & $\mathrm{O}$ & 0 & & & 0 & & 0 & & & MTP & 99 \\
\hline Czechia-RU, LR-0 & $\mathbf{U}$ & Hex & 0 & 0 & 0 & & & & & & 0 & & & MTP & 99 \\
\hline $\begin{array}{l}\text { Int. Handbook of ECSBE, } \\
\text { Latt }\end{array}$ & $\mathbf{P}$ & Sq & 0 & & & & & & & & & & & $\mathbf{M}$ & 99 \\
\hline $\begin{array}{l}\text { Int. Handbook of ECSBE, } \\
\text { Hom }\end{array}$ & $\mathbf{P} / \mathbf{U}$ & Hom & 0 & & & & & & & & & & & $\mathbf{M}$ & 99 \\
\hline US, ESADA & $\mathbf{P} / \mathrm{U}$ & Sq & $\mathrm{O}$ & 0 & & & & & & & & & & $\mathbf{M}$ & 99 \\
\hline US, SAXTON & $\mathbf{P} / \mathbf{U}$ & Sq. & 0 & 0 & $\mathrm{O}$ & & & & & & & & & $\mathbf{M}$ & 99 \\
\hline OECD, VENUS-2 & $\mathbf{P} / \mathbf{U}$ & $\mathrm{Sq}$ & 0 & $O$ & & & & & & $\mathrm{O}$ & & & & $\mathbf{M}$ & 00 \\
\hline OECD, KRITZ & $\mathbf{P} / \mathbf{U}$ & $\mathrm{Sq}$ & 0 & 0 & & 0 & & & & & & & & $\mathbf{M}$ & 0? \\
\hline RU, BFS(IPPE) & $\mathbf{P} / \mathbf{U}$ & Hex & $\mathrm{O}$ & $\mathrm{O}$ & & & & & & & & & & $\mathbf{M}$ & 0? \\
\hline RU, SUPR(IPPE) & $\mathbf{P} / \mathbf{U}$ & Hex & $\mathrm{O}$ & 0 & $\mathrm{O}$ & 0 & & & 0 & 0 & $\mathrm{O}$ & & $\mathrm{O}$ & MTP & 0? \\
\hline \multicolumn{16}{|c|}{ Calculational benchmarks } \\
\hline RU/US, Cell & $\mathbf{U}$ & Hex & 2 & & 2 & 9 & 2 & 9 & & & & 2 & 0 & MT & 97 \\
\hline RU/US, Cell & $\mathbf{P}$ & Hex & $\theta$ & & $\theta$ & $\theta$ & $\theta$ & $\theta$ & & & & $\theta$ & $\theta$ & MT & 97 \\
\hline RU/US, PWR FA & $\mathbf{P}$ & $\mathbf{S q}$ & 9 & 9 & 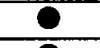 & 2 & 2 & 2 & 2 & & & 9 & & $\mathbf{M}$ & 97 \\
\hline RU/US, VVER FA & $\mathbf{U}$ & Hex & 0 & 9 & 9 & 9 & 9 & 9 & 9 & 8 & & 0 & & MT & 98 \\
\hline RU/US, VVER FA & $\underline{\mathbf{P}}$ & Hex & 9 & 9 & 9 & 9 & 9 & 2 & 0 & 요 & & 2 & & MT & 98 \\
\hline RU/US, 7 VVER FAs & $\mathbf{U} / \mathbf{P}$ & Hex & 9 & 2 & 0 & 0 & 0 & 0 & & & & 9 & 0 & MT & 98 \\
\hline RU/Fr/Germ, VVER FA & $\mathbf{U}$ & Hex & 9 & 9 & 9 & 2 & 2 & 0 & 9 & 2 & 9 & 8 & 0 & MT & 99 \\
\hline RU/Fr/Germ, VVER FA & $\mathbf{P}$ & Hex & 2 & 0 & 2 & 2 & 8 & 9 & 2 & 9 & 0 & 0 & 0 & MT & 99 \\
\hline RU/Fr/Germ, 7 VVER FAs & $\mathbf{U} / \mathbf{P}$ & Hex & 9 & 9 & 0 & 2 & 2 & - & 0 & & & & 0 & MT & 99 \\
\hline OECD, BWR, FA & $\mathbf{P}$ & $\mathrm{Sq}$ & 9 & 2 & & $?$ & & & & & 9 & 9 & & $\mathbf{M}$ & 99 \\
\hline OECD, PWR, Cell, FA & $\mathbf{P}$ & $\mathrm{Sq}$ & 2 & 0 & & O & & & & & & 9 & & $\mathbf{M}$ & 00 \\
\hline $\begin{array}{l}\text { RU/US, } 7 \text { and } 19 \text { VVER } \\
\text { FAs }\end{array}$ & $\mathbf{U} / \mathbf{P}$ & Hex & 0 & - & 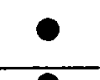 & - & - & - & 0 & - & ? & - & ? & MTPB & 00 \\
\hline RU/US, VVER-1000, Core & $\mathbf{U} / \mathbf{P}$ & Hex & 0 & 9 & 0 & 9 & 9 & 2 & 9 & ? & 9 & & ? & TPB & 01 \\
\hline
\end{tabular}




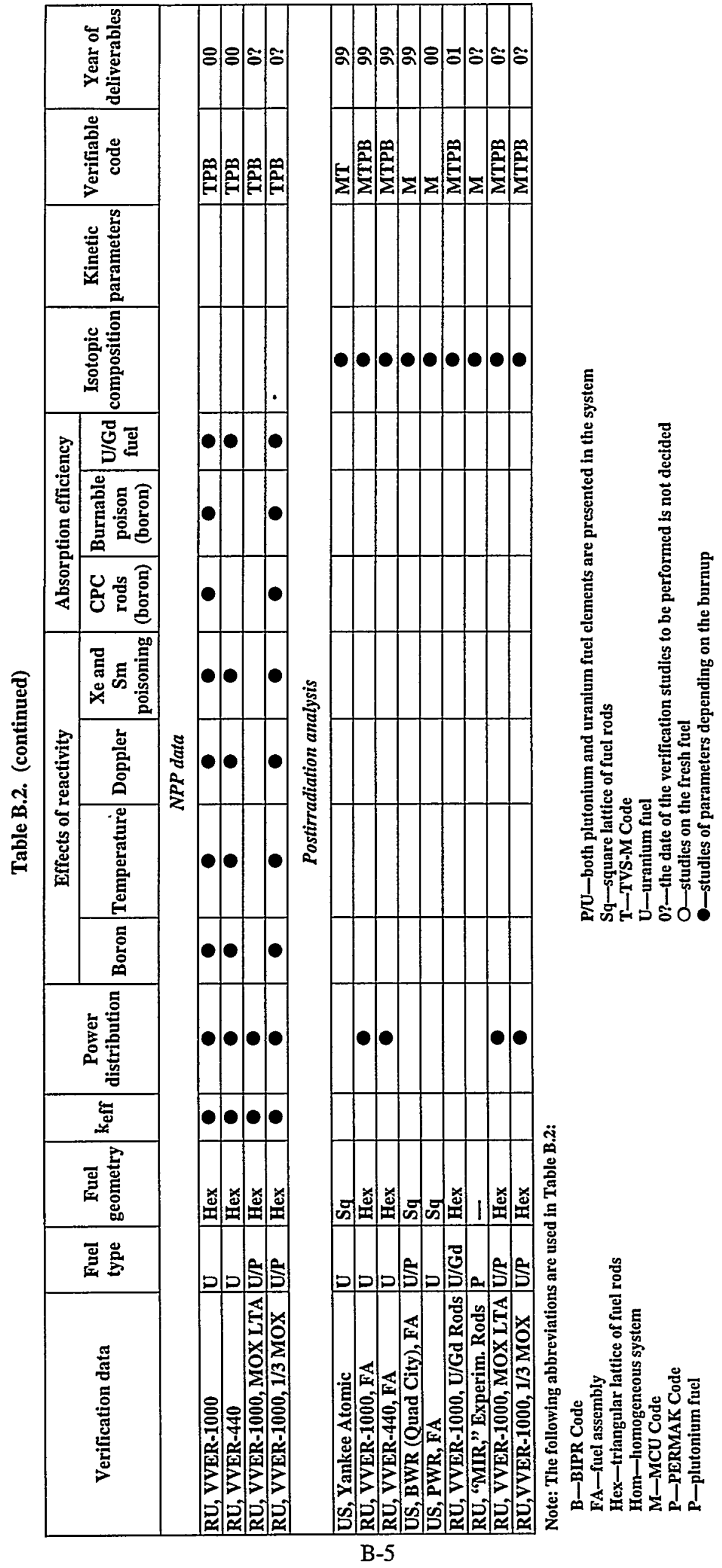


Appendix C

LEVEL 1 ROADMAP

C-1 
C-2 


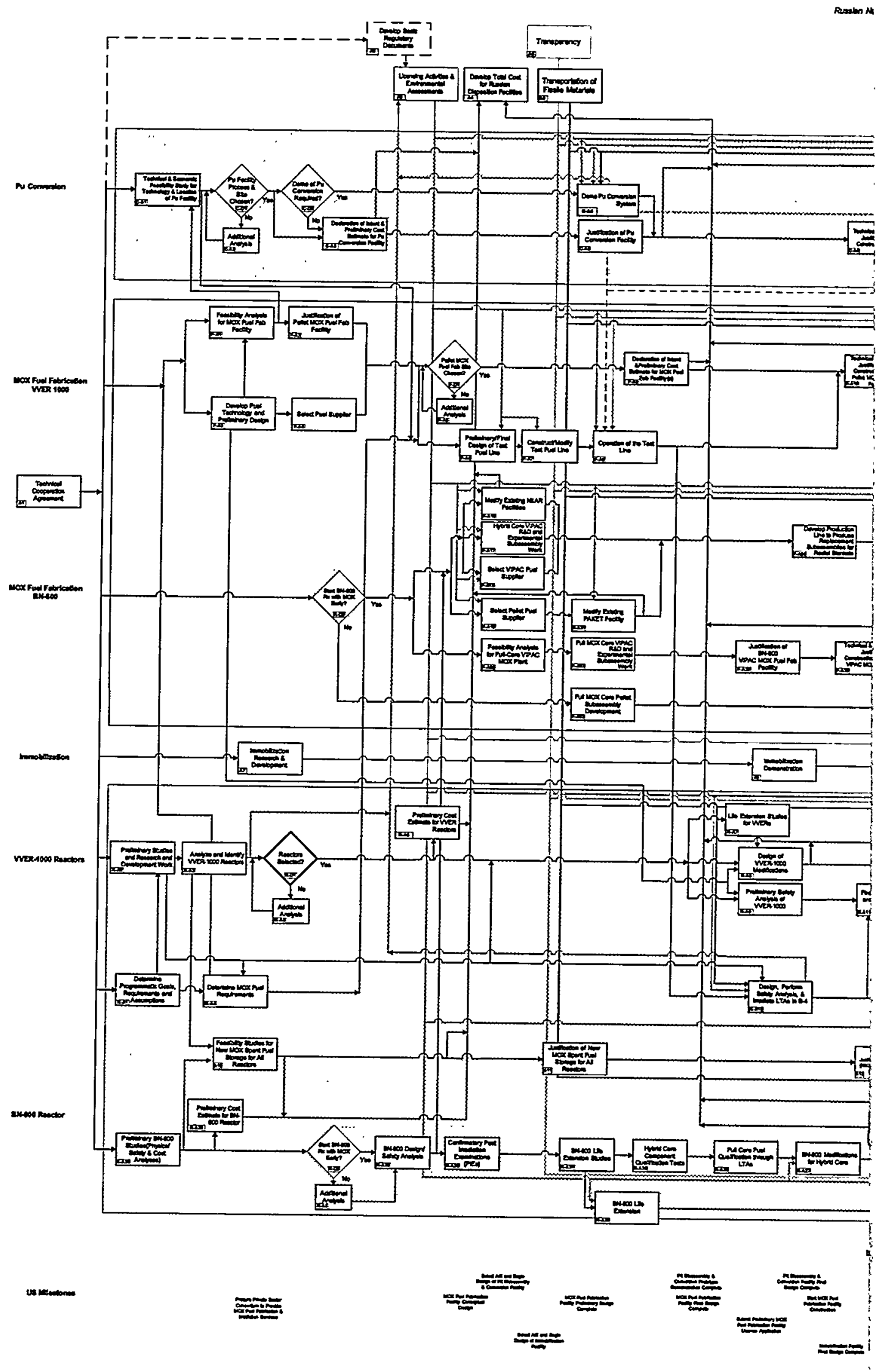

Fig. C.1 Russian Nuclear Materials 1

C- 


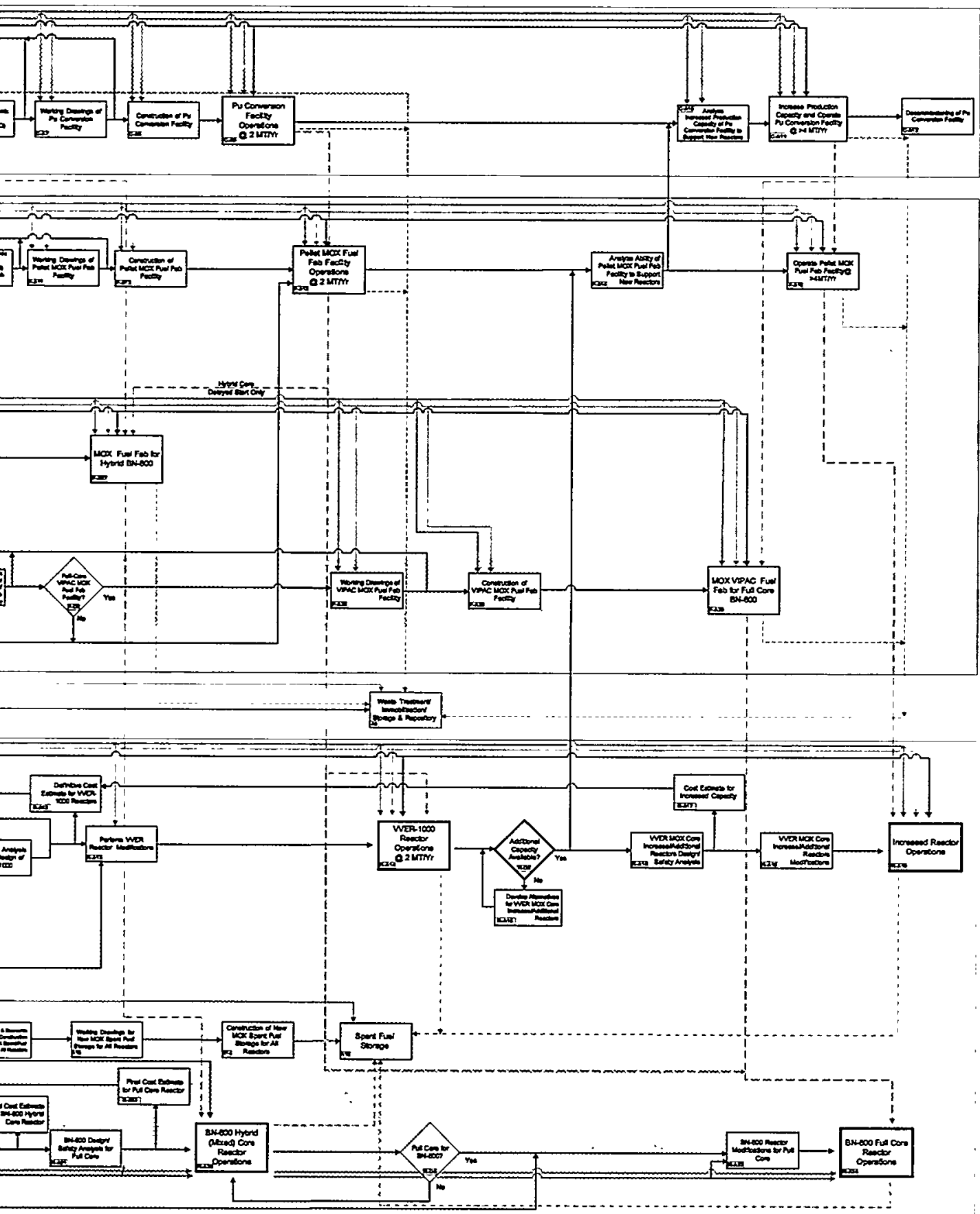

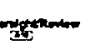

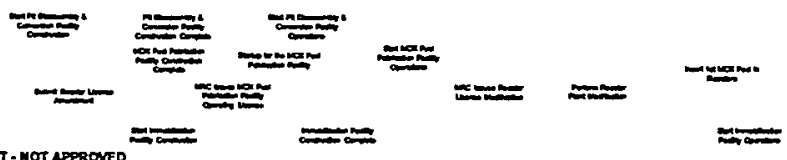

sposition Program logic, Level 1. 


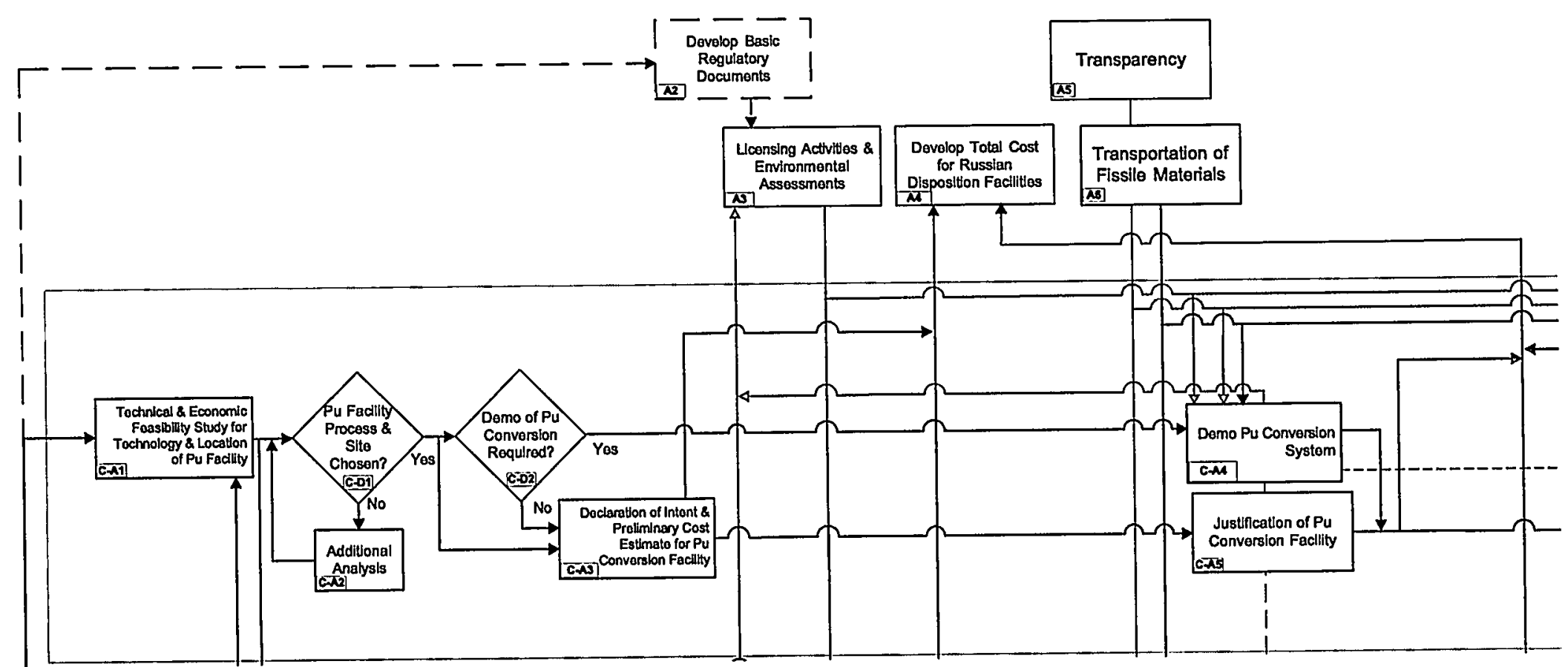

Fig. C.1(a)-(c) Russian Nuclear Materials Disposition Program logic, Level 1. 
ORNL 2000-1276C EFG

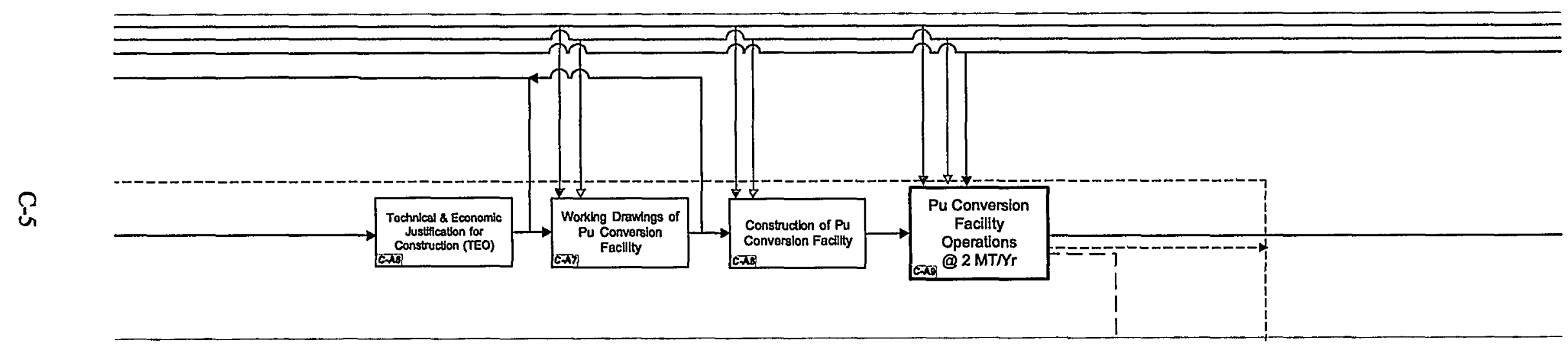

Fig. C.1(a) (continued). 
ORNL 2000-1277C EFG

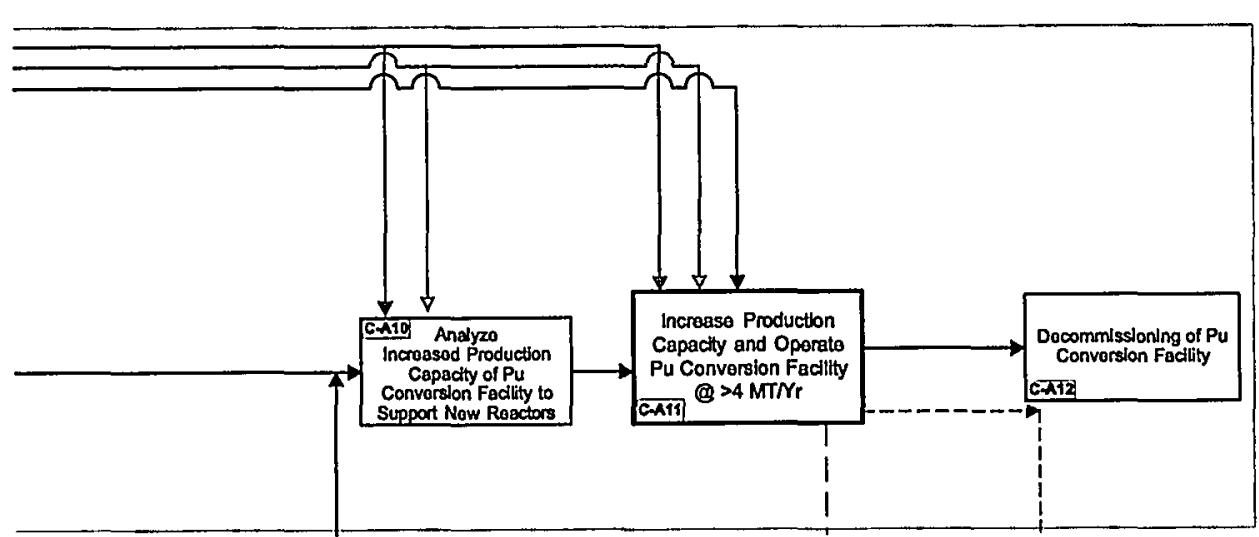

Fig. C.1(a) (continued). 
ORNL 2000-1278C EFG

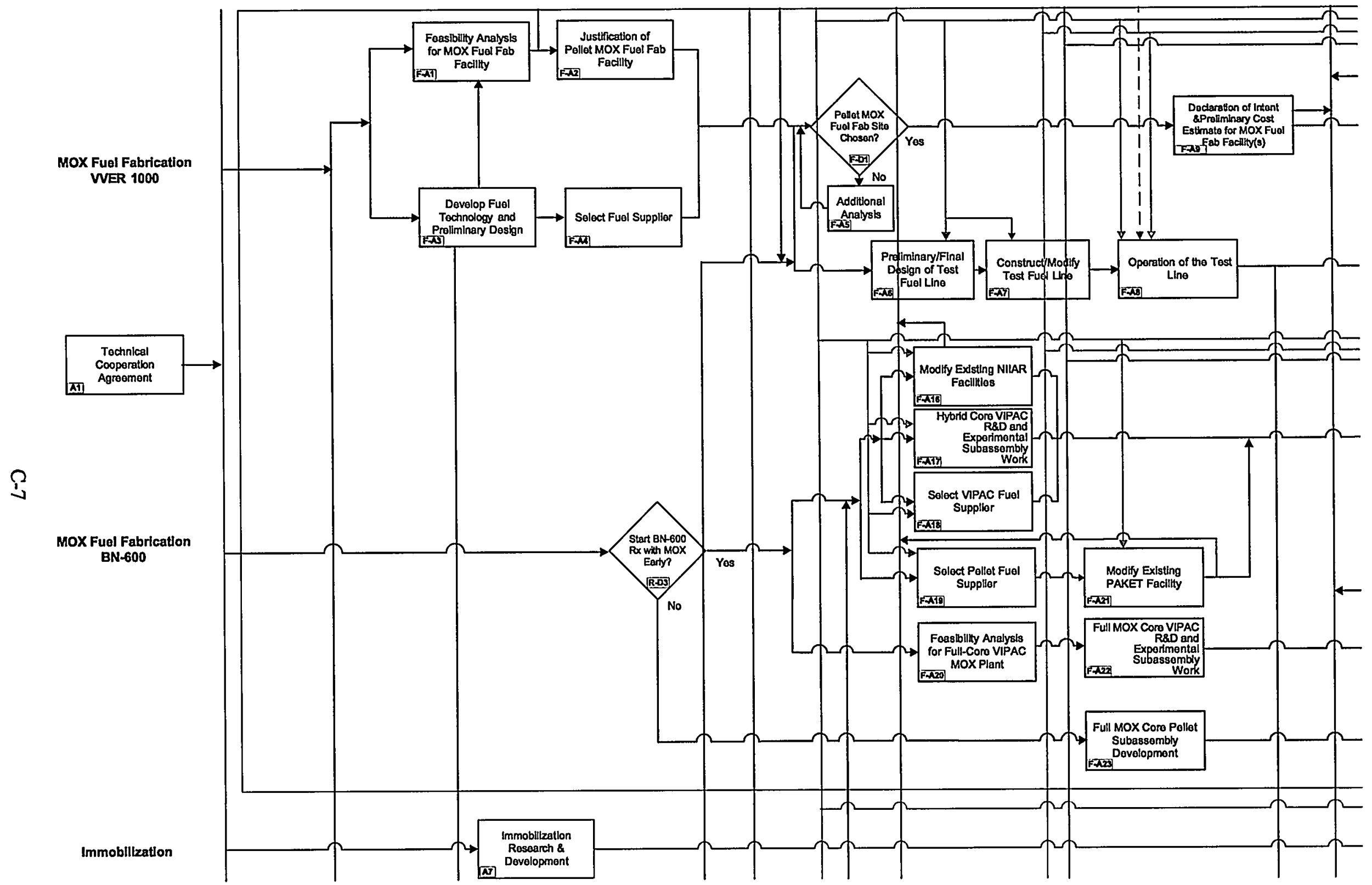

Fig. C.1(b) 


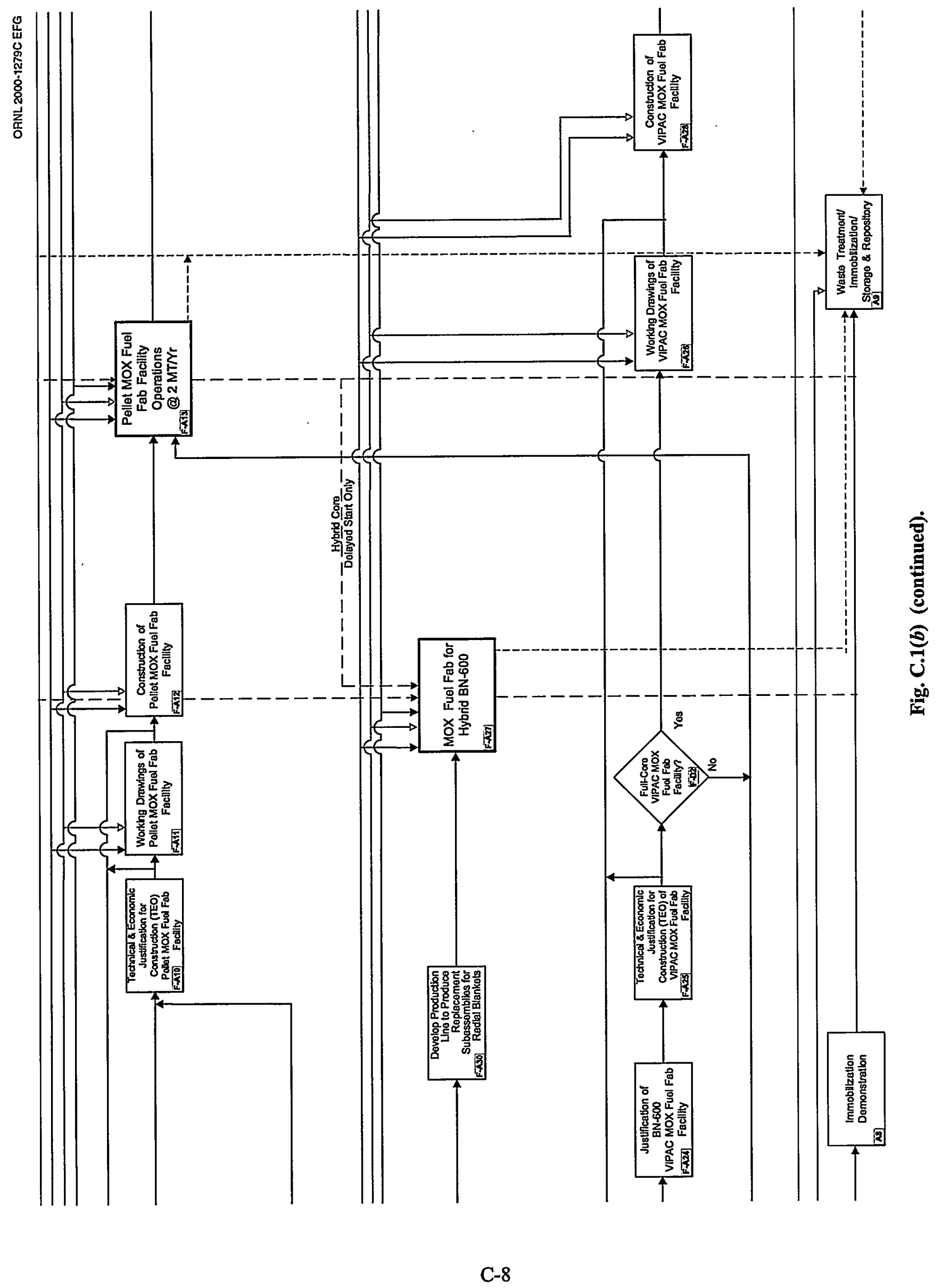




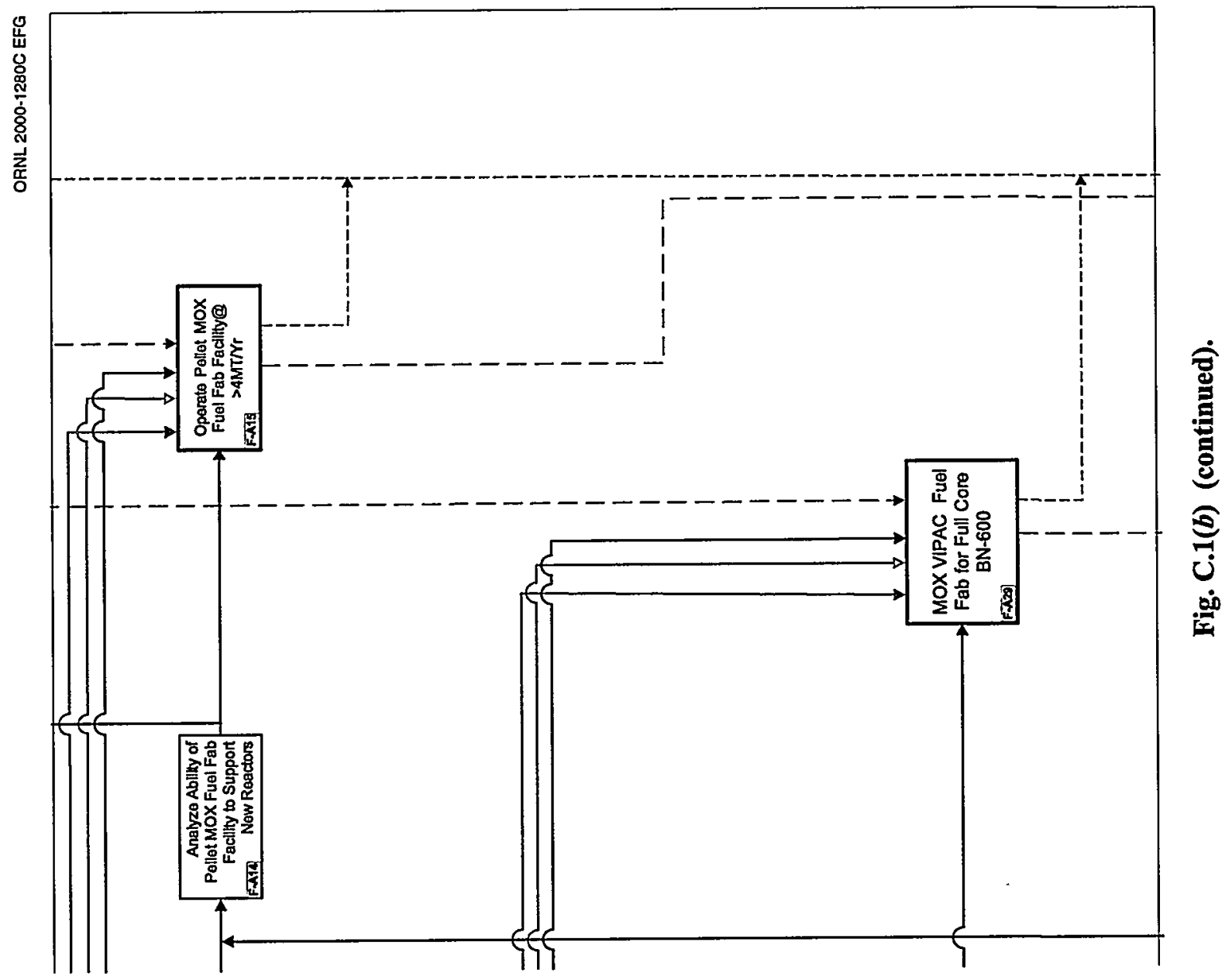




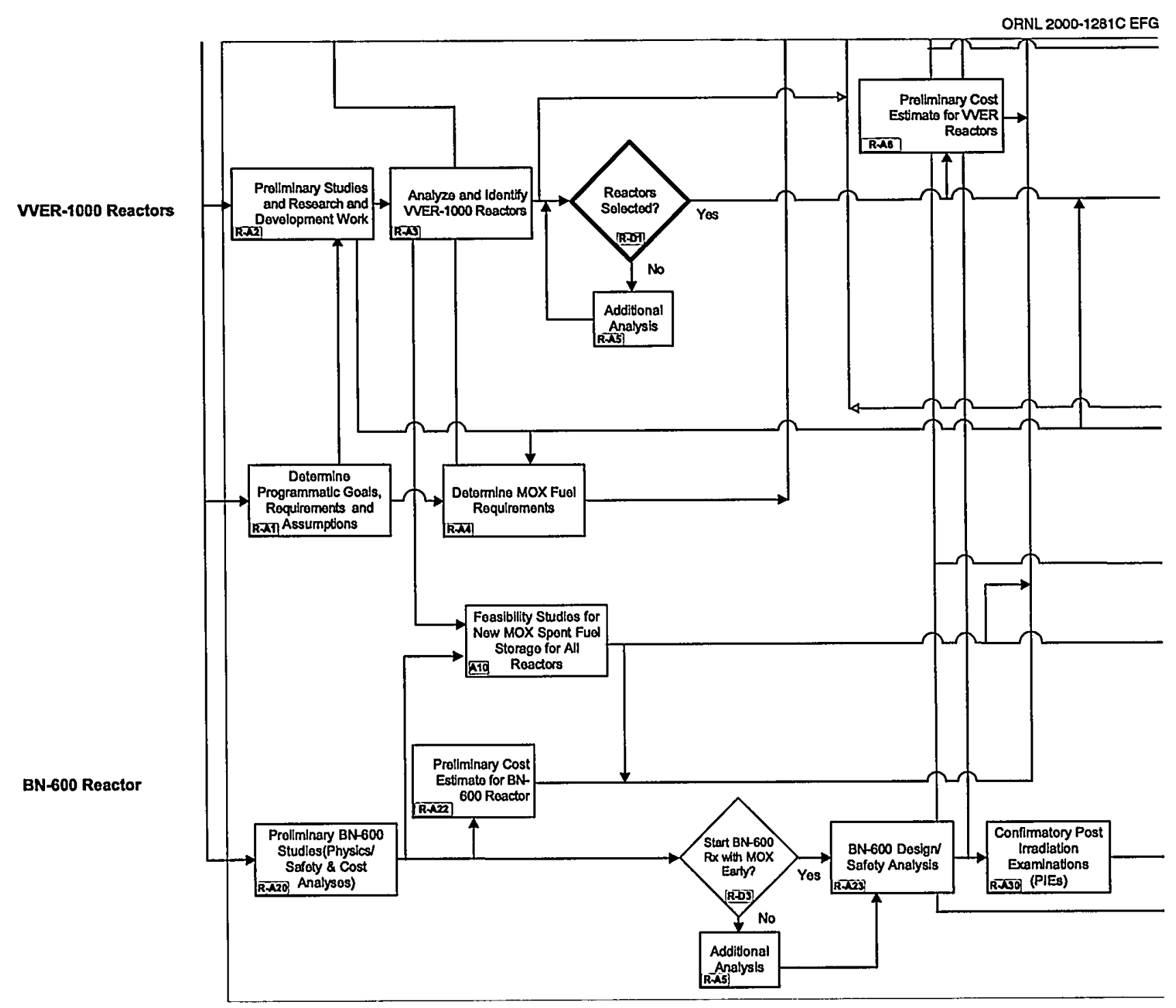

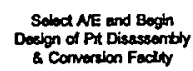




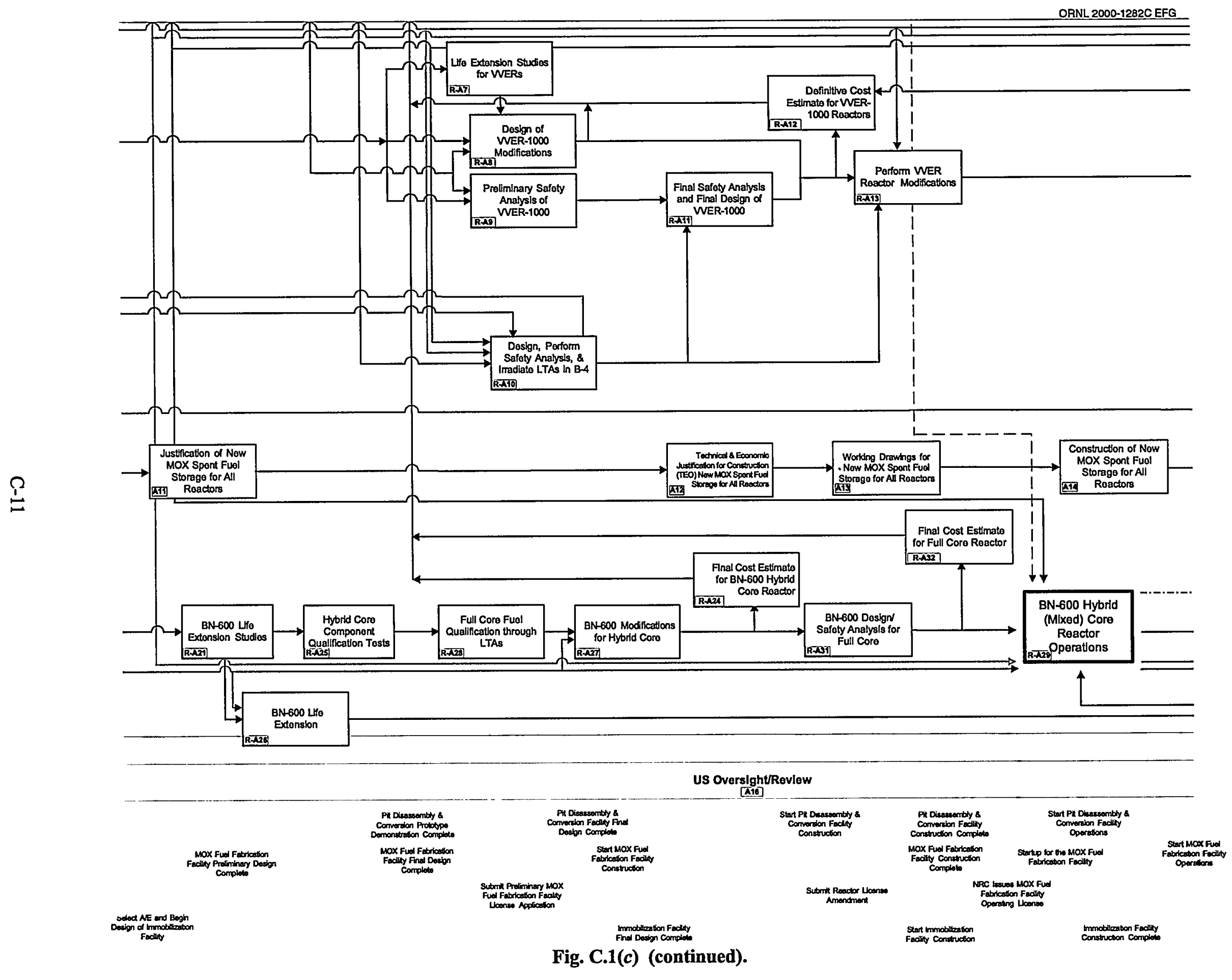


ORNL 2000-1283C EFG

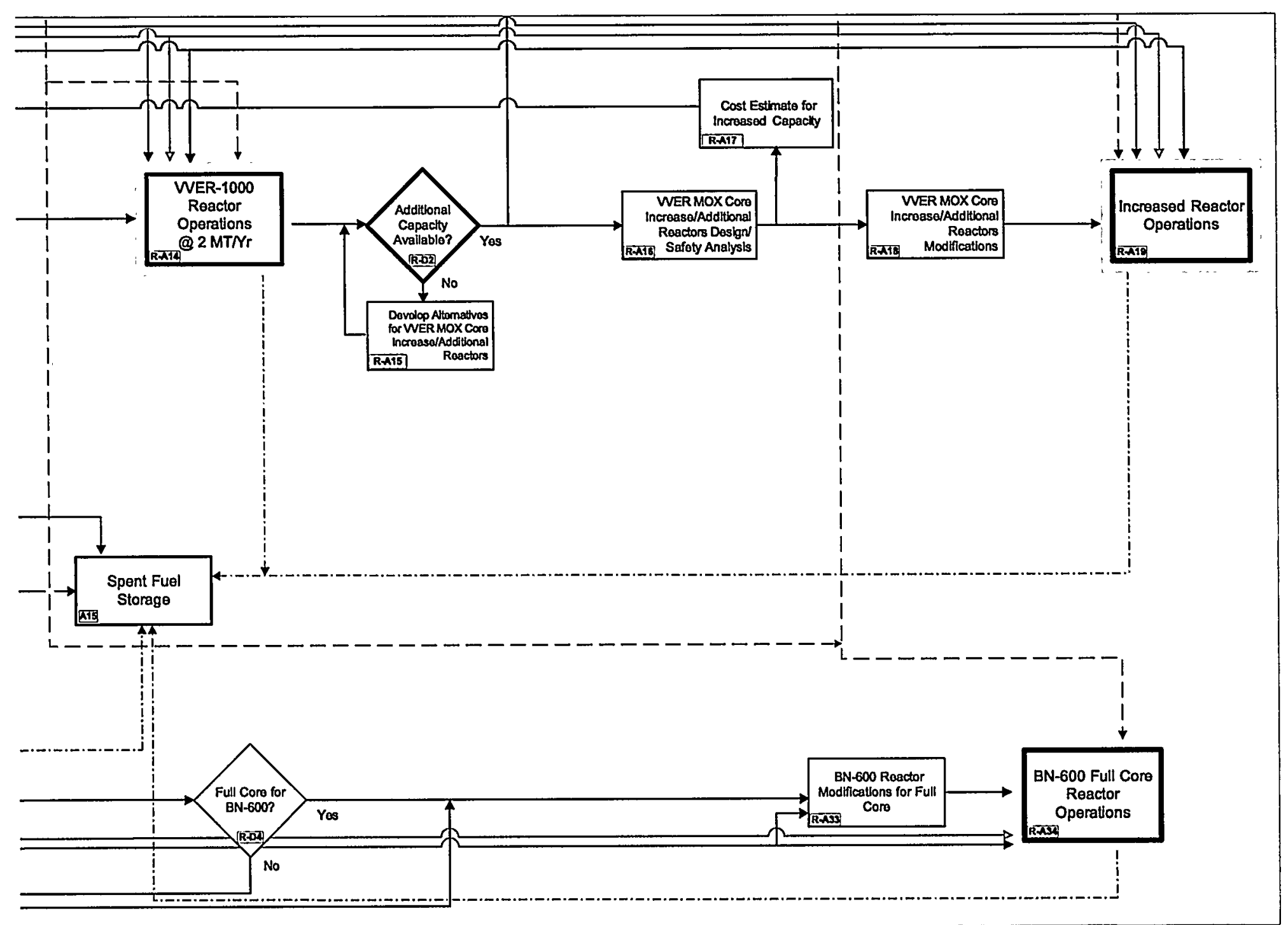

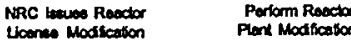

hoort lat Mox frow h

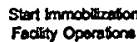

Fig. C.1(c) (continued). 
Appendix D

INPUT TO LEVEL 2+ ROADMAP

D-1 


\begin{tabular}{|c|c|c|}
\hline $\mathbb{D}$ & WES & Task Name \\
\hline 1 & 1 & Technical Cooperation Agreement \\
\hline 2 & 2 & Basic Regulatory Documents \\
\hline 3 & 2.1 & Regulatory documents for WVER-1000 with MOX Fuel Avallable \\
\hline 4 & 3 & Plutonium Conversion \\
\hline 5 & 4 & MOX Fuel Fabrication For BN-600 \\
\hline 6 & 5 & MOX Fuel Fabrication VVER-1000 \\
\hline 7 & 5.1 & Preliminary MoX Fuel Properties for Safety Analyses Available \\
\hline 8 & 5.2 & MOX Fuel for Pre-SUPR Crittcal Experiments Available \\
\hline 9 & 5.3 & LTAs Avallable \\
\hline 10 & 5.4 & MOX Fuel for SUPR Critical Experiments Avallable \\
\hline 11 & 5.5 & MOX Fuel Properties for Safety Analyses Available \\
\hline 12 & 5.6 & MOX Fuel Available (Phase 1 of Mission) \\
\hline 13 & 5.7 & Additional MoX Fuel Available (Phase 2 of Mission) \\
\hline 14 & 6 & VVER-1000 Reactors \\
\hline 15 & 6.1 & Determine Programmatic Goals, Requirements and Assumptions \\
\hline 16 & 6.1 .1 & Upgrading of the Branch Comprehensive Program of WG Plutonium Dispiosition in VVER-1000 \\
\hline 17 & 6.1.2 & Development of Russian Nuclear Materlal Dispositton Program Loglc ( ROADMAPs, Gantt Charts) \\
\hline 18 & 6.2 & Preliminary Studies and R\&D Works \\
\hline 19 & 6.2 .1 & Perform Reactor Physics and Analytical Work \\
\hline 20 & 6.2 .1 .1 & Upgrading, Vorification and GAN Cortiffcation of Computor Codos \\
\hline 21 & $\overline{6.2 .1 .1 .1}$ & Noutronlcs Codos for Calculation of WVER core with MOX Fuol \\
\hline 22 & 6.2.1.1.1.1. & Verification and Cortification of tho MCU/ORIGEN-S prociso codo \\
\hline 23 & 6.2.1.1.1.1.1. & Critical Experiments with WER-type UOX Fuel ("?" RRC KI, ZR-6, LR-0) \\
\hline 24 & $\overline{6.2 .1 .1 .1 .1 .2}$ & Critical Experiments with U and Pu Fuel from Intermational Handbook of ECSBE \\
\hline 25 & $\overline{6.2 .1 .1 .1 .1 .13}$ & US Critical Experiments with MOX Fuel (SAXTON, ESADA) \\
\hline 26 & $\overline{6.2 .1 .1 .1 .1 .1 .4}$ & European Critical Experiments with MOX Fuel (OECD - VENUS-2, KRITZ)) \\
\hline 27 & $\overline{6.2 .1 .1 .1 .1 .1 .5}$ & Calculational 8enchmarks (US, France, Gemany, OECD ) \\
\hline 28 & 6.2.1.1.1.1.1.6 & Postiradiation Data of PWR and BWR Fuel (UOX and MOX) \\
\hline 29 & 6.2.2.1.1.1.1.7 & Preparing the Verification Reports \\
\hline 30 & 6.2.1.1.1.1.8 & Certification of MCU/ORIGEN-S code for MOX Fuel Calculations in GAN \\
\hline 31 & 2.1.1.1.1.8.1 & Prepare the Documentation for Certification and submit it to GAN Certificalion Center \\
\hline 32 & 2.1.1.1.1.1.8.2 & Examination of the Documentation by Experts and Certification Commission \\
\hline 33 & $\overline{2.1 .1 .1 .1 .18 .3}$ & Sclentific and Engineering Center Issue the Code Certificate (Llcense) \\
\hline 34 & 6.2.1.1.1.1.1.9 & Additional Verilication of the MCU/ORIGEN-S precision code \\
\hline
\end{tabular}




\begin{tabular}{|c|c|c|}
\hline D & WBS & Task Name \\
\hline 35 & 2.1 .1 .1 .1 .9 .1 & Russian Critical Experiments with MOX Fuel at IPPE Faclity (Pre-SUPR) \\
\hline 36 & 2.1 .1 .1 .1 .9 .2 & Russian Critical Experiments with MOX Fuel at SUPR Facility \\
\hline 37 & 2.1 .1 .1 .1 .9 .3 & Postirradiation Data of MOX LTA \\
\hline 38 & 2.1 .1 .1 .1 .9 .4 & Postiradiation Data of Mission MOX Fuel Assembly \\
\hline 39 & $6 . \overline{2.1 .1 .1 .2}$ & Vorification and Certification of tho RRC KI onginearing code packago (TVS-M,BIPR, PERMAK Codes) \\
\hline 40 & 6.2 .1 .1 .1 .2 .1 & Critcal Experiments with WER-type UOX Fuel ("?" RRC KI, ZR-6, LR-0) \\
\hline 41 & $\overline{6.2 .1 .1 .1 .2 .2}$ & Operational Data of WER with UOX Fuel \\
\hline 42 & 6.2 .1 .1 .1 .2 .3 & Postirradiation Data of WER Fuel (UOX) \\
\hline$\overline{43}$ & 6.2 .1 .1 .1 .2 .4 & Calculational Benchmarks (MCU/ORIGEN, US, France, Germany) \\
\hline 44 & 6.2 .1 .1 .1 .2 .5 & Preparing the Verification Reports \\
\hline 45 & 6.2.1.1.1.2.6 & Certification of the RRC KI engineering code package in GAN RF \\
\hline 46 & 2.1 .1 .1 .2 .6 .1 & Preparing the Documentalion for Certification and sending it to Certification Center \\
\hline 47 & $2,1.1 .1 .2 .6 .2$ & Examination of the Documentation by Experts and Certification Commlssion \\
\hline 48 & 2.1 .1 .1 .2 .6 .3 & Sclentific and Engineering Center Issue the Code Cerificate \\
\hline 49 & 6.2.1.1.1.2.7 & Additional Verification of the RRC KI engineering code package \\
\hline 50 & 2.1 .1 .1 .2 .7 .1 & Russian Critical Experiments with MOX Fuel at SUPR Facility \\
\hline 51 & 2.1 .1 .1 .2 .7 .2 & LTAs Operational Data \\
\hline 52 & 2.1 .1 .1 .2 .7 .3 & Postirradiation Data of MOX LTA \\
\hline 53 & 2.1 .1 .1 .2 .7 .4 & Operational Data Mission MOX Fuel Assembly operational Data \\
\hline 54 & 2.1 .1 .1 .2 .7 .5 & Postirradiation Data of Mission MOX Fuel Assembly \\
\hline 55 & $\overline{6.2 .1 .1 .1 .2 .8}$ & New Certification of the RRC Kl engineering code package in GAN RF \\
\hline 56 & 2.1 .1 .1 .2 .8 .1 & Preparing the Documentation for Certification and sending it to Certification Center \\
\hline 57 & 2.1.1.1.2.8.2 & Examination of the Documentation by Experts and Certification Commission \\
\hline 58 & 2.1 .1 .1 .2 .8 .3 & Scientific and Engineering Center Issue the Improved Code Certificate \\
\hline 59 & 6.2.1.1.1.3 & Upgrading and verification 3-D neutron-kinatic codes \\
\hline 60 & 6.2 .1 .1 .1 .3 .1 & Verification NOSTRA Code \\
\hline 61 & 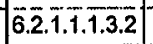 & Verification BIPR8-KN Coda \\
\hline 62 & 6.2.1.1.2 & Codes for accident analysis \\
\hline 63 & 6.2.1.1.2.1 & TRAP Package (GIDROPRESS) \\
\hline 64 & 6.2 .1 .1 .2 .2 & Certification of RALAP5 code in GAN \\
\hline 65 & 6.2.1.1.2.2.1 & Prepare the Documentation for Certification and submit it to GAN Certification Center \\
\hline 66 & 6.2 .1 .1 .2 .2 .2 & Examination of the Documentation by Experts and Certification Commission \\
\hline 67 & 6.2 .1 .1 .2 .2 .3 & Scientific and Engineering Center Issue the Code Certificate \\
\hline 68 & 6.2.1.1.2.3 & Develop, Verily and Certify Combined 3-D Neutronics and Thermal Hydraulics Code \\
\hline 69 & 6.2 .1 .1 .2 .3 .1 & Develop Combined BIPR8-KN and RELAP5 Code \\
\hline 70 & $6.2 .1 \cdot 1.2 .3 .2$ & Verification of Combined BIPR8-KN and RELAP5 Code, including Balakovo-4 Tests \\
\hline 71 & 6.2 .1 .1 .2 .3 .3 & Preparing the Verification Reports \\
\hline
\end{tabular}




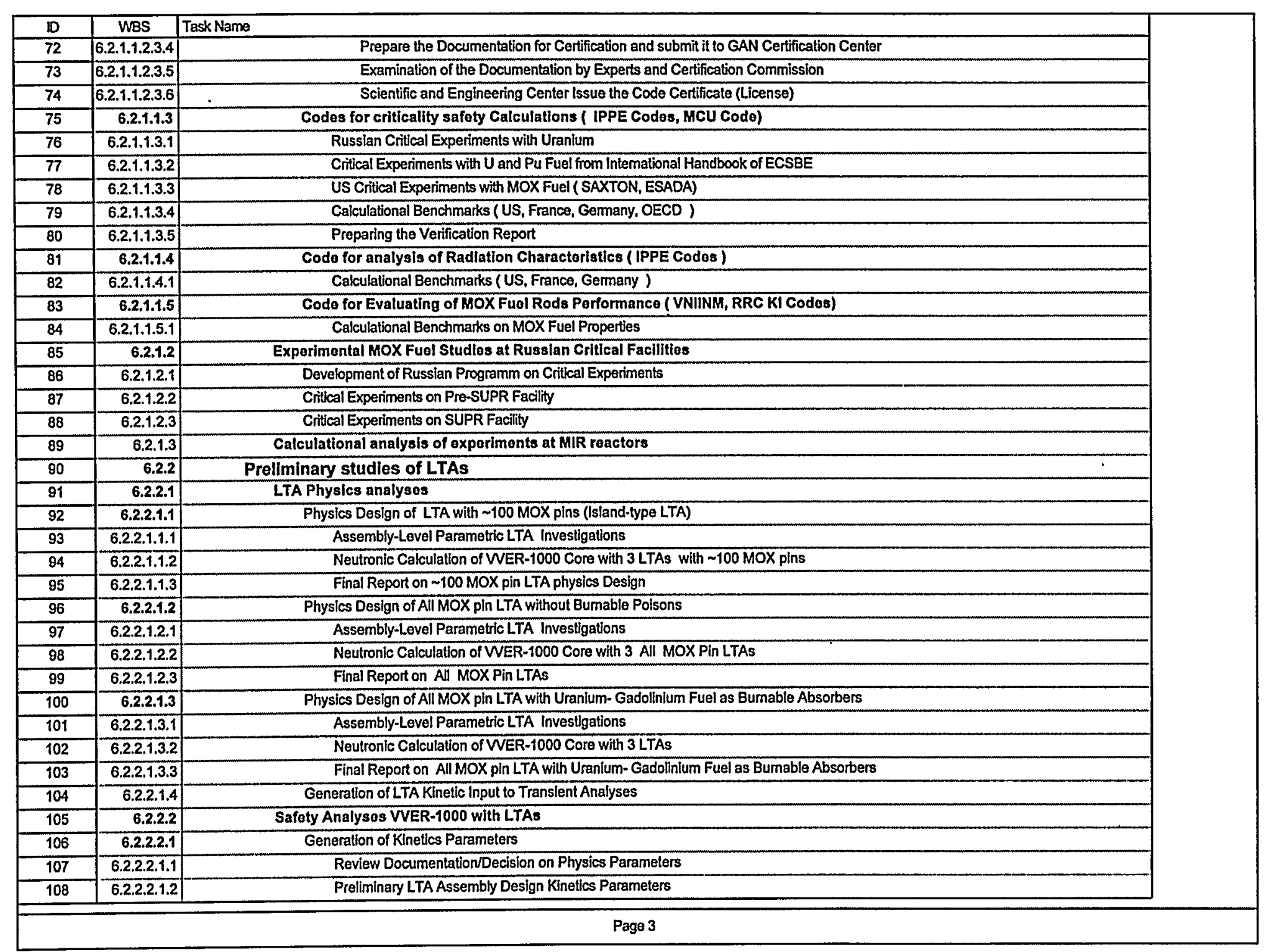




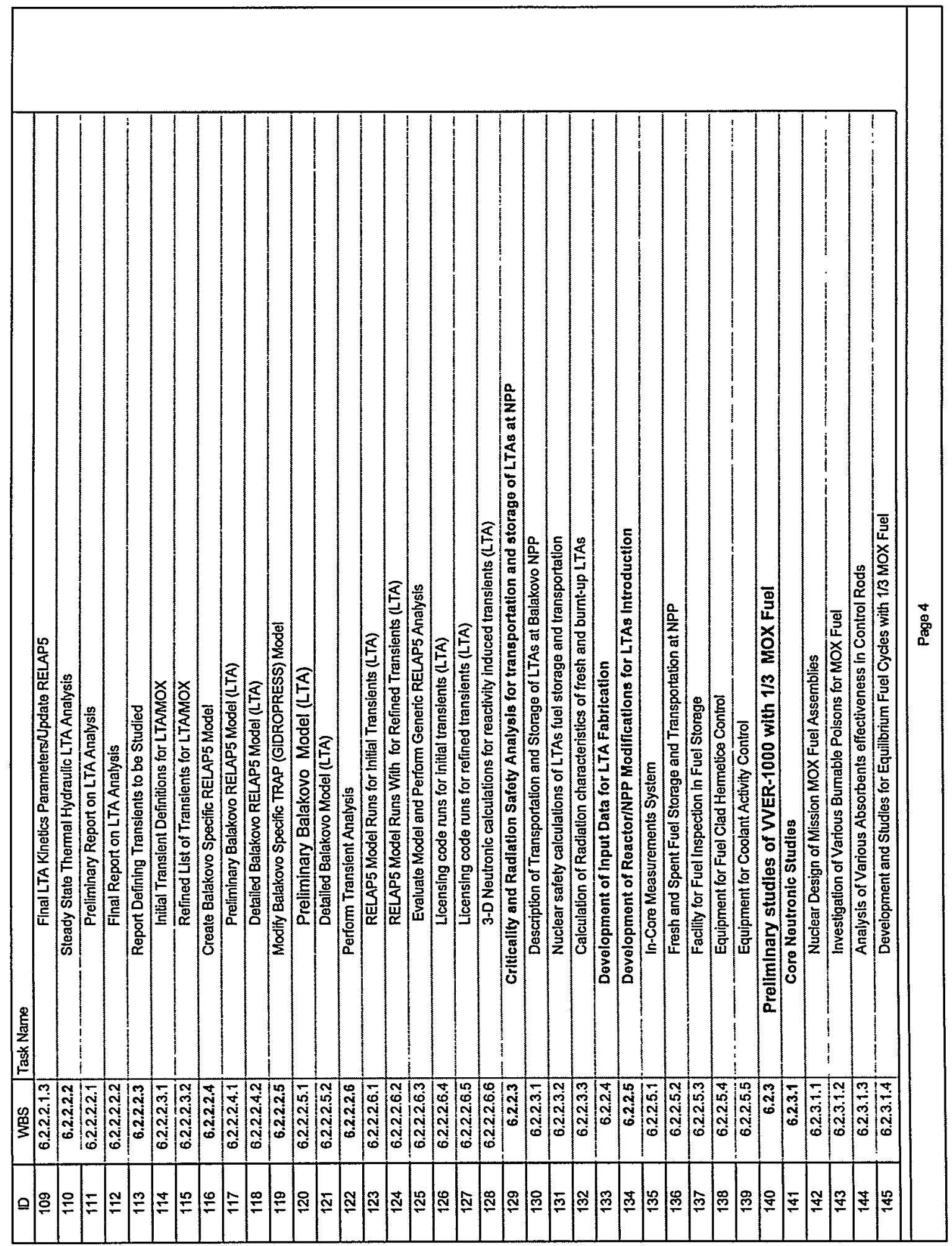




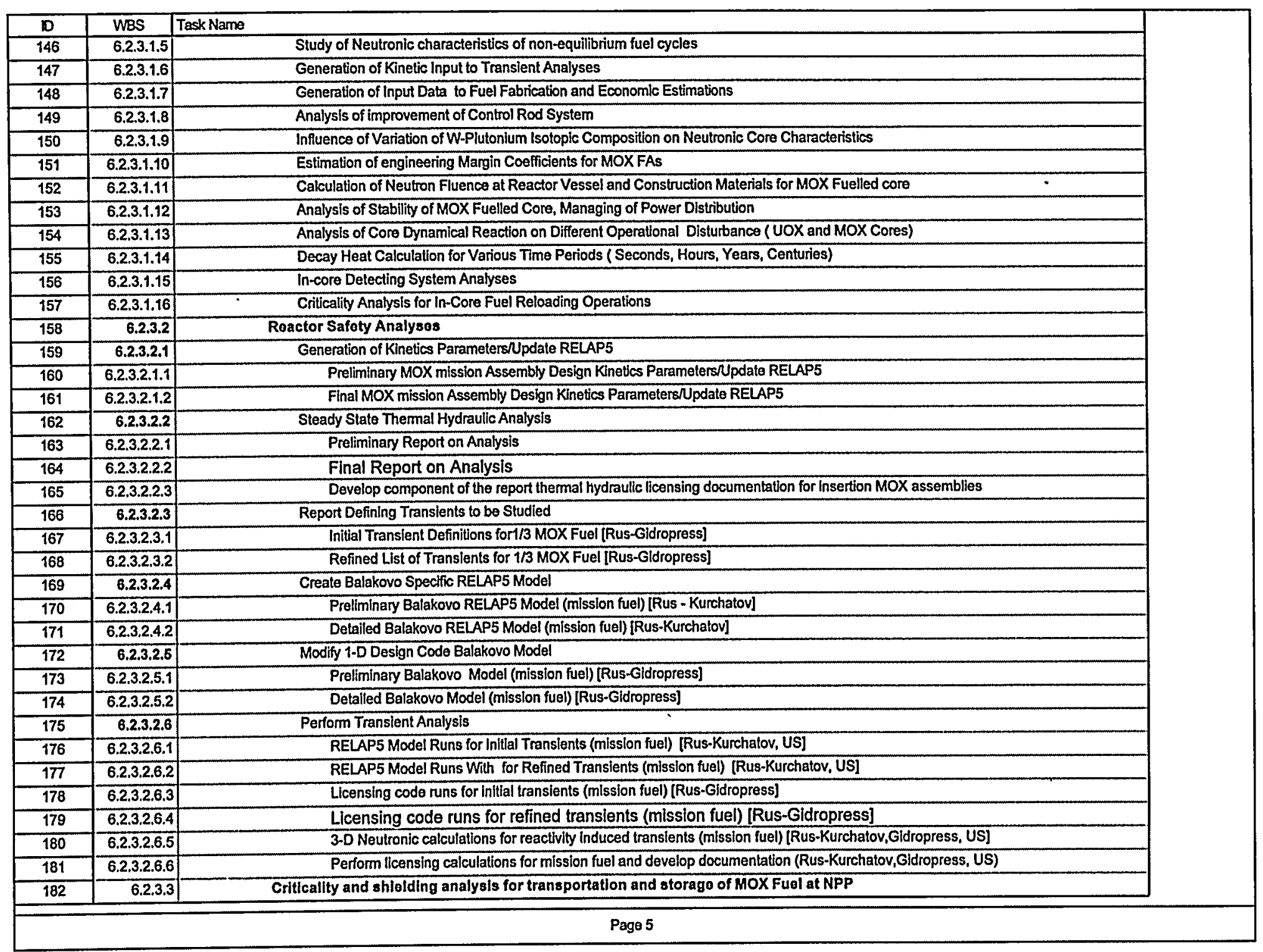




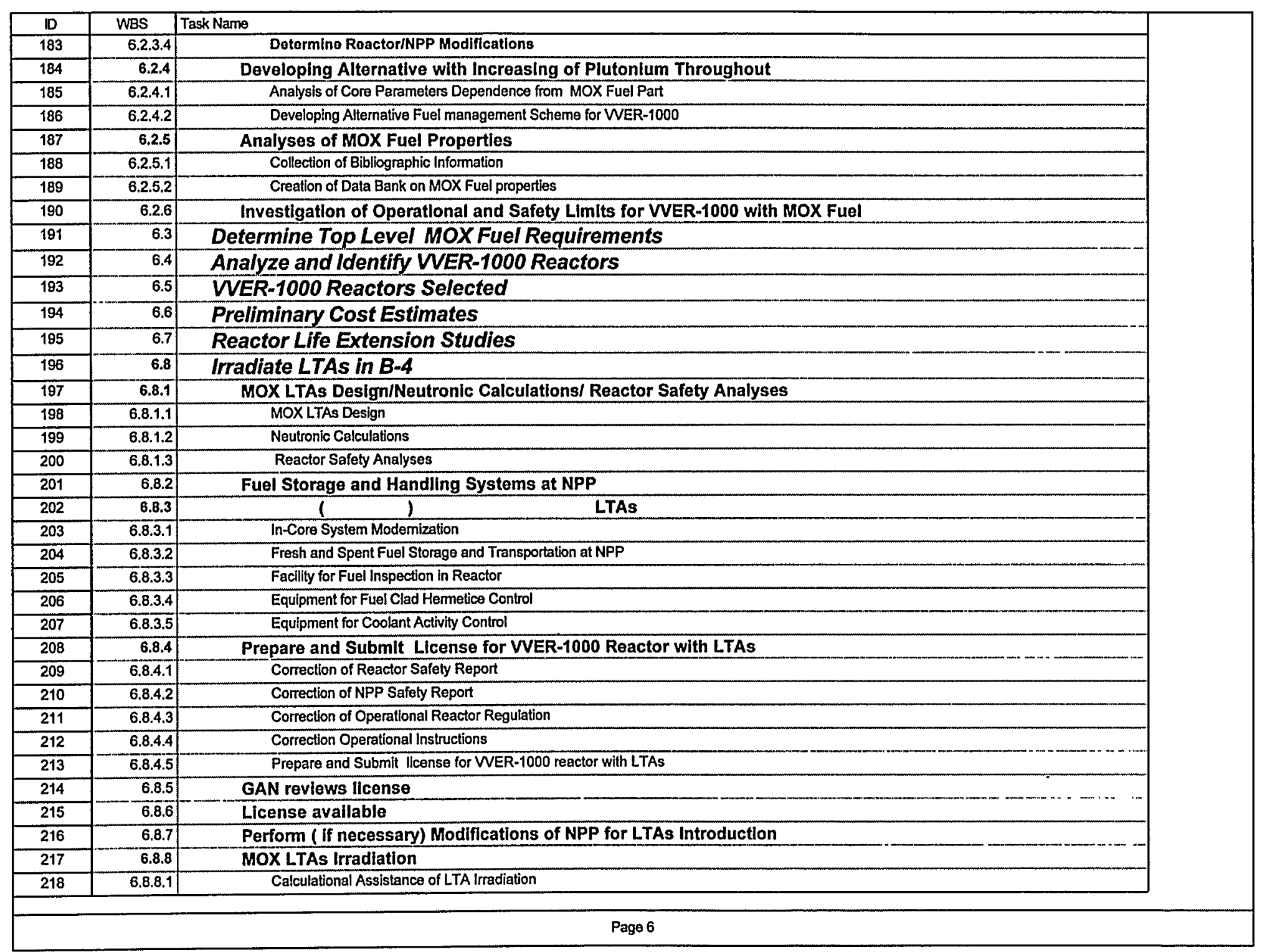




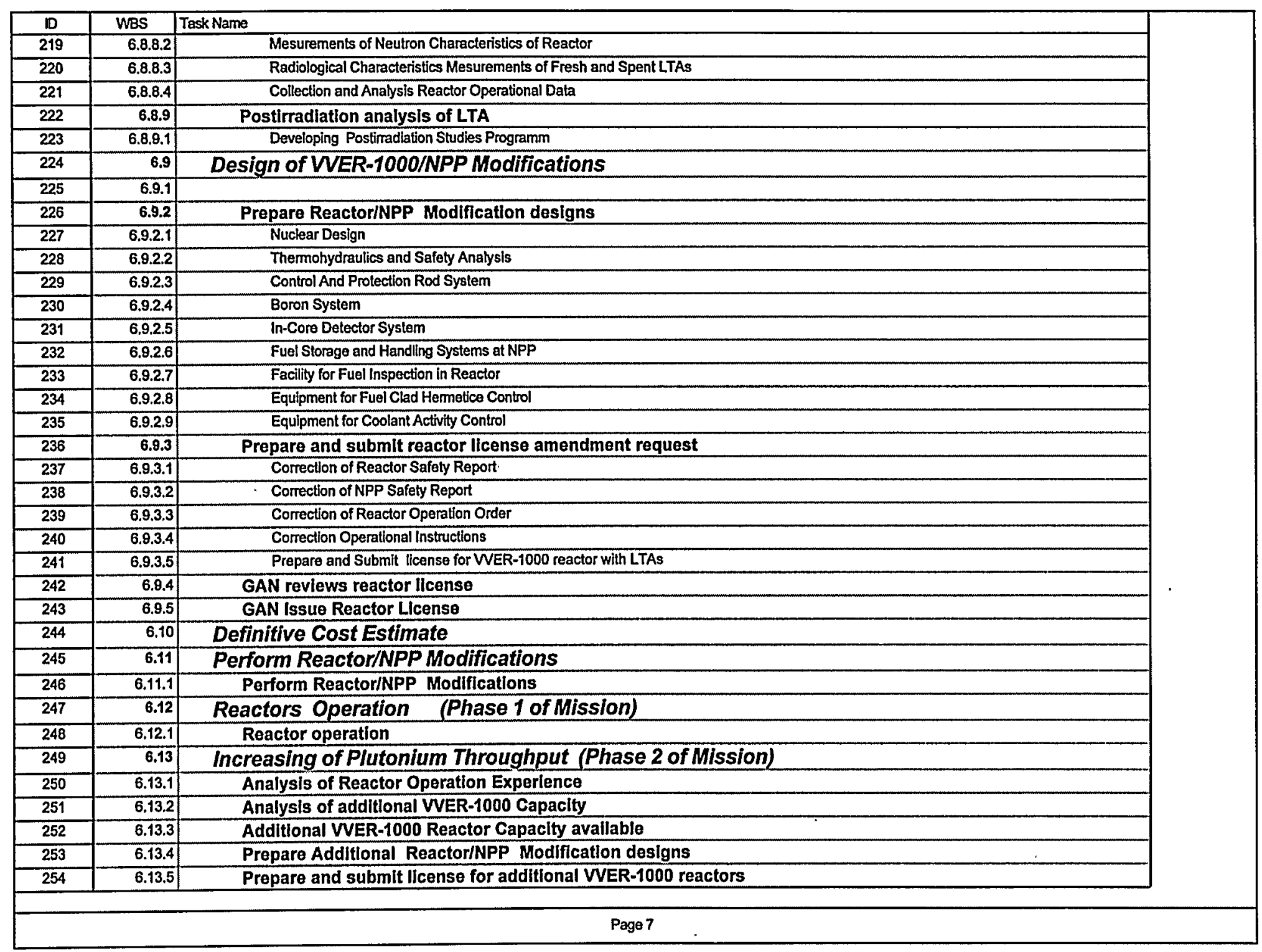




\begin{tabular}{|c|c|c|}
\hline ID & WBS & Task Name \\
\hline 255 & 6.13 .6 & GAN reviews reactor license \\
\hline 256 & 6.13.7 & Definitive Cost Estimate \\
\hline 257 & 6.13.8 & GAN Issue Reactor License \\
\hline 258 & 6.13.9 & Perform Additional Reactor/NPP Modifications \\
\hline 259 & 6.13 .10 & Reactor operation \\
\hline 260 & & BN-600 Reactors \\
\hline 261 & 8 & Other Activities \\
\hline 262 & 8.1 & Transportation of Fissile Materials \\
\hline 263 & 8.1 .9 & Cask for Fresh LTAs transportation avallable \\
\hline 264 & 8.1 .2 & Cask for Spent LTAs transportation available \\
\hline 265 & 8.1 .3 & Casks for Fresh Mission MOX Fuel Assemblies transportation available \\
\hline 266 & 8.1 .4 & Casks for Spent Mission MOX Fuel Assemblles transportation available \\
\hline 267 & 8.2 & MOX Spent Fuel Storage \\
\hline 268 & 8.3 & Radiological, Ecological and Social Aspects of the Use MOX Fuel \\
\hline 269 & 8.3 .1 & Radlological, Ecological and Social Problems for LTAs operation at Balakovo-4 have been decided \\
\hline 270 & 8.3 .2 & Radiological, Ecologlcal and Social Problems for Mission MOX Fuel operation at VVER-1000 have been decid \\
\hline 271 & 8.4 & Safeguards and Security Systems at the Use of MOX \\
\hline 272 & 8.4 .1 & Safeguards and Security Systems for LTAs operation at Balakovo- 4 Avallable \\
\hline 273 & 8.4.2 & Safeguards and Security Systems for Mission MOX Fuel operation at WVE-1000 Available \\
\hline
\end{tabular}


Appendix E

PROPOSED LEVEL 2 ROADMAP NOT LINKED TO LEVEL 1 


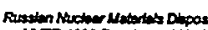

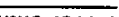

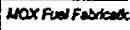

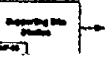
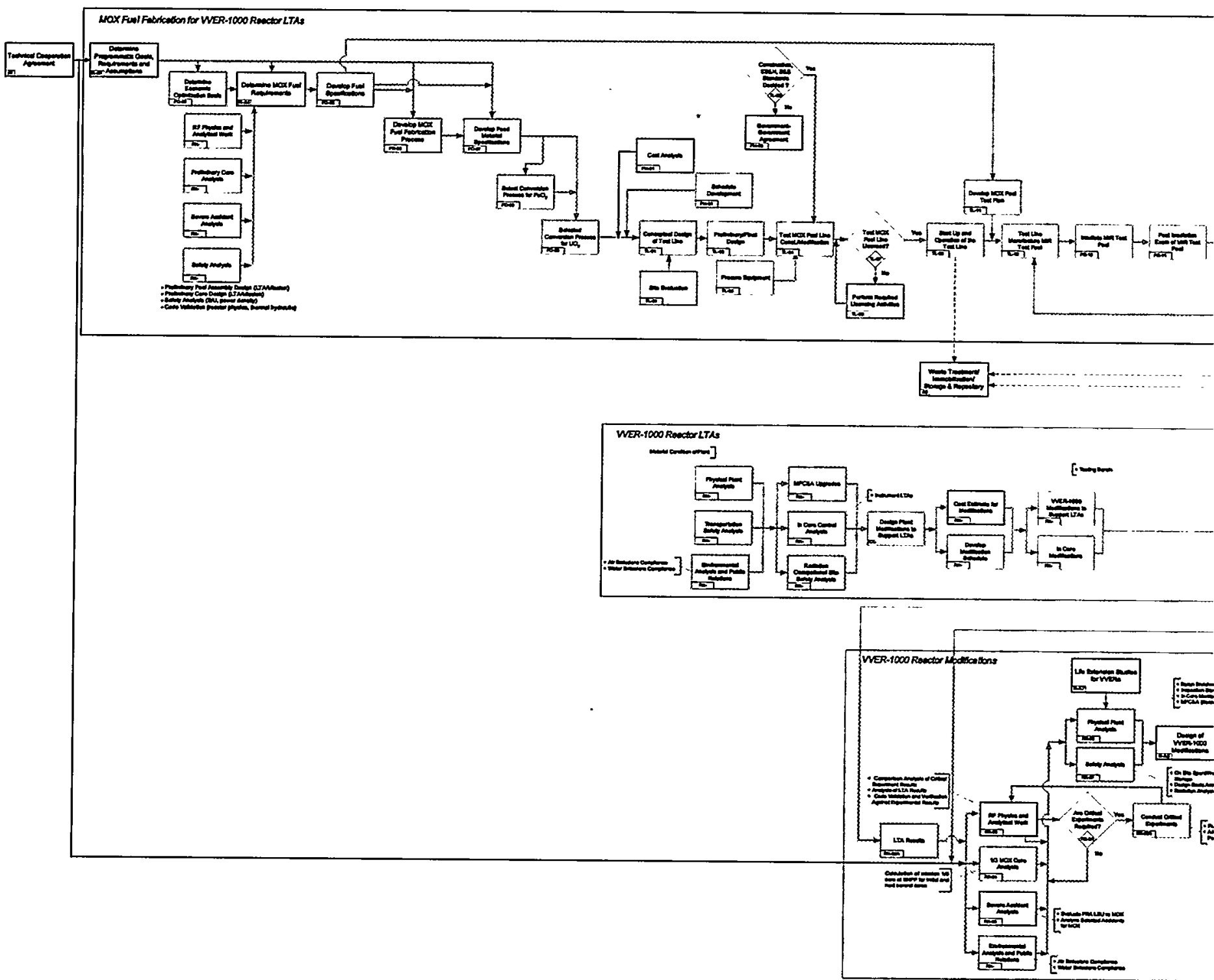

Fig. E.1 Russian Nuclear Materials Disposition Progra 

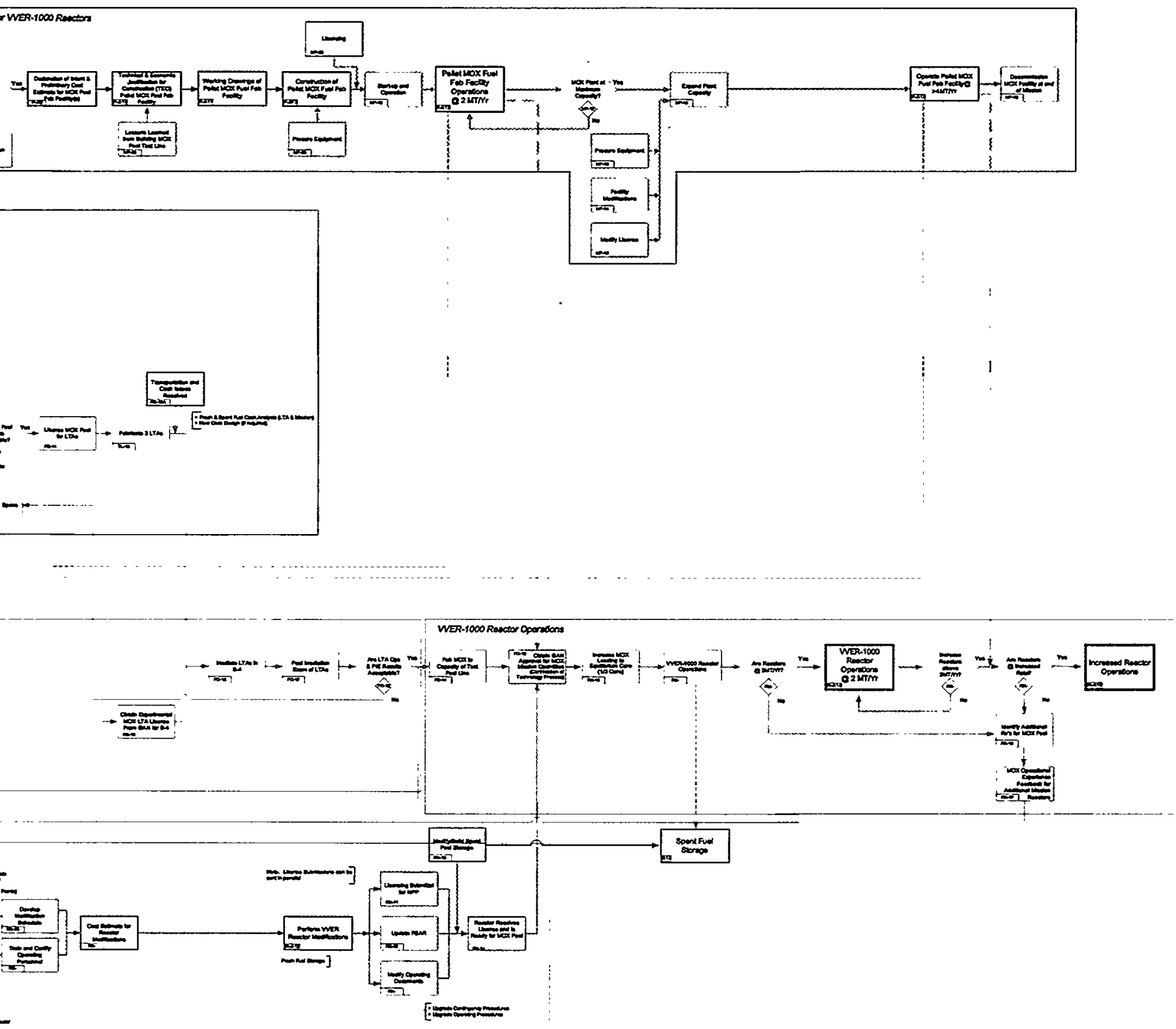
logic, VVER-1000 reactor and nuclear fuels level 2. 
ORNL 2000.1287C EFG

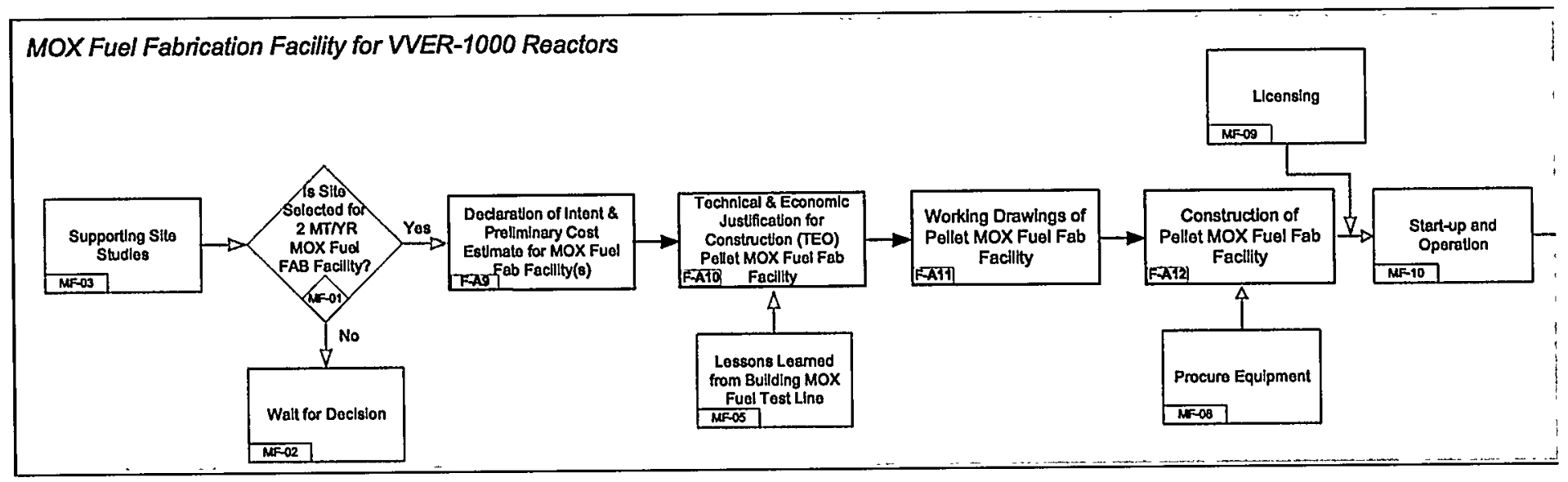

Fig. E.1(a) MOX fuel fabrication facility for VVER-1000 reactors. 


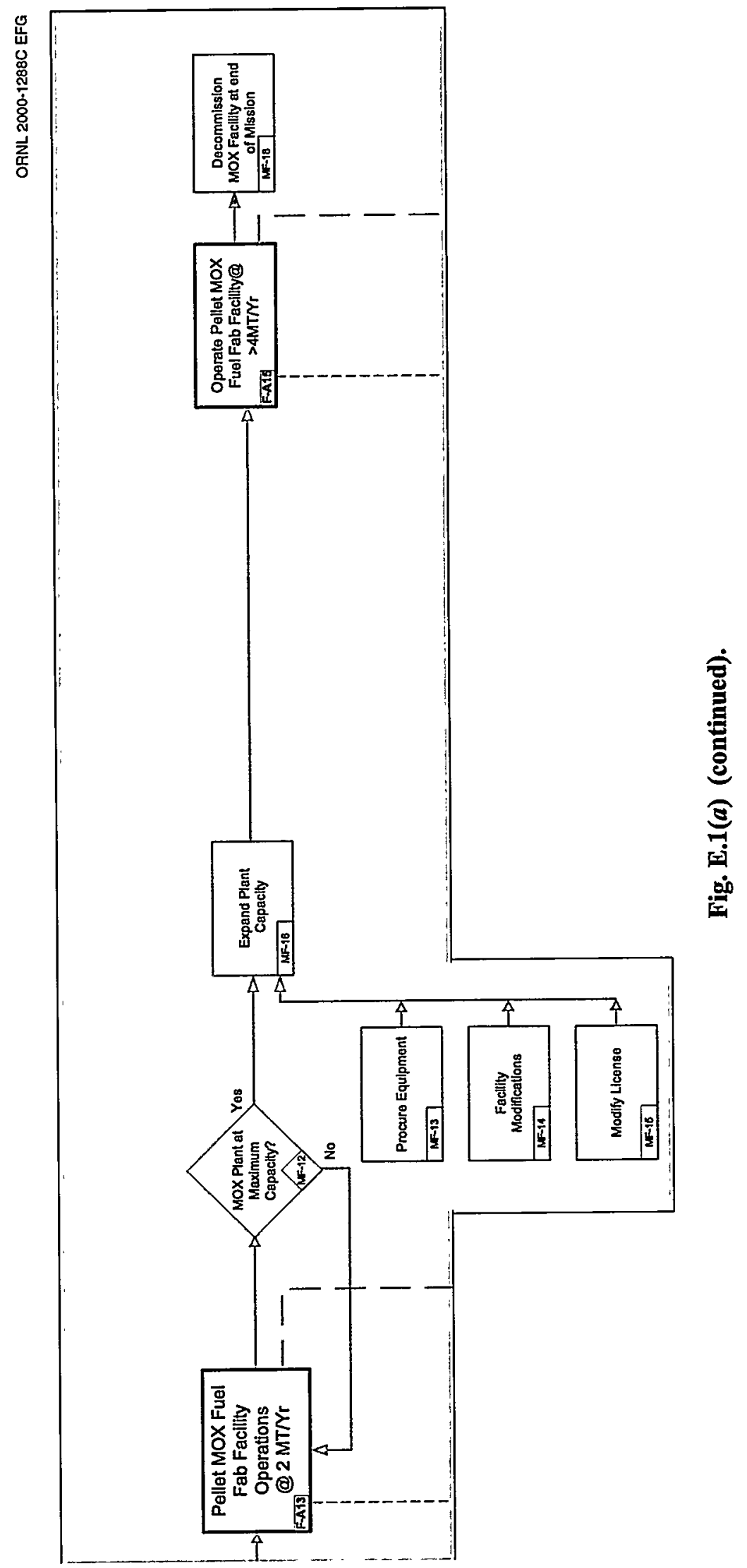

E-5 
ORNL 2000-1289C EFG

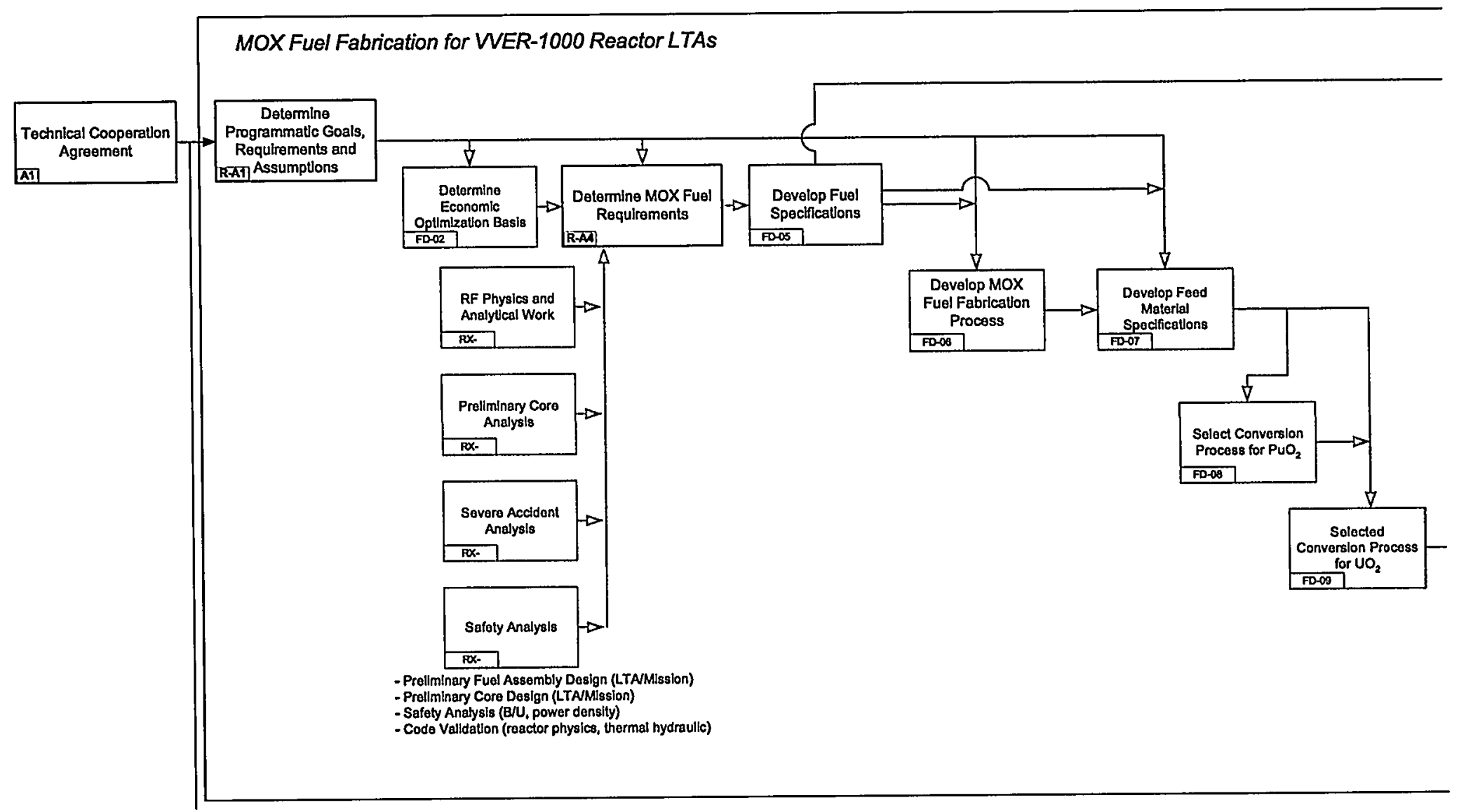

Fig. E.1(b) MOX fuel fabrication for VVER-1000 reactor LTAs. 
ORNL 2000-1290C EFG

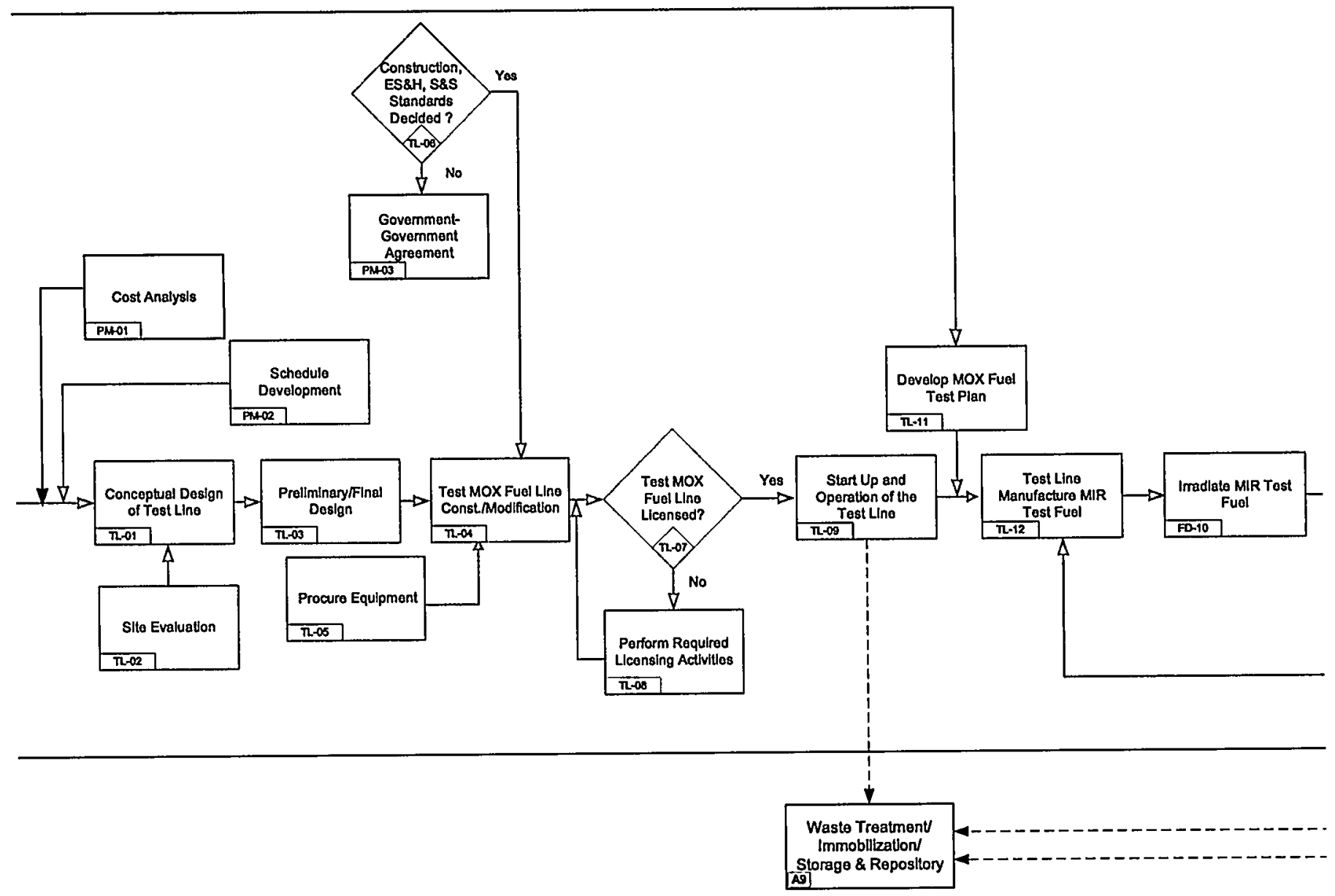

Fig. E.1(b) (continued). 


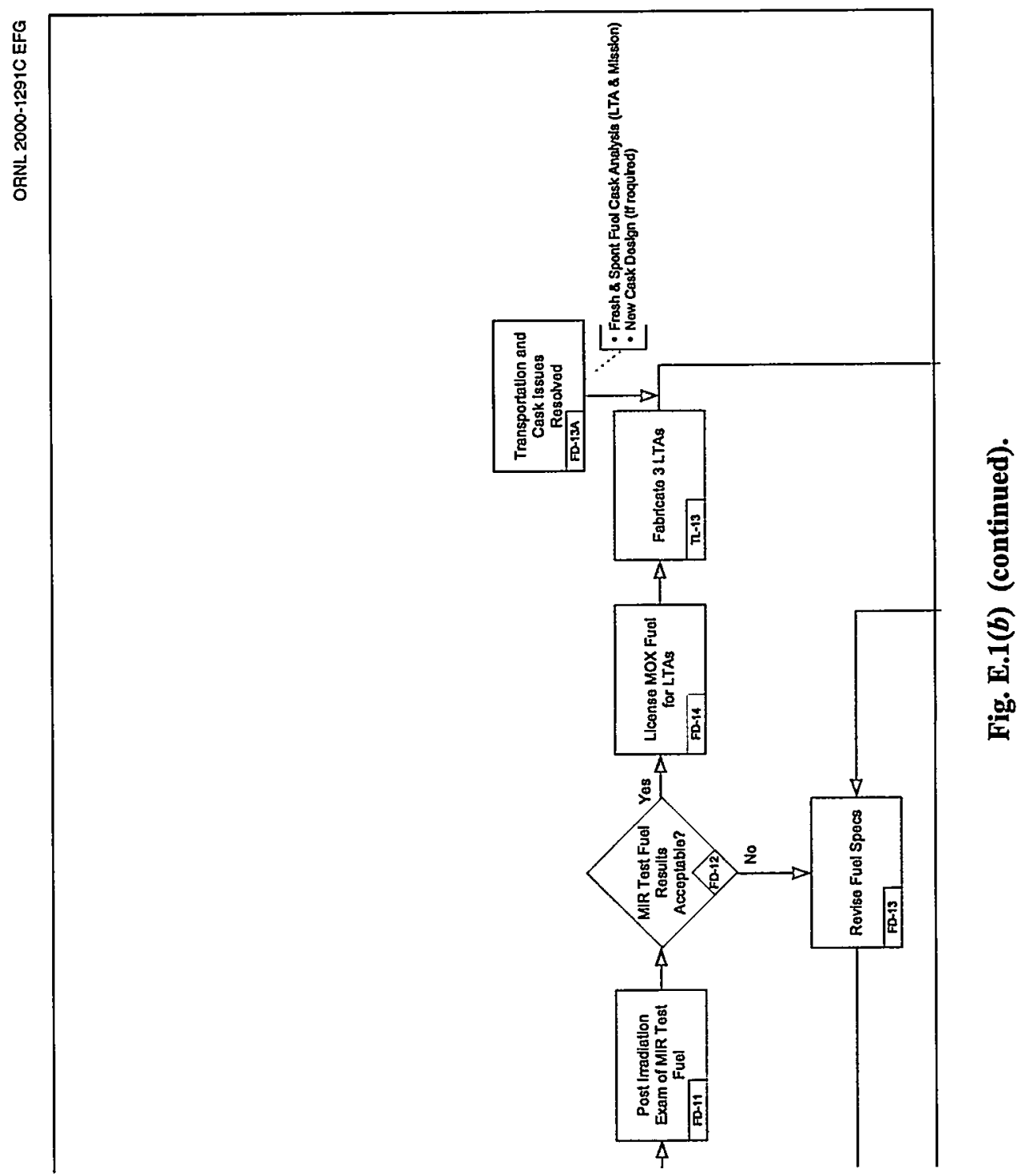


ORNL 2000-1292C EFG

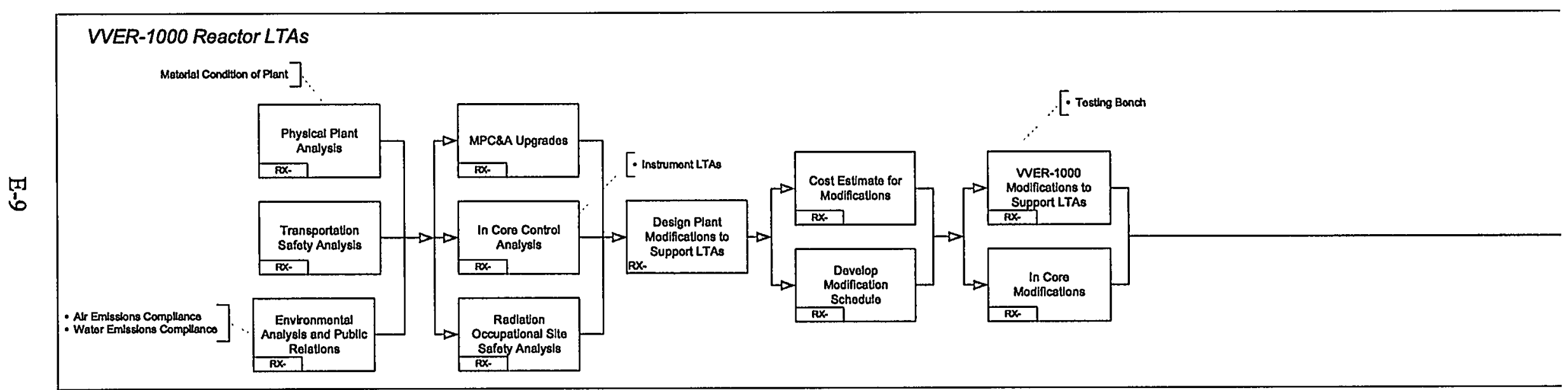

Fig. E.1(c) VVER-1000 reactor LTAs. 


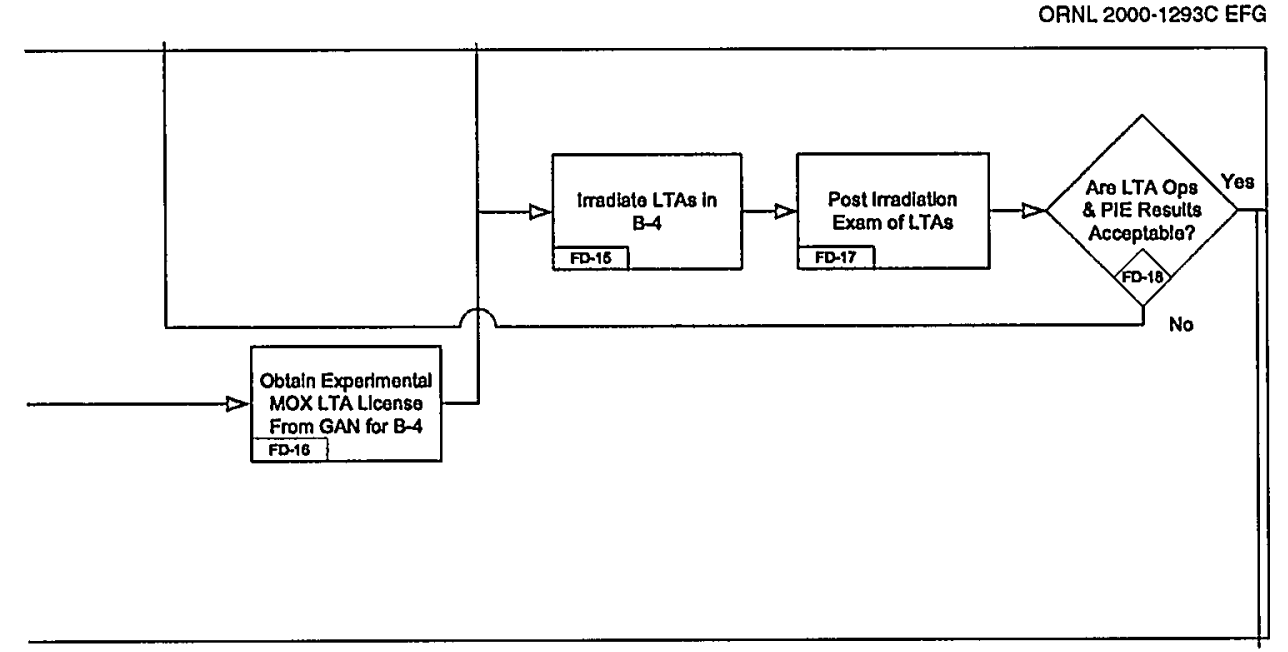

Fig. E.1(c) (continued). 
ORNL 2000-1294C EFG

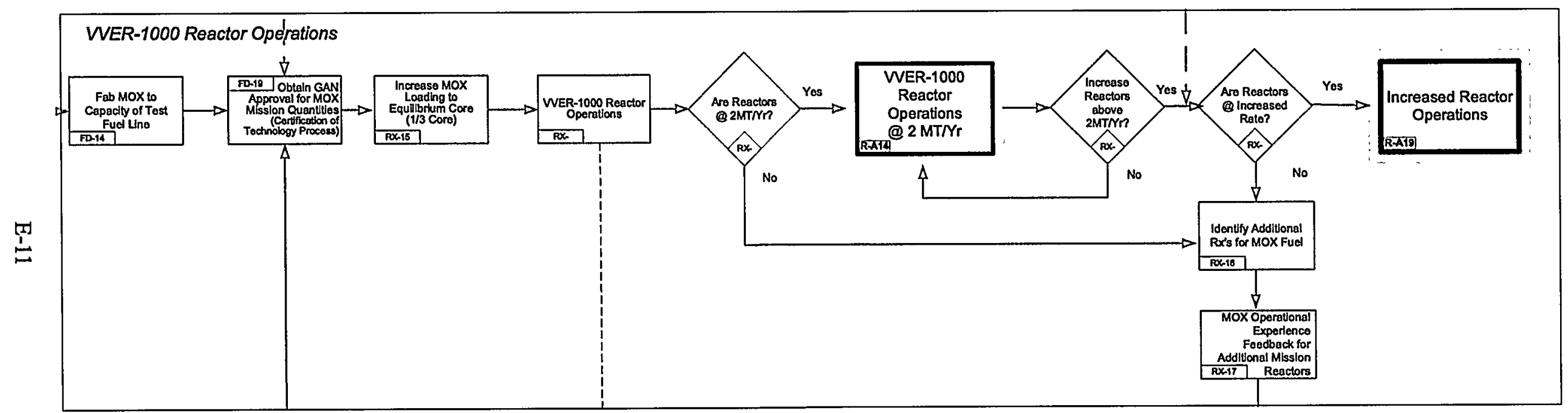

Fig. E.1(d) VVER-1000 reactor operations. 
ORNL 2000.1295C EFG

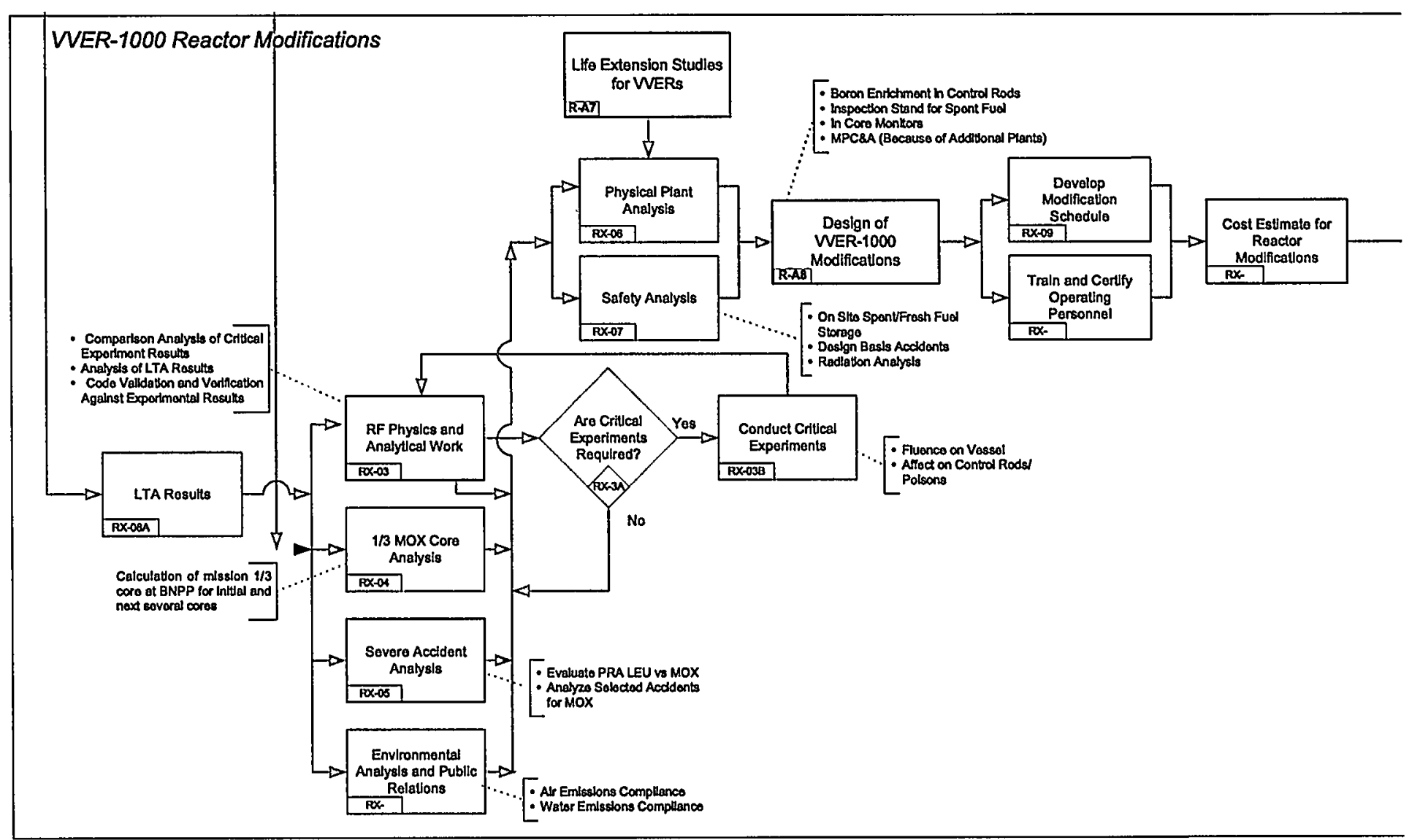

Fig. E.1(e) VVER-1000 reactor modifications. 
ORNL 2000-1296C EFG
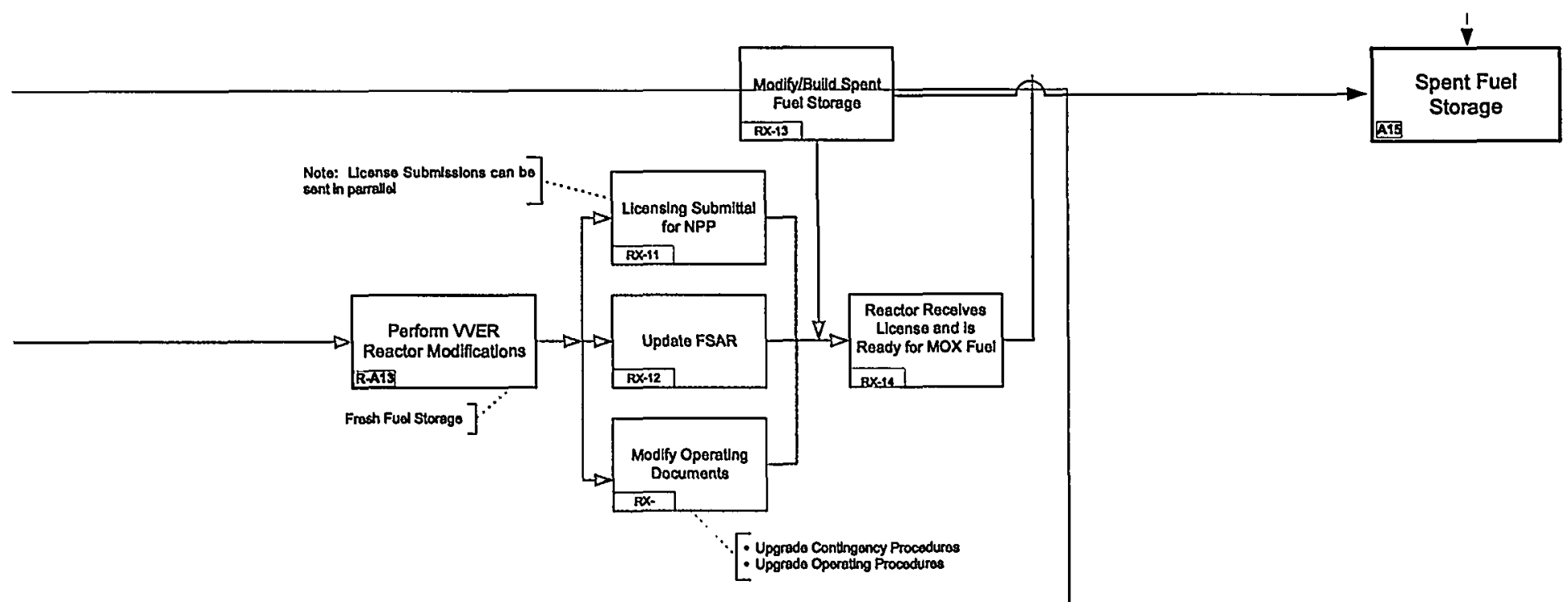

Storage

Fig. E.1(e) (continued). 
ORNL/TM-2000/133

\section{INTERNAL DISTRIBUTION}
1-5. B. B. Bevard
6. B. S. Cowell
7. F. C. Difilippo
8. R. J. Ellis
9. S. E. Fisher
10-14. J. C. Gehin
15. S. R. Greene
16. D. T. Ingersoll
17. M. A. Kuliasha
18. S. B. Ludwig

19. G. E. Michaels

20. D. L. Moses

21. C. V. Parks

22-26. R. T. Primm III

27. D. J. Spellman

28. C. C. Southmayd

29. Central Research Library

30-31. ORNL Laboratory Records (OSTI)

32. ORNL Laboratory Records (RC)

\section{EXTERNAL DISTRIBUTION}

33. M. L. Adams, Department of Nuclear Engineering, Texas A\&M University, Zachry 129, College Station, TX 77843

34. D. Alberstein, Los Alamos National Laboratory, MS-K551, P.O. Box 1663, Los Alamos, NM 87545

35. Dr. Kiyonori Aratani; Surplus Weapons Plutonium Disposition Group; International Cooperation and Nuclear Material Control Division; Japan Nuclear Cycle Development Institute; 4-49 Muramatsu, Tokai-mura, Naka-gun, Ibaraki-ken, Japan

36. J. Baker, Office of Fissile Materials Disposition, U.S. Department of Energy, MD-3, 1000 Independence Avenue SW, Washington, DC 20585

37. A. Caponiti, Office of Fissile Materials Disposition, U.S. Department of Energy, MD-3, 1000 Independence Avenue SW, Washington, DC 20585

38. M. S. Chatterton, Office of Nuclear Reactor Regulation, MS O10B3, U.S. Nuclear Regulatory Commission, Washington, DC 20555-0001

39. Mr. Richard H. Clark, Duke/Cogema/Stone \& Webster, 400 South Tryon Street, WC-32G, P.O. Box 1004, Charlotte, NC 28202

40. N. Fletcher, Office of Fissile Materials Disposition, U.S. Department of Energy, MD-3, 1000 Independence Avenue SW, Washington, DC 20585

41. L. Holgate, Office of Fissile Materials Disposition, U.S. Department of Energy, MD-1/2, 1000 Independence Avenue SW, Washington, DC 20585

42. L. Jardine, Lawrence Livermore National Laboratory, P.O. Box 808, MS-L166, Livermore, CA 94551

43. Richard W. Lee, Office of Nuclear Reactor Regulation, MS O10B3, U.S. Nuclear Regulatory Commission, Washington, DC 20555-0001

44. J. O. Nulton, Office of Fissile Materials Disposition, U.S. Department of Energy, MD-3, 1000 Independence Avenue SW, Washington, DC 20585

45. Mr. Steve Nesbit, Duke/Cogema/Stone \& Webster, 400 South Tryon Street, WC-32G, P.O. Box 1004, Charlotte, NC 28202 
46. Nagao Ogawa; Director and General Manager; Plant Engineering Department; Nuclear Power Engineering Corporation; Shuwa-Kamiyacho Building, 2F; 3-13, 4-Chome Toranomon; Minato-Ku, Tokyo 105-0001, Japan

47. Dr. Stephen L. Passman, Booz-Allen \& Hamilton, 555 13th Street, NW, No. 480E, Washington, DC 20004

48-52. Dr. Alexander Pavlovitchev, Russian Research Center "Kurchatov Institute," Institute of Nuclear Reactors, VVER Division, VVER Physics Department, 123182, Kurchatov Square, 1, Moscow, Russia

53. K. L. Peddicord, Associate Vice Chancellor, Texas A\&M University, 120 Zachry, College Station, TX 77843-3133

54. U. Shoop, Office of Nuclear Reactor Regulation, MS O10B3, U.S. Nuclear Regulatory Commission, Washington, DC 20555-0001

55. E. Siskin, Office of Fissile Materials Disposition, U.S. Department of Energy, MD-1/2, 1000 Independence Avenue SW, Washington, DC 20585 